\title{
Rehabilitation of timber railroad bridges using glass fiber reinforced polymer composite wraps
}

Aaron W. Smith

West Virginia University

Follow this and additional works at: https://researchrepository.wvu.edu/etd

\section{Recommended Citation}

Smith, Aaron W., "Rehabilitation of timber railroad bridges using glass fiber reinforced polymer composite wraps" (2004). Graduate Theses, Dissertations, and Problem Reports. 1462.

https://researchrepository.wvu.edu/etd/1462

This Thesis is protected by copyright and/or related rights. It has been brought to you by the The Research Repository @ WVU with permission from the rights-holder(s). You are free to use this Thesis in any way that is permitted by the copyright and related rights legislation that applies to your use. For other uses you must obtain permission from the rights-holder(s) directly, unless additional rights are indicated by a Creative Commons license in the record and/ or on the work itself. This Thesis has been accepted for inclusion in WVU Graduate Theses, Dissertations, and Problem Reports collection by an authorized administrator of The Research Repository @ WVU. For more information, please contact researchrepository@mail.wvu.edu. 


\title{
REHABILITATION OF TIMBER RAILROAD BRIDGES USING GLASS FIBER REINFORCED POLYMER COMPOSITE WRAPS
}

\begin{abstract}
By
Aaron W. Smith

A thesis submitted to the College of Engineering and

Mineral Resources at West Virginia University in partial fulfillment of the requirements for the degree of
\end{abstract}

\author{
Master of Science \\ In \\ Civil Engineering
}

Hota V.S. GangaRao, Ph.D., P.E., Chair Samer H. Petro, P.E.

Udaya B. Halabe, Ph.D., P.E.

Department of Civil and Environmental Engineering

$$
\begin{gathered}
\text { Morgantown, West Virginia } \\
\mathbf{2 0 0 4}
\end{gathered}
$$

Keywords: Retrofitting, Timber, Wraps

Copyright 2004 Aaron W. Smith 


\title{
REHABILITATION OF TIMBER RAILROAD BRIDGES USING GLASS FIBER REINFORCED POLYMER COMPOSITE WRAPS
}

\section{ABSTRACT}

By

\author{
Aaron W. Smith
}

This study involves the rehabilitation and load testing of $50^{+}$year old open deck timber railroad bridges on the South Branch Valley Railroad (SBVR) in Moorefield, WV. The rehabilitation involved repairing substructure elements including a "Pile cap/pile" joint and an above ground pile with Glass Fiber Reinforced Polymer (GFRP) composite wraps, in combination with phenolic formaldehyde adhesives. Static and dynamic testing was performed to determine the dynamic behavior and the live load distribution of the superstructure. This research study is the second phase of a two-phase study with an ultimate objective to investigate the rehabilitation of timber railroad bridges using GFRP composite materials. The rehabilitation associated with Phase I of this research program involved the superstructure and substructure elements also, and had a beneficial affect on the overall performance of the bridge as noted by a $40 \%$ reduction in deflection.

Static and dynamic load test data were acquired using an 80-ton locomotive supplied by SBVR. The test results show an improvement in load distribution in the rehabilitated pile bent. Dynamic load allowance (DLA) factors were also obtained and in several cases were found to increase in value with increasing locomotive speed.

To verify bonding capabilities of creosote treated $50^{+}$year old timber with GFRP composite wraps and evaluate the recovery of strength of repaired timber beams, four full scale ( 8 "x16" 12 ') timber stringers were tested in a controlled laboratory setting in four point bending configuration. Two control specimens were tested to failure in bending. The specimens were then repaired using GFRP composite wraps applied in the area of maximum moment. A second pair of control specimens was also tested to failure in shear, and also repaired using GFRP composite wraps applied in the maximum shear zones. All of the repaired beams were then retested in four point bending. All repaired test specimens showed significant signs of strength regain. The results from testing the creosote treated southern pine beams before and after repair with GFRP are presented. 
This thesis is dedicated to my grandparents and parents;

Grover and Virginia Marion,

Charles and Edith Smith, William and Cynthia Smith.

Without their love and support this would never have been possible. 


\section{ACKNOWLEDGEMENTS}

I am greatly indebted to my advisor and committee chairman, Dr. Hota V.S. GangaRao, P.E. for his invaluable guidance throughout this research. I would also like to express my deepest thanks to Mr. Samer H. Petro, P.E. who was not only a committee member but also the Principle Investigator on this research project. Without his guidance and technical contributions this research would never have come to fruition. I would like to thank Dr. Udaya Halabe, P.E. for his assistance in reviewing the thesis.

I thank John Philbrick, Dana Humberson, Sirinivas Aluri, Rex Cyphers, Donald Tusing, Jeffery Teagarden, Rob Cunningham, and Geoffrey Smith for their assistance in the laboratory and field experimentation. I would also like to thank Lynne Jacobs for her administrative help. I thank the Federal Railroad Administration for providing the financial support for Project DTFRDV-00-G-60018, through the Constructed Facilities Center. 


\section{Table of Contents}

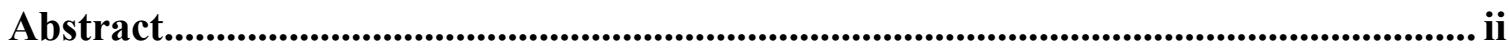

Acknowledgments ................................................................................................ iv

List of Tables ................................................................................................................................. viii

List of Figures................................................................................................................................. ix

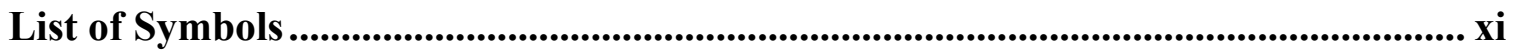

Chapter 1. Introduction ............................................................................................... 1

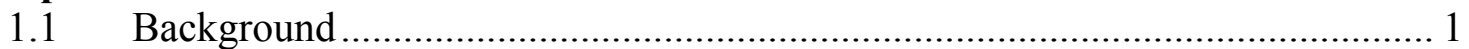

1.2 Objectives of Research ............................................................................ 4

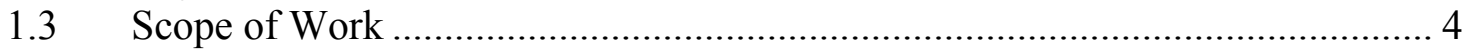

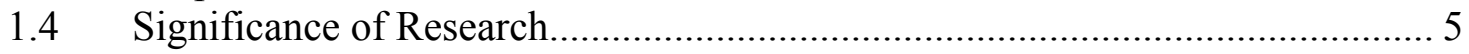

Chapter 2 - Literature Review.............................................................................6

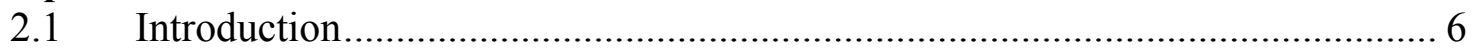

2.2 Timber Railroad Bridges.......................................................................... 6

2.3 Modern Methods for Rehabilitating Timber Railroad Bridges........................ 7

2.4 FRP Composites in External Rehabilitation of Timber .................................. 9

2.5 Timber Railroad Bridge Evaluation............................................................ 12

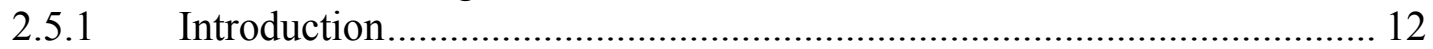

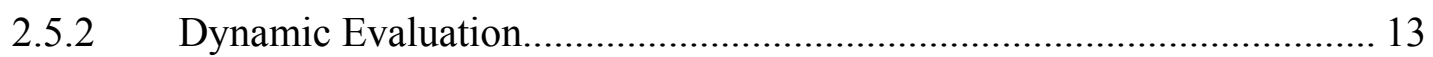

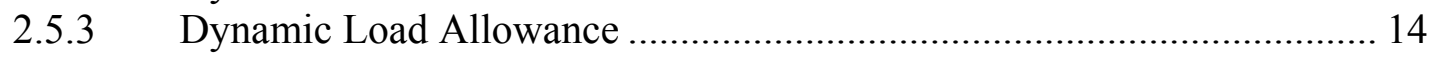

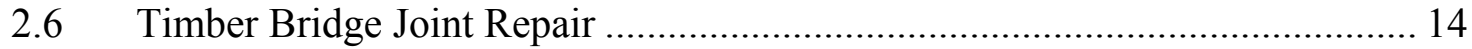

Chapter 3 - Laboratory Experiments .................................................................... 17

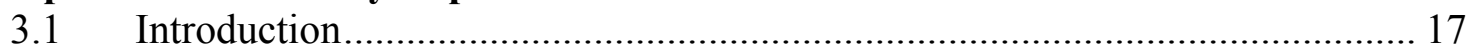

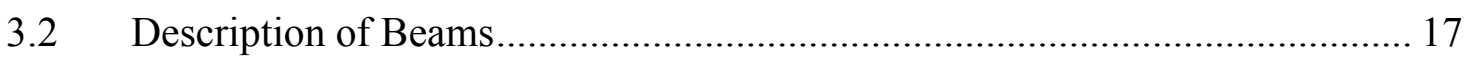

3.3 Unreinforced Control Bending Tests .......................................................... 19

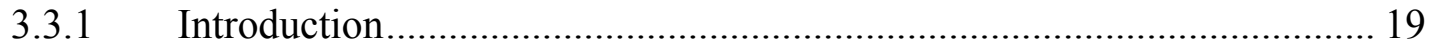

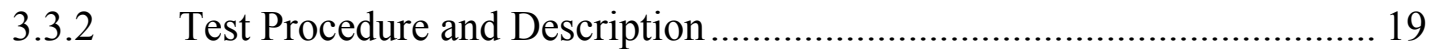

3.3.3 Beam Two - Control Specimen (Bending).......................................... 20

3.3.4 Beam Four - Control Specimen (Bending) .......................................... 22

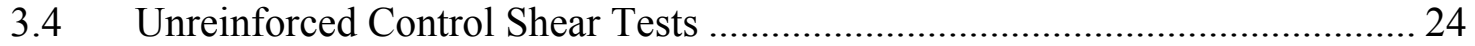

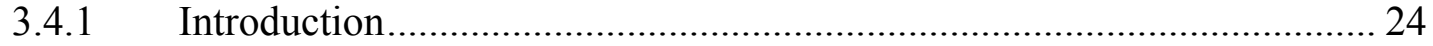

3.4.2 Test Procedure and Descriptions ......................................................... 25

3.4.3 Beam One - Control Specimen (Shear) .................................................. 25

3.4.4 Beam Three - Control Specimen (Shear) .............................................. 27

3.5 Properties of Undamaged Intact Specimens ............................................... 28

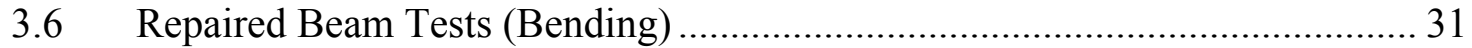

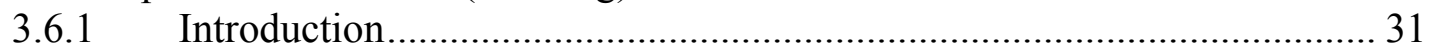

3.6.2 Repair Procedure \& Test Setup............................................................. 31

3.6.3 Beam Two - Repaired Bending Test .................................................. 34

3.6.4 Beam Four - Repaired Bending Test.............................................. 36 


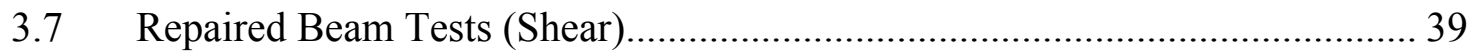

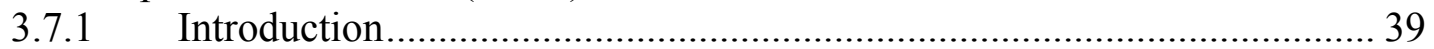

3.7.2 Repair Procedure \& Test Setup............................................................. 39

3.7.3 Beam One - Repaired Beam............................................................ 40

3.7.4 Beam Three - Repaired Beam .......................................................... 43

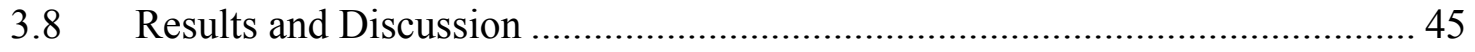

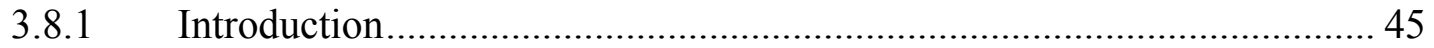

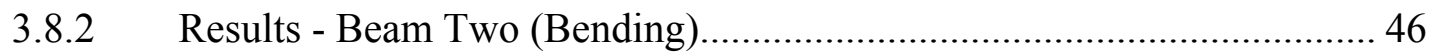

3.8.3 Results - Beam Four (Bending) ............................................................ 48

3.8.4 Results - Beam Two Repaired............................................................... 48

3.8.5 Results - Beam Four Repaired ........................................................... 51

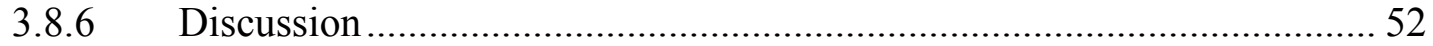

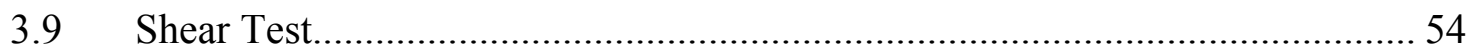

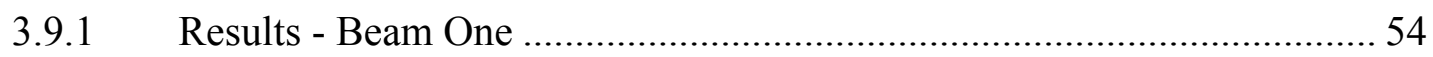

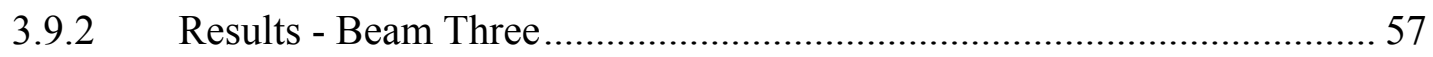

3.9.3 Results - Beam One Repaired ............................................................ 57

3.9.4 Results - Beam Three Repaired.......................................................... 58

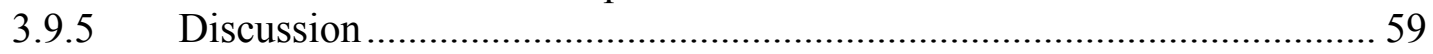

Chapter 4. Bridge Rehabilitation and Field Testing .......................................................... 61

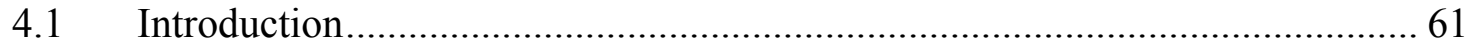

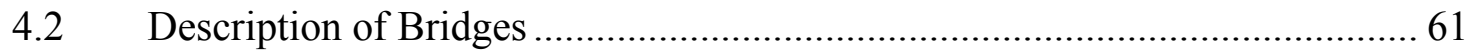

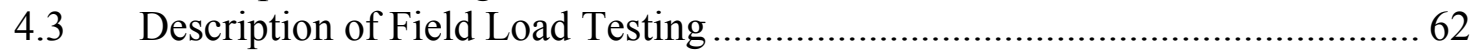

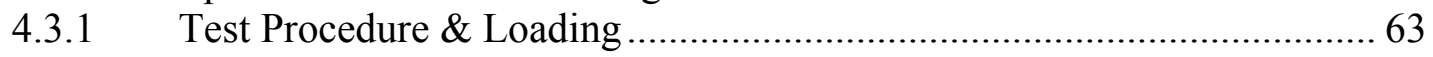

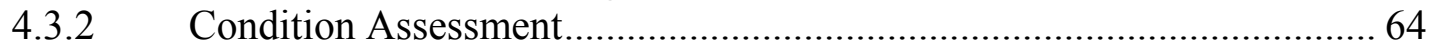

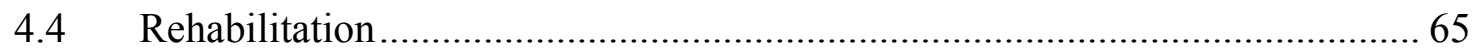

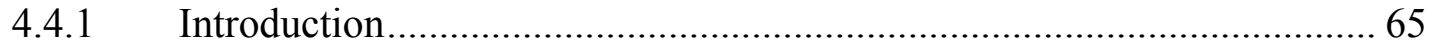

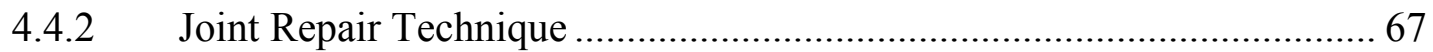

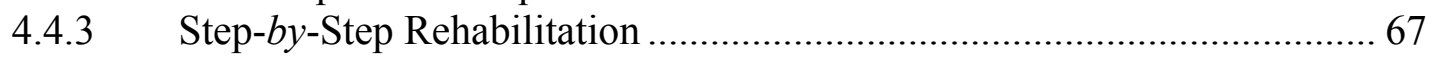

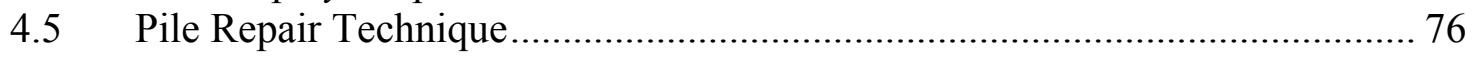

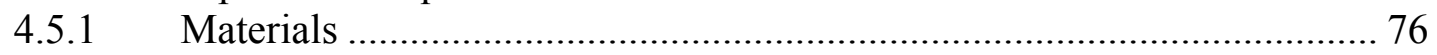

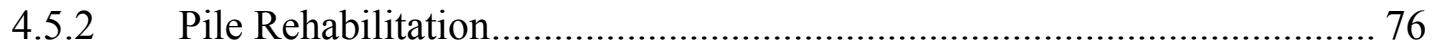

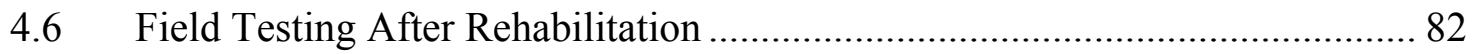

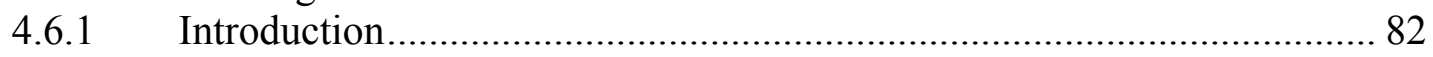

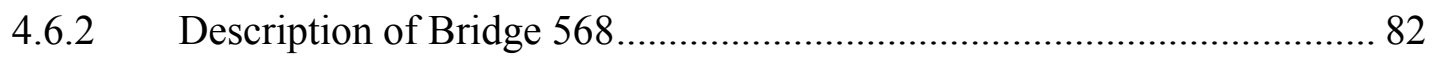

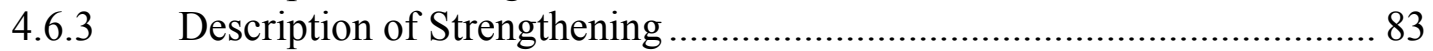

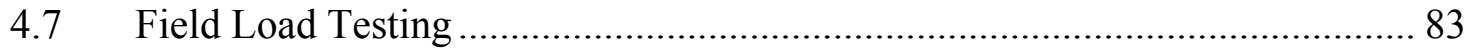

4.7.1 Test Procedure \& Loading ............................................................... 85

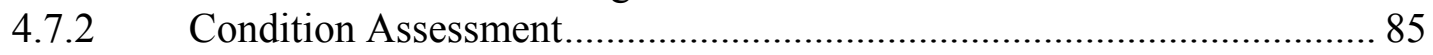

Chapter 5 - Results \& Discussion of Field Testing ……................................................... 88

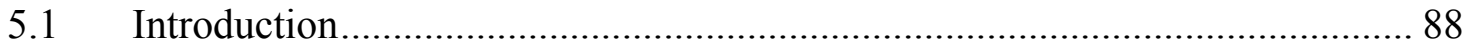

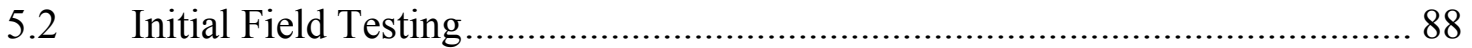

5.2.1 Dynamic Amplification Factors (DAFs) .............................................. 88

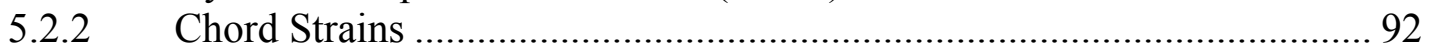

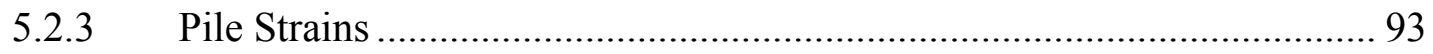

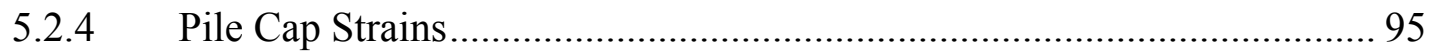

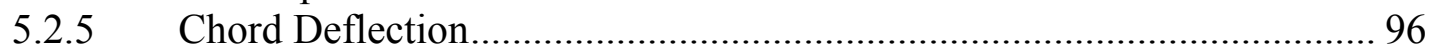




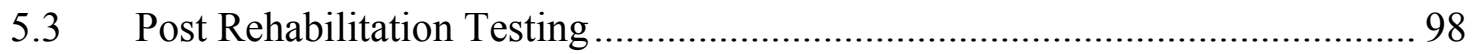

5.3.1 Dynamic Amplification Factor (DAFs) ............................................... 98

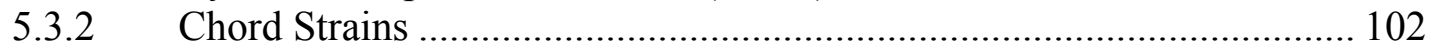

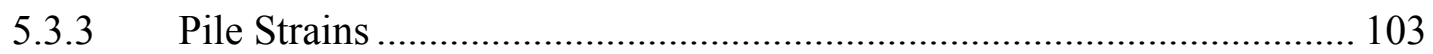

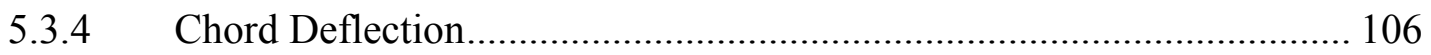

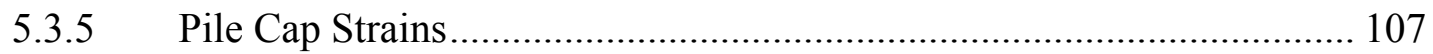

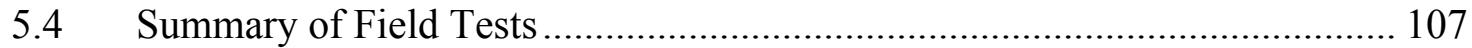

Chapter 6. Conclusions and Recommendations..................................................... 109

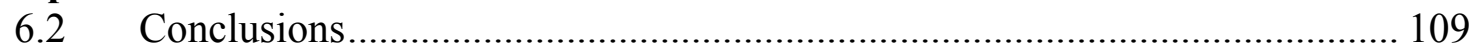

6.2.1 Field Testing ...................................................................................... 109

6.2.2 Laboratory Experiments................................................................ 110

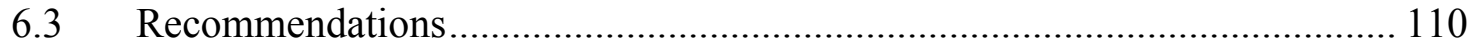

Bibliography …………………............................................................................................. 111 


\section{List of Tables}

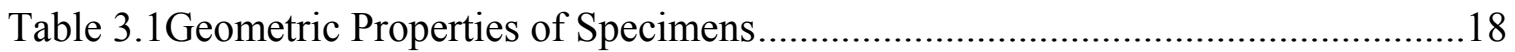

Table 3.2 Summary of Tests of Control Specimens ………..........................................28

Table 3.3 Comparison of Bending Test Results ………...............................................53

Table 3.4 Summary of Shear Test Results ....................................................................60 


\section{List of Figures}

Figure 1.1 Typical debris of timber trestle railroad bridges .......................................2

Figure 1.2 Rehabilitation completed in Phase I of this project........................................

Figure 2.1 Typical epoxy injection rehabilitation..................................................

Figure 2.2 Schematic of concrete joint rehabilitation (Imbsen, 2000) ...........................15

Figure 3.1 Diagram of wood beam retrofitted with GFRP …................................... 18

Figure 3.2 Four Point Loading Configuration ........................................................ 19

Figure 3.3 Bending Test Setup ..................................................................................20

Figure 3.4 Control Beam Two - Bending Failure ................................................... 21

Figure 3.5 Load vs. Deflection for Control Specimen Beam Two ..................................21

Figure 3.6 Significant Horizontal Shear Failure in Control Beam Two ..........................22

Figure 3.7 Horizontal Shear Crack propagated throughout beam width (Beam 4) ...........23

Figure 3.8 Load vs. Deflection for Control Specimen Four ...........................................23

Figure 3.9 Sudden Bending Failure in Beam Four .........................................................24

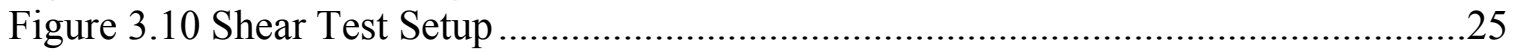

Figure 3.11 Beam One Horizontal Shear Cracking ...................................................26

Figure 3.12 Load vs. Shear Strain for Control Specimen One ......................................27

Figure 3.13 Load vs. Shear Strain for Control Specimen Three.....................................28

Figure 3.13(a) Load vs. Micro Shear Strain for Three-Point Bending .............................30

Figure 3.13(b) Load vs. Micro Shear Strain for Four-Point Bending...............................30

Figure 3.14 Typical of Bending GFRP wrapped area..................................................32

Figure 3.15 Load vs. Deflection Rehabilitated Specimen Beam Two..............................34

Figure 3.16 Separation of GFRP wrap from wood substrate (view from above) ..............35

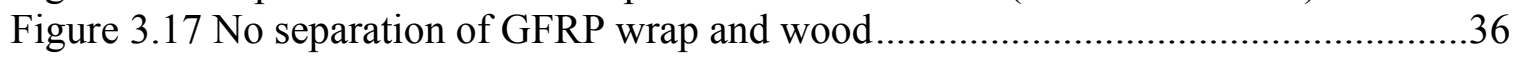

Figure 3.18 Horizontal Shear Crack Propagating Outward ...........................................36

Figure 3.19 Load vs. Deflection for Beam Four Rehabilitated Specimen........................37

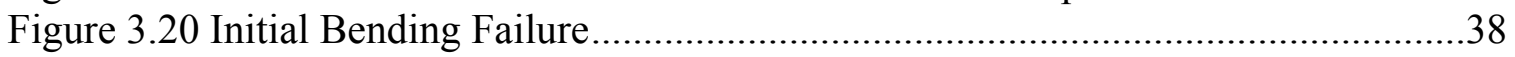

Figure 3.21 Secondary Horizontal Shear Failure.........................................................39

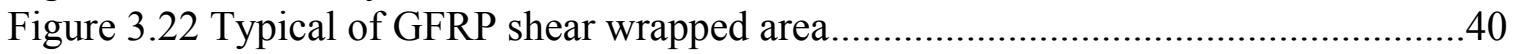

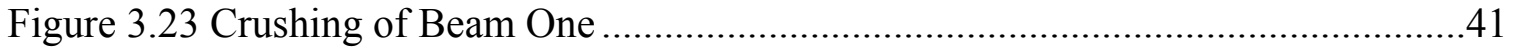

Figure 3.24 Initial Separation of GFRP wrap and wood ...........................................42

Figure 3.25 Horizontal Shear Failure (Beam One) .......................................................42

Figure 3.26 Load vs. Shear Strain of Rehabilitated Beam One .....................................43

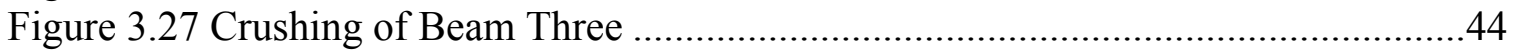

Figure 3.28 Load vs. Shear Strain for Rehabilitated Beam Three .................................45

Figure 3.29 Actual and Transformed Section of Beam Two .......................................49

Figure 3.30 Beam Two - Load vs. Deflection Comparison ............................................52

Figure 3.31 Beam Four - Load vs. Deflection Comparison .............................................53

Figure 3.32 Beam One - Load vs. Shear Strain Comparison ........................................55

Figure 3.33 Beam Three - Load vs. Shear Strain Comparison ......................................56

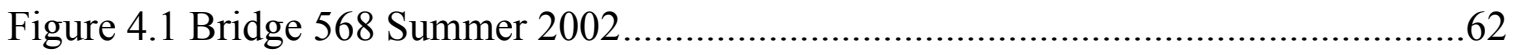


Figure 4.2 Instrumentation lay-out of the Fourth Span...................................................63

Figure 4.3 80-TON SBVR Locomotive on Bridge 570 in Moorefield, WV .....................64

Figure 4.4 Areas of decay contained in the fifth pile bent.............................................65

Figure 4.5 Removal of decay from "pile cap/pile" joint..................................................66

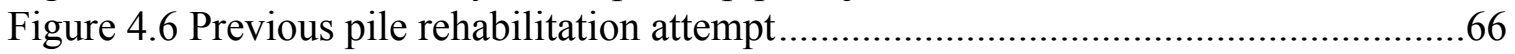

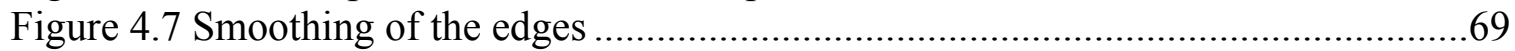

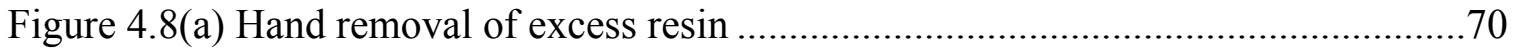

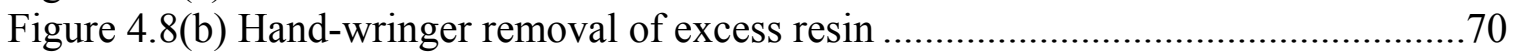

Figure 4.9 Wet hand lay-up application of GFRP to pile cap........................................72

Figure 4.10 Steps 1-8 of the wrapping sequence of a pile cap/pile joint ............................73

Figure 4.11 Showing plywood being clamped …………...........................................74

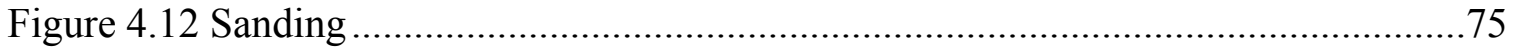

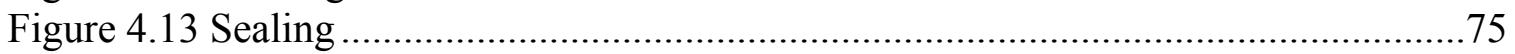

Figure 4.14 Existing Pile (12" and 6" Diameters, respectively)......................................77

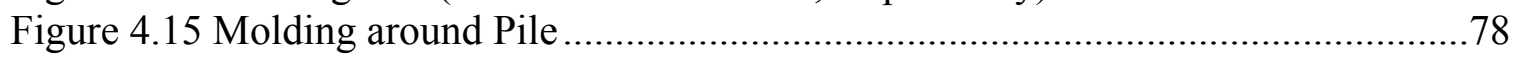

Figure 4.16 Filling of mold with bulk filler material...................................................79

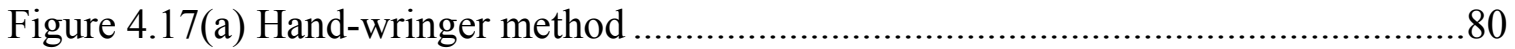

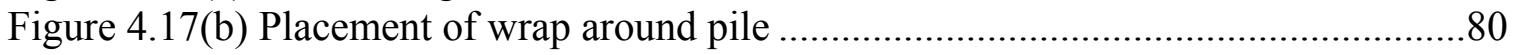

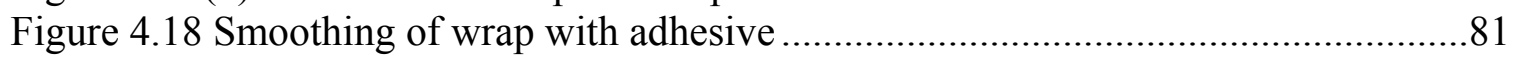

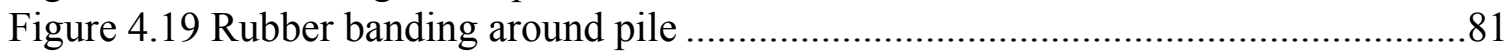

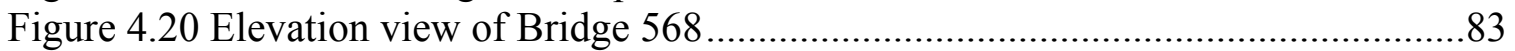

Figure 4.21(a) Instrumentation lay-out post rehabilitation ............................................8

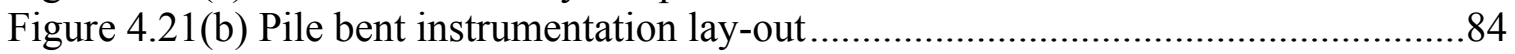

Figure 4.22 Static Testing of Bridge 568 post rehabilitation.............................................85

Figure 4.23 Discoloration of pile bent rehabilitated in Summer 2000 ............................86

Figure 4.24 Visual Inspection of GFRP composite materials post curing.........................87

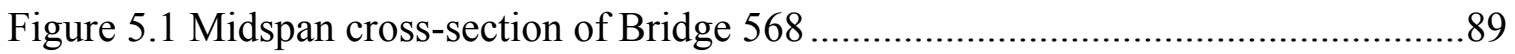

Figure 5.2 Dynamic Amplification Factor at various speeds for Bridge 568 ....................90

Figure 5.3 Dynamic Amplification Factor based on Strain for Bridge 568......................91

Figure 5.4 Bridge 568 Span 4 Strain Distribution ......................................................92

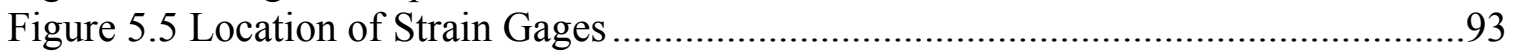

Figure 5.6 Bridge 568 span 4 pile strain distribution for varying speeds .........................94

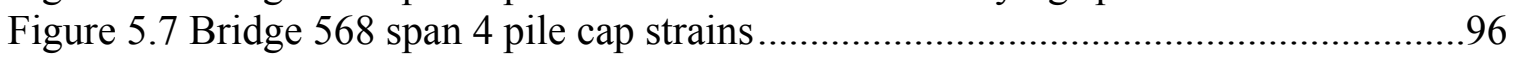

Figure 5.8 Bridge 568 North and South Chord midspan deflections.................................97

Figure 5.9 Dynamic Amplification Factors (at various speeds) due to deflection ............99

Figure 5.10 Dynamic Amplification Factors (at various speeds) due to strain ...............101

Figure 5.11 Bridge 568 Span 4 Strain Distribution .......................................................103

Figure 5.12 Post Rehabilitation Strain Gage Location ...................................................104

Figure 5.13 Span 4 pile strain distribution (at varying speeds) post rehabilitation .........105

Figure 5.14 North and South Chord midspan deflections post rehabilitation...................107 


\section{List of Symbols}

GFRP $=$ Glass Fiber Reinforced Polymer

$\mathrm{L}=$ Total length of beam between reaction points, in

a = shear span, distance from reaction point to load point, in

$\mathrm{P}$ = Maximum (Total) load, $\mathrm{lb}$

$\kappa=$ constant, equal to $6 / 5$ for rectangular beam sections

LVDT $=$ Linear Variable Displacement Transducer

$\Delta_{\max }=$ measured bending and shear deflection at midspan, in

$\mathrm{EI}_{\mathrm{exp}}=$ experimental flexural rigidity, $\mathrm{psi}$

$\mathrm{EI}_{\text {bending }}=$ pure bending flexural rigidity, psi

$\mathrm{P} / \Delta_{\max }=$ slope of load vs. deflection curve

MOR $=$ Modulus of Rupture, $p s i$

$b_{w}=$ width of wood section, in

$\mathrm{d}_{\mathrm{w}}=$ depth of wood section, in

$\mathrm{y}_{\mathrm{t}}=$ Centroid of the entire beam, in

$y_{i}=$ Centroid of each element in beam, in

$A_{i}=$ Area of reinforcement element, in ${ }^{2}$

$\mathrm{I}=$ Moment of inertia, in ${ }^{4}$

$\mathrm{I}_{\mathrm{xt}}=$ Cross-sectional transformed moment of inertia, in ${ }^{4}$

$\mathrm{b}_{\mathrm{w}}=$ wood beam width, in

$\mathrm{h}_{\mathrm{i}}=$ Height of each element, in

$\mathrm{d}_{\mathrm{i}}=$ Distance from the Centroid of each element to the neutral axis, in

$\mathrm{n}=$ Modular ratio

$b_{t}=$ Transformed beam width, in

$b_{r}=$ Reinforcement thickness, in

$\mathrm{M}=$ maximum moment, $\mathrm{lb}$-in

$\mathrm{c}=$ distance from the extreme fiber to the neutral axis, in

$\bar{y}=$ Distance from centroid of area to neutral axis, in

$\mathrm{V}=\frac{P}{2}, \mathrm{lb}$ 


$$
\begin{aligned}
& \mathrm{G}=\text { Shear Modulus, } \mathrm{psi} \\
& \gamma=\text { shear strain } \\
& \mathrm{Q}=\text { First moment of area, in }{ }^{3} \\
& \mathrm{G}_{\mathrm{r}}=\text { transformed shear modulus, } \mathrm{psi} \\
& \tau_{\mathrm{max}}=\text { maximum shear strength } \\
& \mathrm{Q}_{\mathrm{t}}=\text { transformed first moment of area, } \mathrm{in}^{3} \\
& \text { DAF }=\text { Dynamic Amplification Factor }
\end{aligned}
$$




\section{Chapter 1. Introduction}

\subsection{Background}

Approximately 35,000 timber railroad bridges are in service in the United States (Mee et al. 1994). Many of these timber bridges contain multiple span trestles that are approximately 50 - 100 years old (Radford, 2000). The average length of these bridges is around 120 feet, comprising of three to five spans, with each span being 12-14 feet in length (Mee et al. 1994). With the recent increases in railway car axle loads and exposure to the environment, many of these bridges have reached the end of their service life. Furthermore, recent unstable weather patterns have caused severe flooding resulting in debris impacting these bridges and damaging the timber substructure and pile bents. Flooding can be particularly damaging. Floodwaters can carry large amounts of dead trees and debris, which can impact the supports and cause failure. In addition, during periods of flash flooding, piers and abutments can be undermined. More recently, in West Virginia, flood waters have risen above the railroad tracks undermining the abutments and causing the supports to tilt and wash off the superstructure spans. Figure 1.1 displays debris impacting the low profile, open deck timber trestle railroad bridges throughout West Virginia. Figure 1.1 also shows Bridge 568 along the South Branch Valley Railroad (SBVR) in Moorefield, WV. This bridge was selected for rehabilitation by SBVR in Phase I and Phase II of this project. 


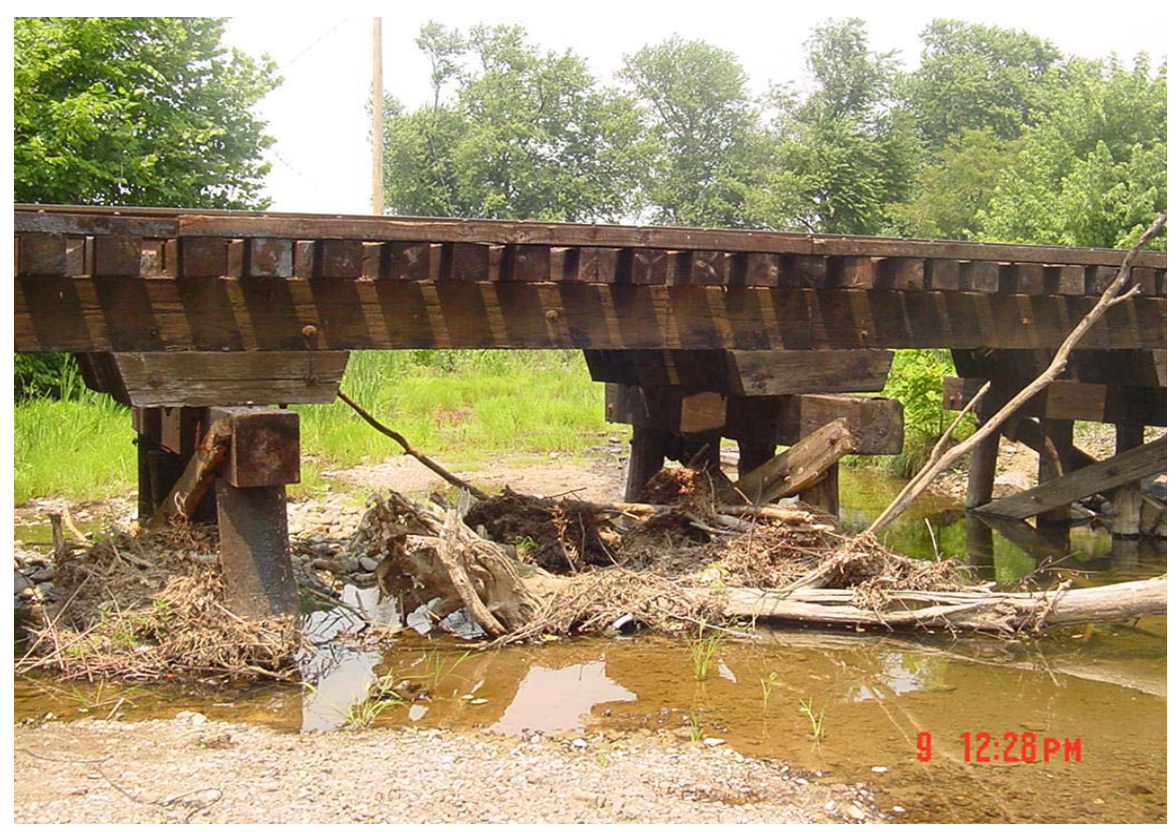

Figure1.1 Typical debris of timber trestle railroad bridges

To maintain and improve the load carrying capacity of these deteriorating timber bridges, several rehabilitating alternatives for superstructure and substructure elements are currently being investigated. Some of these options include bridge replacement or use of fiber composite material, and/or repair of in-service deteriorated members with glass fiber reinforced polymer (GFRP) composite materials. Utilizing these technologies, the service life of a timber bridge can be extended allowing the bridge to remain in service.

The Phase I of this research program conducted by the Constructed Facilities Center of West Virginia University (WVU-CFC), and funded by the Office Research and Development, USDOT/FRA investigated the effectiveness of the using GFRP composite wraps with phenolic-based adhesives as a rehabilitation alternative for timber railroad bridges. Three open deck sawn timber stringer bridges owned by the SBVR, West Virginia, were load tested prior to and after rehabilitation. Figure 1.2 illustrates a bridge member rehabilitated during Phase I of this program. Some of the accomplishments of Phase I of this research program include:

- Development of techniques to rehabilitate timber stringers, piles and pile caps of in-service timber bridges using GFRP composite wraps 
- Rehabilitated superstructure and substructure members of three in-service timber railroad bridges

- Reduction of midspan stringer deflection post rehabilitation by approximately 44\% (King \& GangaRao, 2001).

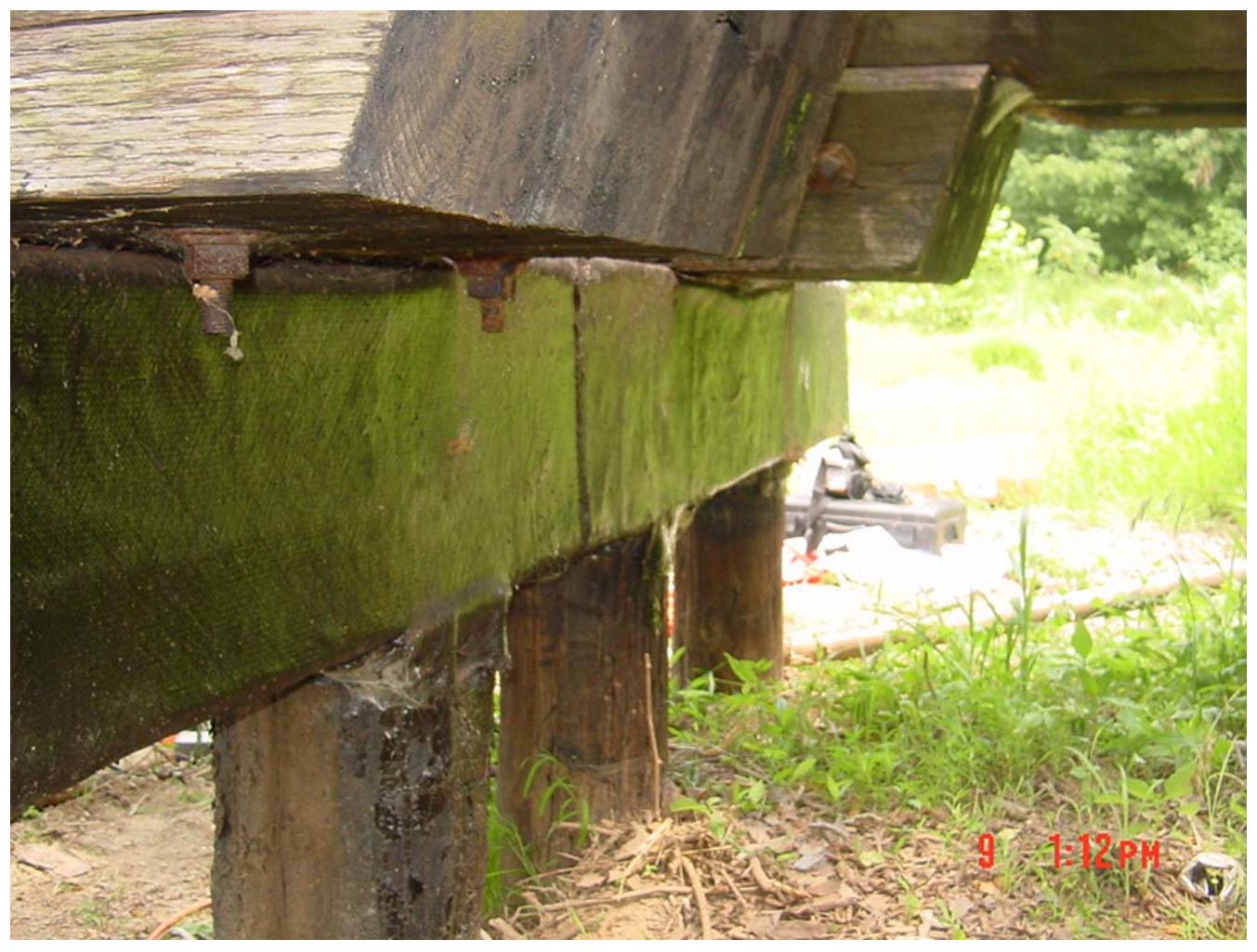

Figure1.2. Rehabilitation Completed in Phase I of this project

Phase II of this research program extended the bridge rehabilitation program developed in Phase I, to include rehabilitation of different substructure timber members, including "pile cap/pile" joints and piles using several different wrapping techniques. The rehabilitation also used GFRP fabrics on the same structures rehabilitated in the Phase I program located in Moorefield, West Virginia. 


\subsection{Objectives of Research}

The primary goals of this research program are to evaluate and demonstrate the application of glass fiber reinforced polymer (GFRP) composite wraps as a viable rehabilitation alternative for joints on two (2) in-service timber bridges in Moorefield, West Virginia owned by the South Branch Valley Railroad. The specific objectives are to:

- Develop methods of rehabilitating "joints" of an in-service timber railroad bridge without the disruption of rail traffic, using GFRP composites

- Evaluate the dynamic response of in-service timber railroad bridges, before and after rehabilitation.

- Conduct a literature review detailing developing technologies for the rehabilitation of timber railroad bridges and current testing methodologies used to evaluate in-service timber railroad bridges.

- Develop simple analytical models to predict moment and shear capacities of strengthened members.

\subsection{Scope of Work}

This research aims at developing techniques and methodologies for the rehabilitation and repair of in-service timber railroad bridges. Chapter 2 discusses modern techniques used to rehabilitate timber bridges, along with current methods used in the dynamic testing of timber railroad bridges. Chapter 3 describes methods for repairing deteriorated stringers removed from the SBVR, tested to failure by WVU-CFC, and repaired using GFRP composites. Chapter 4 discusses the implementation and monitoring of the rehabilitation of two (2) timber railroad bridges using GFRP composites. Innovative methods discussed in Chapter 4, for strengthening joints within timber railroad bridges were developed and implemented on an in-service bridge along the SBVR. Chapter 4 also provides a detail description of the testing program, methodologies developed, and the monitoring of these repairs through dynamic testing. 
The results of the field-testing program developed in Phase II of this project are discussed in Chapter 5. Chapter 6 presents the conclusions and recommendations.

\subsection{Significance of Research}

Conventional rehabilitation or repair techniques of in-service timber railroad bridges include member replacement and bridge reconstruction among other techniques. These methods are costly and time consuming. Both may require the interruption of rail traffic resulting in delays and economic losses.

Therefore, the goal of this research is to develop methods and techniques that allow for the in-situ rehabilitation of timber railroad bridges without interrupting rail traffic. With that goal in mind, this research describes the rehabilitation of timber rail bridges utilizing GFRP composite materials. The proposed methods as described in the following chapters were used to repair decayed or deteriorated members and improve load carrying capacity. Using these techniques, timber railroad bridges can maintain increasing service loads and extend their service life beyond the foreseeable future. 


\section{Chapter 2 - Literature Review}

\subsection{Introduction}

A detailed literature review was conducted to determine the traditional and modern methodologies used to repair and rehabilitate in-service timber railroad bridges. Journal articles and technical papers were reviewed using several sources, such as; MountainLynx (WVU Library and statewide library system), Applied Science \& Technology databases, Compendex, and the Internet. In addition, dissertations and technical reports from a number of universities were reviewed.

\subsection{Timber Railroad Bridges}

There are approximately 100, 900 railroad bridges in the United States, of those, $35 \%$ are of timber construction (Mee et al. 1994). Until the early $20^{\text {th }}$ century, timber was the most commonly used material for railroad bridge construction. With the insurgence of concrete and steel into the bridge construction sector as low maintenance, low cost alternatives, timber became a cost effective solution for the construction of short span highway and railroad bridges with low profiles. Consequently, a large number of inservice timber railroad bridges contain timber trestles. A study performed by Byers (1996) suggested that the service life of a typical timber trestle bridge is 72 years, with a range of $35-95$ years. This indicates that most in-service timber trestle bridges were constructed over 50 years ago and were not designed to carry the service loads of current rail traffic.

Over the past several decades, allowable axle loadings remained constant at 30 tons, but due to an increase in axle loadings, that regularly reaches 35 tons and the reduction in new construction, most of the existing timber railroad bridges within the United States require rehabilitation and repair (Radford, 2000). The most common techniques used to rehabilitate timber railroad bridges to accommodate the increase in loads are replacement and reconstruction. Both replacement and reconstruction are costly 
and time consuming and most likely cause interruption of rail traffic. Based on these facts, the development of methods and techniques to rehabilitate, strengthen, and extend the life of existing timber railroad bridges without interruption of rail traffic are of great importance.

\subsection{Modern Methods for Rehabilitating Timber Railroad Bridges}

Several methods are being developed for use in the rehabilitation of timber railroad bridges. These methods include epoxy injection, shear spiking, and fiber reinforced polymers. Epoxy injection involves the use of a structural epoxy injected into and the damaged area encasing the decayed or deteriorated section of the member. If deterioration is detected within a member, a small hole may be drilled to allow for the injection of the epoxy. Several drawbacks exist to drilling into the interior of a member; the hole exposes the beam to the environment, causing further decay. Figure 2.1 shows a failed epoxy injection rehabilitation attempt of joints within a timber railroad bridge performed by Osmose Holdings Inc. (www.osmose.com).

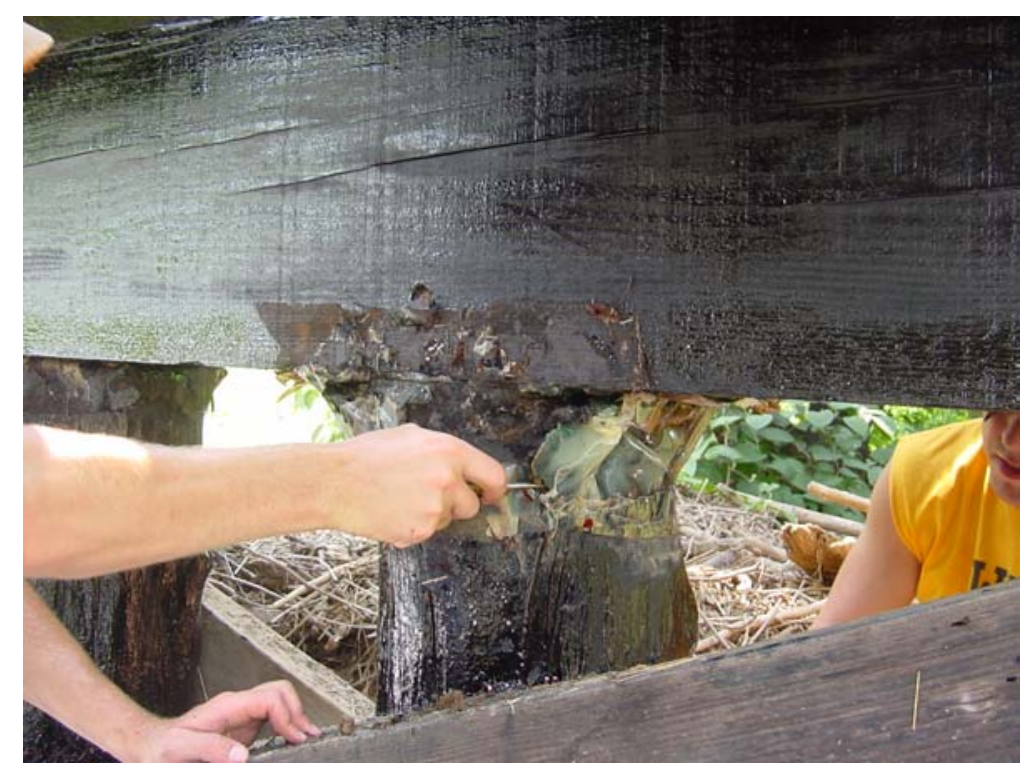

Figure 2.1. Typical epoxy injection rehabilitation.

Shear spiking is another method used primarily to increase the shear capacity of a beam. Composite rods are inserted into predrilled holes matching reinforcement 
diameter, at locations of damage at a spacing that is dictated by the severity of the decay. Before the insertion of the rods, the decayed cavity is filled with an epoxy resin that is compatible with the wood and the composite rod (Radford et al, 2000). Several drawbacks exist to this method, drilling into a decayed area could further weaken the member. Weakening a beam in a decayed state could also lead to failure of the member being rehabilitated. Drilling into a beam exposes the interior of the beam to the elements. Causing rapid decay of the weakened section and leading to further weakening of the beam.

Another modern technique to rehabilitate timber railroad bridges is the use of fiber reinforced polymer (FRP) composites. FRP composite materials are composed of fibers embedded in a polymeric matrix. The interaction between the fibers and the matrix produce high tensile strength along the direction of the fibers. The reinforcing fibers are bound together by a polymer or resin matrix. The main functions of the matrix are to enable load transfer among the fibers and protect the fibers from degradation due to environmental effects. There are three (3) commonly used resins; epoxy, vinylester, and phenolic. The fibers within an FRP composite are the load bearing material. Glass, carbon, and aramid fibers have been used in structural application. The most prevalently used fibers within the construction industry are glass and carbon. Due to the pliable nature of these fibers, it is possible to fabricate many different shapes, which can be used for structural applications. There are three commonly used techniques to shape fibers; primarily winding, pultruding, and hand lay-up. The winding of fibers is achieved by wrapping resin-impregnated fibers around a mandrel. Pultrusion of fibers involves the continuous pulling of fibers through a die to achieve the desired shape. Lay-up fabrication is achieved by placing multiple layers of resin-impregnated fibers or fabrics into the desired shape. FRP composites have been developed for use within the construction industry: some of the industry-based applications include:

- In-place application of resin to sheets of fibers

- Laminates formed from sheets stacked with resin

- Unidirectional and multidirectional sheets or fabrics with resin applied in place, to rehabilitate and strengthen beams, columns, etc. 
Several advantages for using FRP composites are: (A.C.E., 1997)

- FRP composite tensile strength is comparable to that of mild reinforcing steel to stronger than prestressing steel.

- FRP composite materials have densities much less than that of steel (490 $\left.\mathrm{lb} / \mathrm{ft}^{3}\right)$, ranging between $110-162 \mathrm{lb} / \mathrm{ft}^{3}$

- Several other advantages include; ease of fabrication, custom geometry, color and coating, construction and transportation cost, reduction of environmental toxicity, and resistance to corrosion. FRP materials can be recycled and made from recycled plastics.

Disadvantages include high initial cost, creep rupture, and shrinkage.

FRP materials have been widely used to strengthen timber, concrete, steel, masonry, and stone members. Specific applications include the strengthening of columnbeam connections, seismic retrofitting, repair of corrosion damaged beams and columns, bridge decks, concrete and timber pilings, prestressed concrete shells, chimney stacks, lighthouses, roof structures, and prestressed water tanks (Neale, 2000).

\subsection{FRP Composites in External Rehabilitation of Timber}

Several different methods have been developed utilizing FRP composites for the external strengthening of timber members. For example, the critical shear zone reinforcement developed by Triantafillou (1997) in which shear laminates are bonded to wood specimens along the sides of the beams in the maximum shear zones, and bending reinforcement techniques tested by Johns (2000) using CFRP and GFRP laminates bonded to the tension side to improve the flexural strength of wood beams. In addition, prestressing of FRP sheets and their application in the tension zones of beams to improve their load carrying capacity was investigated by Triantafillou (1992). Furthermore, structural upgrade and repair techniques developed by Mosallam et. al. (2000) where CFRP composites were applied to "undamaged" and "pre-cracked" specimens to determine the benefits of FRP composites in damaged beams. Another application of 
GFRP composite materials involved the development of techniques using GFRP to strengthen railroad crossties by providing reinforcement under the steel plates attaching the rails to the crossties (Laosiriphong, 2000).

The process of external strengthening typically involves the surface preparation, primer application (primer usually consists of the resin being applied to the fabric), coating of the FRP fabric or sheet with resin, and the application of this FRP fabric or sheet to the member. The ability to specify the fiber direction within the FRP sheet or fabric allows for the increasing of mechanical properties such as strength and stiffness in different directions depending on the FRP sheet or fabric orientation upon application.

Applying FRP composite wraps to deteriorated wood members is a widely accepted practice for strengthening structural members. The fabric wraps are usually applied in layers to provide a maximum gain in strength and stiffness. Plate bonding is also a popular alternative to the application of composite fiber to strengthening wood members. Plates are normally bonded using epoxies. However, due to the creosote treatment of timber bridge members, some epoxies do not bond well. It is extremely important to achieve optimum bond between the wood substrate and the FRP composite. Therefore, plate bonding to creosote-treated members with phenolic based adhesives compatible with the wood substrate is not an acceptable alternative in rehabilitating timber railroad bridges.

Plevris (1995) utilized FRP materials for the reinforcement of wood members (bonded to the tension face) to evaluate the long term deformations caused by creep and its effect on the bond between the wood and the FRP. Carbon Fiber Reinforced Polymer (CFRP), Aramid Fiber Reinforced Polymer (AFRP) and Glass Fiber Reinforced Polymer (GFRP) were also used for comparative purposes. The author concluded that for wood reinforced with all FRP materials, the creep behavior is dominated by the creep in the wood and that increasing the cross-sectional area of FRP composites play a significant role in limiting deformations in timber (Plevris, 1995).

Also, a study conducted by Triantafillou (1997) evaluating the effects of FRP bonded to the shear-critical zones of wood members, suggested a small amount of shear reinforcement can provide substantial increases in shear capacity. The experimental program was developed by Triantafillou (1997) to assess the effects of FRP externally 
bonded to wood members in shear zones, where previously wood has exhibited very poor strength perpendicular to the grain. It was found that the FRP configuration relative to the grain of the wood member has a significant effect on the efficiency of the FRP reinforcement. This method of shear reinforcement was also found to be cost and work efficient and can be applied without significant influence on the appearance of the beam.

Neale (2000) provided an overview of developing practices using FRP for rehabilitation and strengthening purposes. Research involving the use of FRP wrapping to improve seismic performance of reinforced concrete columns has demonstrated the effectiveness of this technique. FRP wrappings have also shown to enhance flexural ductility, inhibit lap-splice failures, and inhibit shear brittle failures, converting them into inelastic flexural deformation.

A study performed by Johns (2000) indicated that the application of GFRP or CFRP in the flexural bending zones caused an increase in strength for virtually all of the tested samples. Three different wrapping schemes were tested applying three different lengths of GFRP and CFRP to the specimens. Transformed section models were used to predict the strength gain within each wrapping scheme. The strength improvement exceeded the predicted values for all three wrapping schemes. All CFRP or GFRP reinforced samples experienced a $40-100 \%$ increase in the flexural loading capacity over the original.

FRP composite materials are very sensitive to resin combinations. Polymeric Resins used in the FRP itself must be compatible to the adhesive and both of these resins must be compatible to the substrate to which it is being applied. A thorough study of primer/resin combinations was performed by Laosiriphong (2000). The author tested the bond strength and durability of five different primer/resin combinations (within the Resorcinol Formaldehyde group) when applied to creosote-treated wood crossties. Within this study, different combinations of primer/resin were subject to advanced aging techniques (Chow et al, 1987). To evaluate the durability of phenolic-based adhesives, Laosiriphong (2000) compared the flexural rigidity (EI) of GFRP wrapped half-scale crossties with aged GFRP wrapped creosote-treated crossties. Laosiriphong (2000) used a six cycle accelerated aging process developed by Chow (1987) to simulate 20 years of natural aging. Each of the six cycles involved changes in temperature, pressure, and 
moisture during which the phenolic-based adhesive bond-line is subjected to severe swelling and shrinkage. The flexural rigidity (EI) dropped by $17 \%$ for the aged specimens. However, Laosiriphong (2000) also tested non-wrapped creosote-treated aged and non-aged crossties to evaluate the effect of accelerated aging on the wood without the GFRP wrap. Laosiriphong (2000) also noted a decrease of 17\% between the aged and non-aged samples. Therefore, Laosiriphong (2000) concluded that no significant reduction in flexural rigidity is attributed to bond degradation due to aging. The results of tests performed indicated that the primer/resin combination that provided the highest strength was G1149A/G1131A+G1131B.

King \& GangaRao (2001) utilized this primer/resin combination to rehabilitate individual members within superstructure and substructure of in-service timber railroad bridges. The authors selected three timber railroad bridges for static and dynamic testing and rehabilitation. Stringers, pile caps, and piles in advanced stages of decay were rehabilitated with GFRP composite wraps throughout the length of each member.

Results of the static and dynamic testing indicated that relative stiffness of rehabilitated timber stringers and pile caps improved by $100 \%$ over the original substrate. Furthermore, a reduction in bridge deflection of $44 \%$ was observed after the rehabilitation of decayed stringers had been completed. The authors concluded that insitu rehabilitation of timber railroad bridge members could be accomplished effectively utilizing GFRP composite material.

\subsection{Timber Railroad Bridge Evaluation}

\subsubsection{Introduction}

Currently, design practices associated with timber bridges do not allow the consideration of the effects of dynamic loads in the sizing of bridge elements (Uppal et al, 1990). With the increase of wheel axle loads throughout the rail industry, the dynamic loads that timber bridges are experiencing are exceeding the original design loadings. With the combination of excessive axle loading and increasing age of many timber bridges, several studies have been sponsored by the Association of American Railroads 
(Wipf, 2000), and the Transportation Institute of the University of Manitoba (Uppal, 1990) to study the effects of dynamic loading on timber bridges. The following section contains a review of several of these studies.

\subsubsection{Dynamic Evaluation}

Wipf (2000) conducted dynamic load testing on three spans of an open-deck timber trestle railroad bridge constructed in the 1950's. These spans had been rehabilitated using several different techniques. Within one span a helper stringer made of the material used in the original construction (Douglas fir) had been added to the chord. Another span contained glued laminated timber (glulam) stringers. The original timber stringers had been replaced within the chord using glulam stringers. By applying instrumentation to three spans of the same bridge, an accurate depiction of the vertical live load distribution was gathered. Tests were run at 2, 15, 30 and $40 \mathrm{mph}$. These velocities allowed a representative evaluation in the change of the dynamic bridge response under identical loading. To provide this load, a test train consisting of one locomotive and three hopper cars was used. Data collected included stringer midspan deflection, stringer dynamic amplification, chord load distribution, and dynamic load distribution. These tests concluded that dynamic load and dynamic amplification factors could be calculated using deflection data collected during testing. Individual stringers do not act as a unit under dynamic testing. This was found on all three spans tested. These phenomena could be contributed to uneven chord bearing on bents and uneven tie bearing on the chords. Wipf (2000) concluded that glulam chord performed better than the sawn stringer chord, even when a helper stringer was added.

The effects of dynamic train loading on a timber railroad bridge were also studied by Uppal (1990). Two timber bridges were selected for testing one bridge was a four-span ballast-deck pile trestle and the other an open-deck pile trestle. Both were constructed approximately in the early 1940's. No previous rehabilitation had been conducted on either bridge. Both bridges consisted of creosote-treated Douglas fir timber. The trains used for dynamic testing were of different car weights but were similar to those trains normally operated on the rail line for hauling limestone (Uppal et al, 1990). 
The test velocities used on both bridges were crawl speed (1 mph), 5, 10, 15, 20, 30, 40, and $50 \mathrm{mph}$. Initial tests were run using the entire train (i.e., locomotive, cars, and caboose). The cars and caboose were then unhooked and the locomotive alone was used to perform the series of dynamic tests. Data collected from the testing included vertical displacements, accelerations, and damping in the bridge span. The authors concluded that: dynamic load factors for both bridges were found to increase with an increase in train velocity and the dynamic displacement increased with increasing speed in the open-deck span (Uppal, 1990).

\subsubsection{Dynamic Load Allowance}

In designing highway bridges as per AASHTO's Standard Specifications for Highway Bridges $16^{\text {th }}$ Edition, dynamic loading affects are accounted for by applying an impact factor to the static loading calculations. This impact factor is calculated on the basis of span length and is limited to a maximum of 1.3 (Ritter et al, 1995). Due to timber's ability to absorb shock and carry greater loads for short durations, no impact factor has been included in the design of wood bridges (AASHTO, 1996). Ritter et al (1995) concluded that dynamic effects may be significant in short-span timber bridges and recommended the further study of the long term dynamic effects in short-span timber bridges.

\subsection{Timber Bridge Joint Repair}

The current practice to repair joints within timber bridges utilizes epoxy injection. As previously discussed, a molding is placed around the area of decay and fastened to the member using staples or nails. Epoxy is injected into this molding through a small hole. The hole is "sealed" by inserting a wooden peg. Figure 2.1 shows epoxy injection used on a pile cap/pile joint within a timber railroad bridge. The industry in which joint repair using FRP composites has been widely practiced is the area of concrete beam-column seismic retrofit. The rehabilitation method commonly used to retrofit columns is the 
installation of FRP wrappings surrounding the column extending to the joint. Imbsen (2000) performed extensive research to develop FRP wrapping techniques. The wrapping schemes developed provide shear enhancement to zones within a column exposed to severe shear loading during a seismic event. Experiments were conducted testing numerous types of composite casings, including Epoxy E-glass fiber, Epoxy resign-prepreg carbon fiber, prefabricated E-glass, and Epoxy carbon fiber (Imbsen, 2000). Figure 2.2 shows the technique developed by Imbsen to extend column seismic retrofit to the joint.

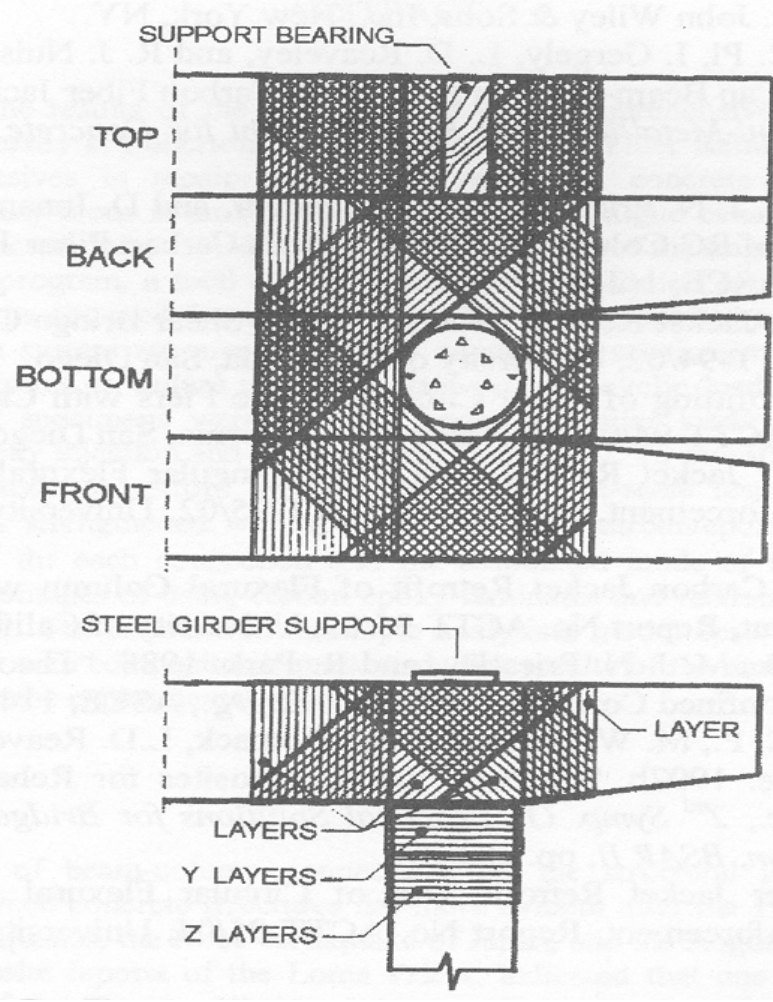

Figure 2.2. Schematic of concrete joint rehabilitation (Imbsen, 2000).

Other attempts at concrete joint reinforcement have embedded FRP composite rods within the concrete forms prior to pouring followed by the application of FRP composite layers at the beam-column connection post curing of the concrete (Prota, 2000). This methodology provides flexural strengthening within the joint (due to the embedded FRP rods), confinement in the occurrence of a failure and shear strengthening 
(produced by the FRP laminate). By combining the use of FRP rods and laminates Prota (2000) experienced a gain of approximately 1.6 times the amount of shear capacity in the strengthened samples, as was seen in the "virgin" samples. Prota (2000) concluded that the combination of FRP rods and laminates is a promising and flexible retrofit technique for concrete beam-column connections. 


\section{Chapter 3 - Laboratory Experiments}

\subsection{Introduction}

The laboratory experiments performed during Phase II of this research project consisted of evaluating the strength and load carrying capacity of "used" wooden railroad bridge stringers that have been tested and failed in bending and shear. The stringers were repaired with external GFRP composite materials. A total of four $50^{+}$year-old creosotetreated southern pine specimens were acquired from SBVR, Moorefield, WV. All specimens were in-service stringers that were deemed deficient or had significant checking and splitting along the length, and were removed by SBVR. All four specimens were tested to failure in bending and shear, and retrofitted using GFRP materials and phenolic-based adhesives. The strengthening schemes were developed by WVU-CFC from prior experimentation and research studies (Laosiriphong, 2000).

The purpose of these laboratory tests was to: (a) validate the effectiveness of phenolic adhesives in combination with GFRP when applied to creosote-treated beams, (b) test the specimen in bending and shear to failure, (c) repair or "retrofit" the failed beams, and (d) evaluate the load carrying capacity of the repaired beams. Two specimens were tested in pure bending, while the other two specimens were tested in shear. Initially, all four control specimens were tested to failure under four point bending. The damaged beams were then repaired using GFRP composite materials and retested to failure. The following sections describe the initial failure of each beam and the repair procedures of the specimen.

\subsection{Description of Beams}

A total of four (4) $50^{+}$year-old southern pine specimens with a length of $12^{\text {' }}$ and a cross-sectional area of 8 " $\times 16$ " were evaluated in this study. Specimens designated as Beam Three and Beam Four were found to have a density of $60 \mathrm{lb} / \mathrm{ft}^{3}$, while specimens 
designated as Beam One and Beam Two were found to have a density of $30 \mathrm{lb} / \mathrm{ft}^{3}$. The varying beam densities are due to the structural grade of the timbers.

Table 3.1 presents the following geometric properties of each specimen: moment of inertia (I), cross-sectional area (A), length (1), width (w), and depth (h).

Table 3.1 Geometric Properties of Specimens

\begin{tabular}{|c|c|c|c|c|}
\hline & Beam One & Beam Two & Beam Three & Beam Four \\
\hline I, Moment of Inertia (in $^{4}$ ) & 2482.6 & 2688 & 2696.9 & 2858 \\
\hline A, Area (in ${ }^{2}$ ) & 124 & 126 & 137.1 & 134 \\
\hline w, Width (in) & 8 & 7.875 & 8.5 & 8.375 \\
\hline 1, Length (in) & 132 & 144 & 144 & 144 \\
\hline h, Depth (in) & 15.5 & 16 & 16.125 & 16 \\
\hline
\end{tabular}

Figure 3.1 shows the wood cross-section retrofitted with GFRP in a U-shaped manner.

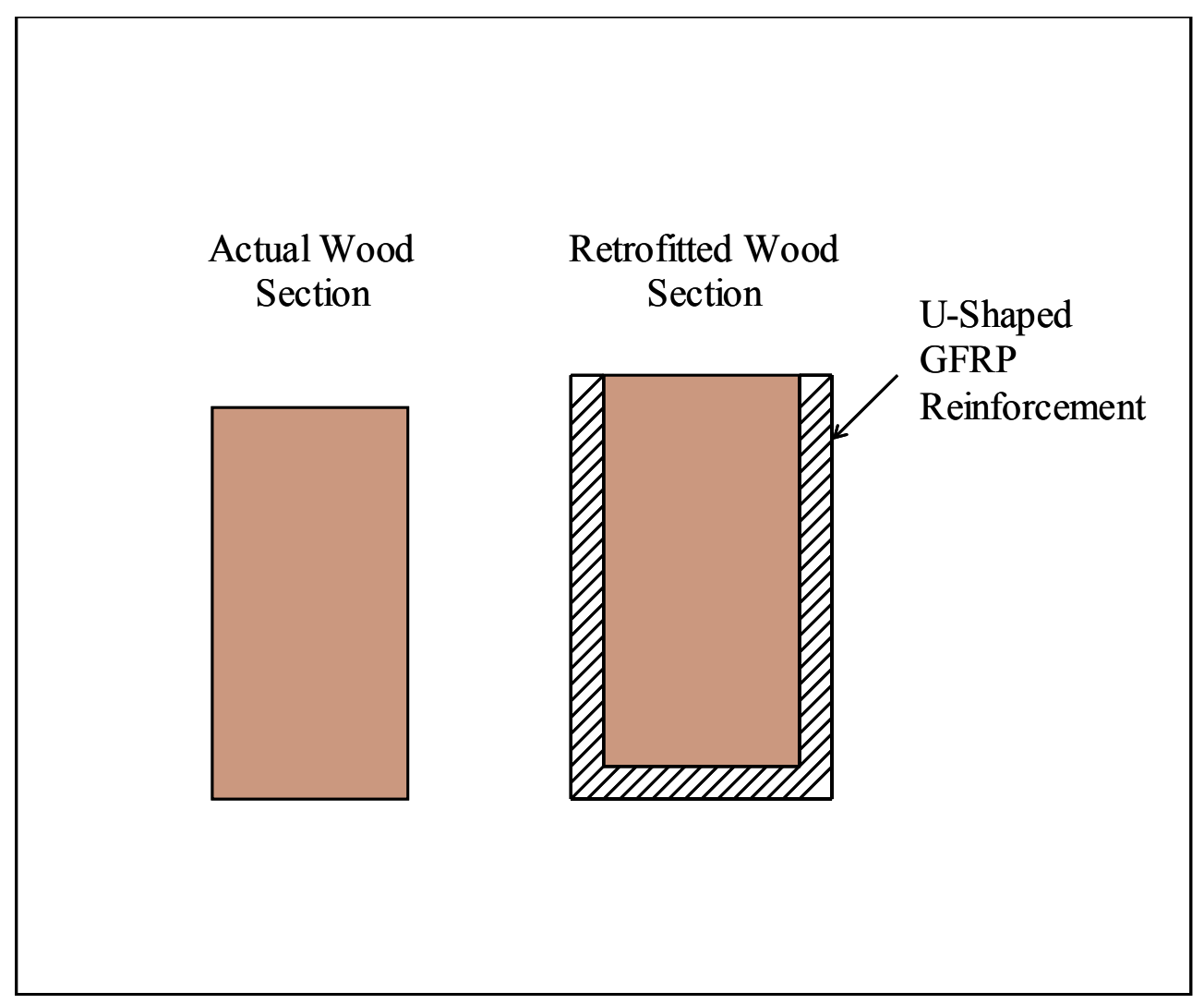

Figure 3.1. Diagram of wood beam retrofitted with GFRP. 


\subsection{Unreinforced Control Bending Tests}

\subsubsection{Introduction}

Two ( 8 in $\times 16$ in $\times 12 \mathrm{ft}$ ), $50^{+}$year-old creosote-treated southern pine timber stringers at moisture content $(\mathrm{MC})$ of $8-9 \%$ were tested to failure under four point loading configuration (Figure 3.2). Bending failure in timber beams is characterized by a horizontal shear check/split initiating along the span at mid-depth of the beam.

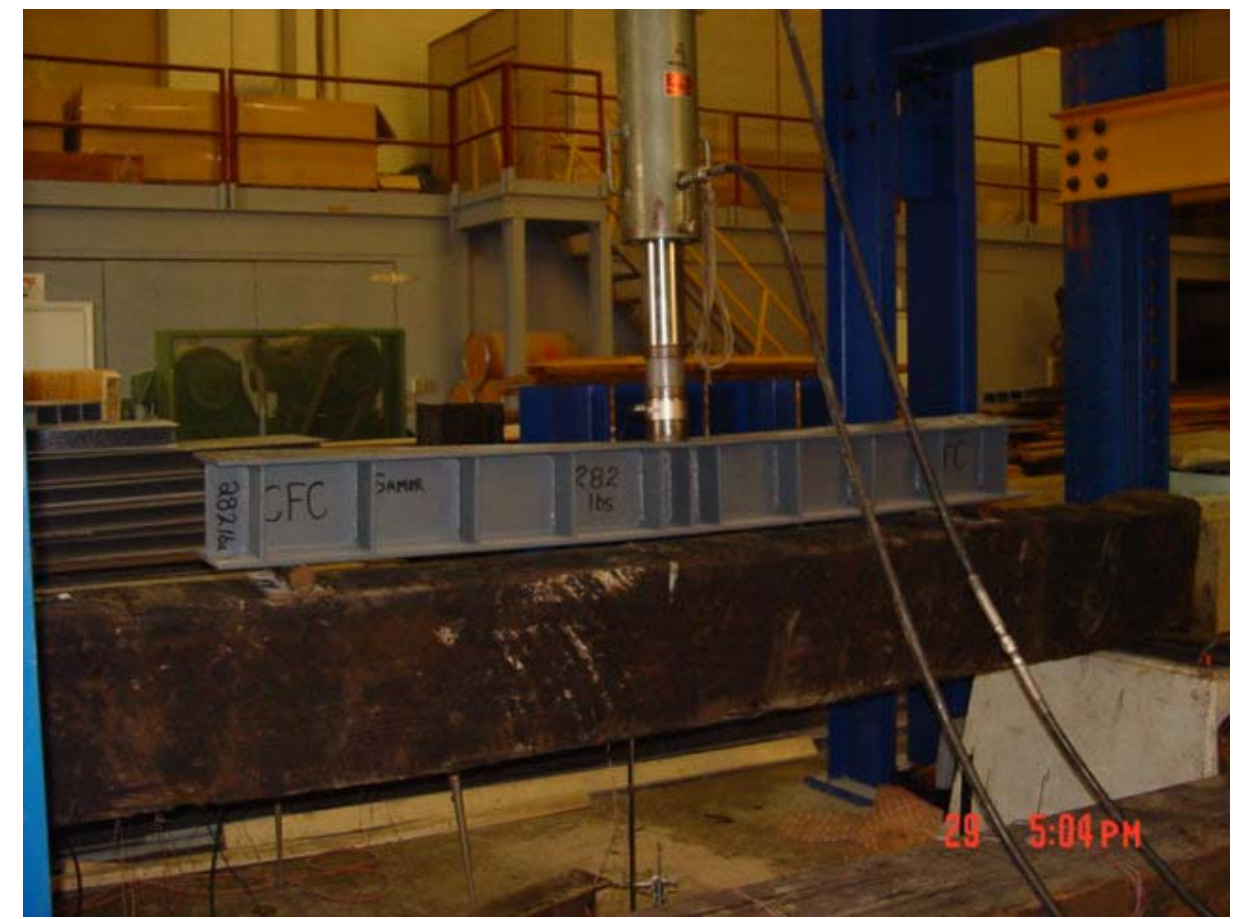

Figure 3.2. Four Point Loading Configuration

\subsubsection{Test Procedure and Description}

Bending tests were performed as per ASTM 198 in four-point bending, as shown in Figure 3.3. The span-to-depth ratio $(\mathrm{a} / \mathrm{h})$ for the bending specimens was 3.375 , and by ASTM 198, a/h $\geq 5$ will induce bending failure. Due to the large depth (i.e., 16 in.) of these specimens, an $\mathrm{a} / \mathrm{h} \geq 5$ could not be attained. All test specimens were instrumented with electrical strain gages placed at midspan on the tension side. Specimens were also instrumented with a rosette strain gage placed at mid-depth to evaluate shear strain. Deflection was also measured using a Linear Variable Differential Transformer (LVDT) placed at midspan. The load was monitored using a load cell. A data acquisition system was used to collect data utilizing "Strain Smart" software. Load versus deflection, 
stress/strain, and load vs. shear strain curves were developed, and modes of failure were identified. The following sections contain summaries of the results of each initial bending failure test.

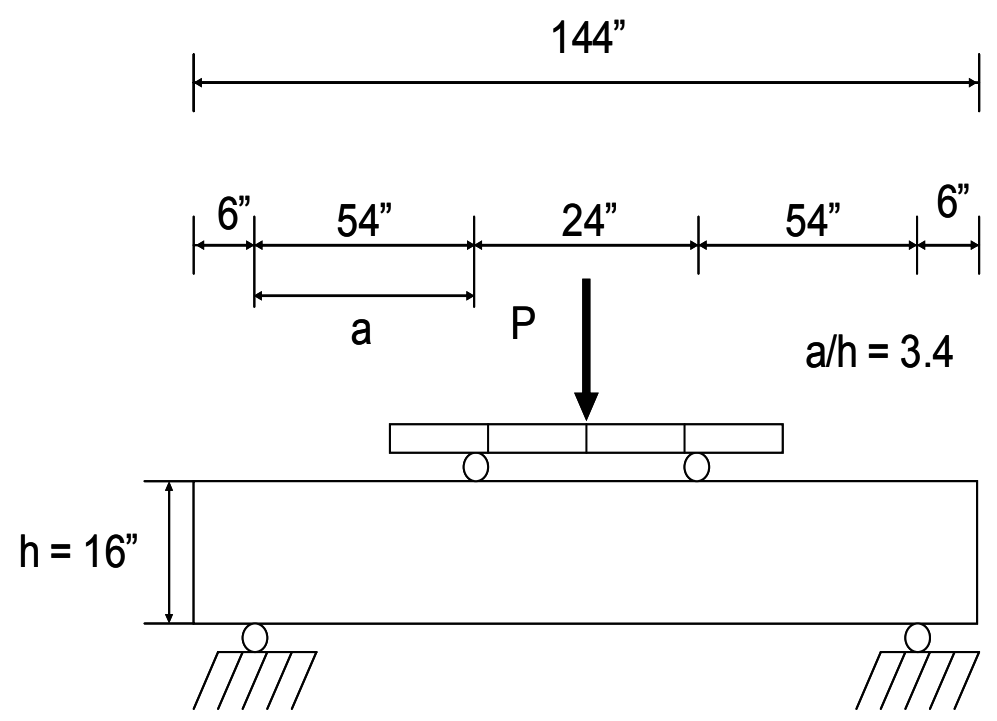

Figure 3.3. Bending Test Setup

\subsubsection{Beam Two - Control Specimen (Bending)}

The control specimen (undamaged and intact) was tested to failure according to ASTM 198. Cracking sounds were audible from the initial loading of the beam and became louder as the load increased. This increase in checking noise was accompanied by a large pop at a loading of approximately 12,000 lb. Loading increased at a linear rate until the beam failed at a loading of $17,060 \mathrm{lb}$. At this point, there was a large popping noise and the load dropped to approximately 14,500 lb. At this point large horizontal shear cracks became visible on both sides of the beam. The beam continued to take loading, surpassing the initial failure. As the load became greater, horizontal shear cracks propagated further towards to ends of the beams. The propagation of the cracks continued along with the checking sounds until the beam reached an ultimate load of $18,070 \mathrm{lb}$. The beam failed in bending (Figure 3.4). The load versus deflection curve for beam two can be seen in Figure 3.5. 


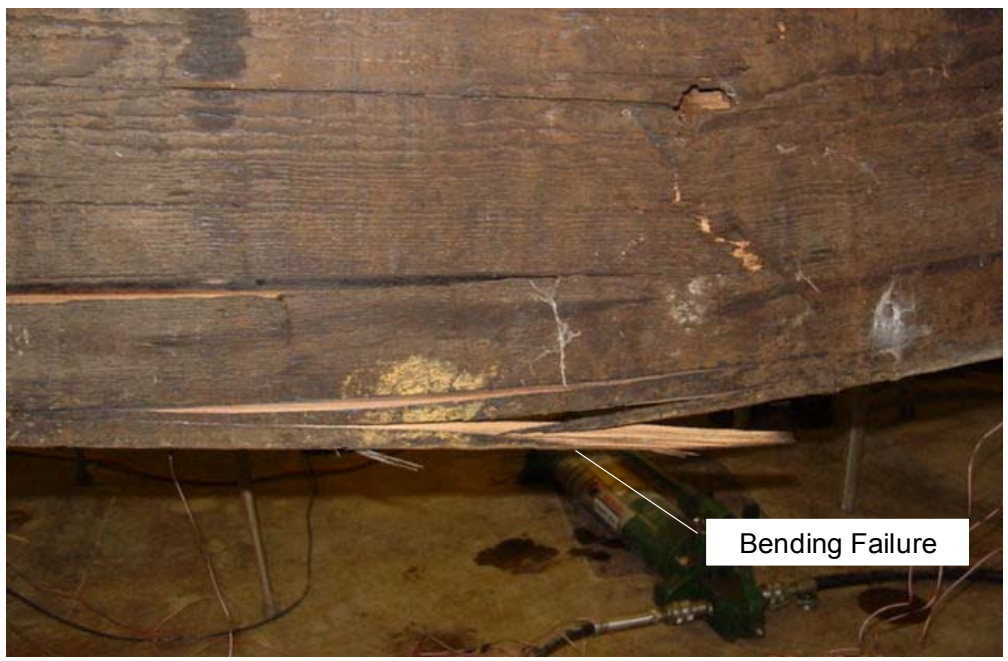

Figure 3.4. Control Beam Two - Bending Failure

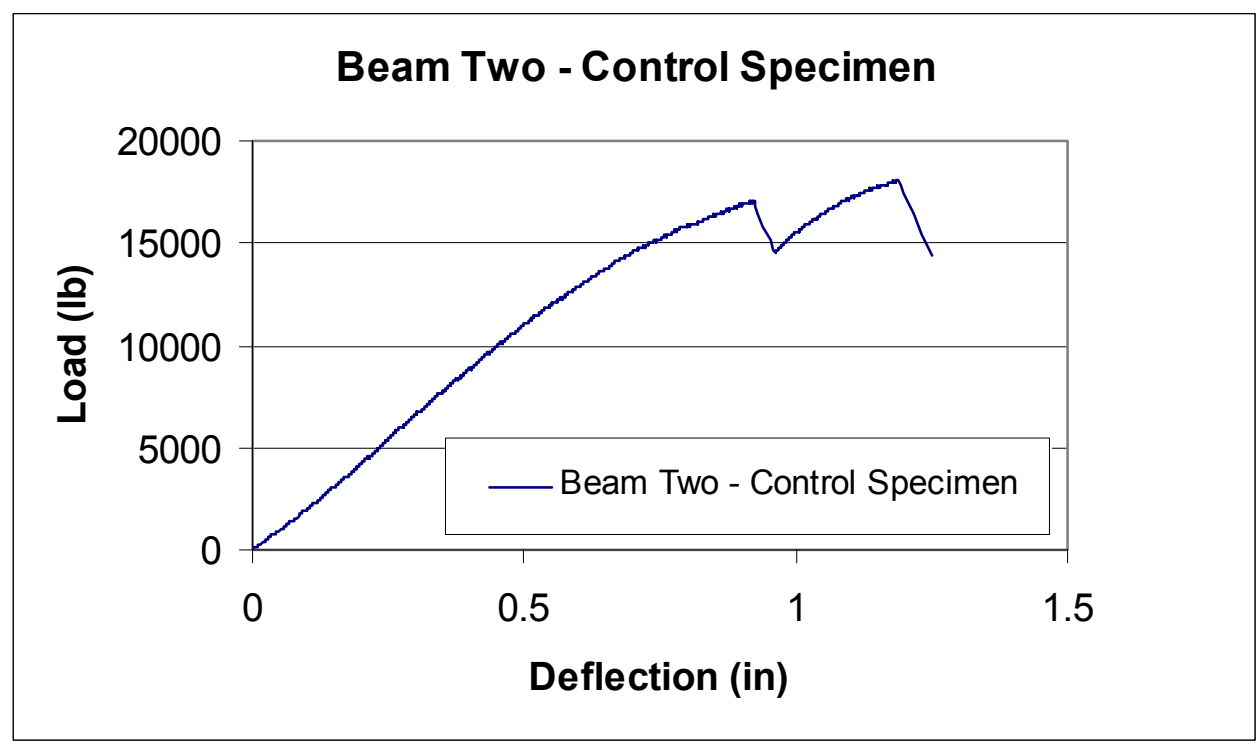

Figure 3.5. Load vs. Deflection for Control Specimen Beam Two

Throughout the length of the experiment, the smell of creosote was very strong. After the load was removed from the beam, it became very apparent that a significant horizontal shear failure had occurred at approximately 2 inches from the bottom of the beam near the support on the left side of the beam (Figure 3.6). It is assumed that this 
failure weakened the beam and initiated the bending failure. The ultimate mode of failure was a sudden horizontal shear failure. The strain at failure of the beam measured at the extreme fibers of the midspan tension side was $3393 \mu \varepsilon$; the maximum measured deflection was 3.74 inches $(\approx \mathrm{L} / 35)$, while the maximum load was $18,070 \mathrm{lb}$.

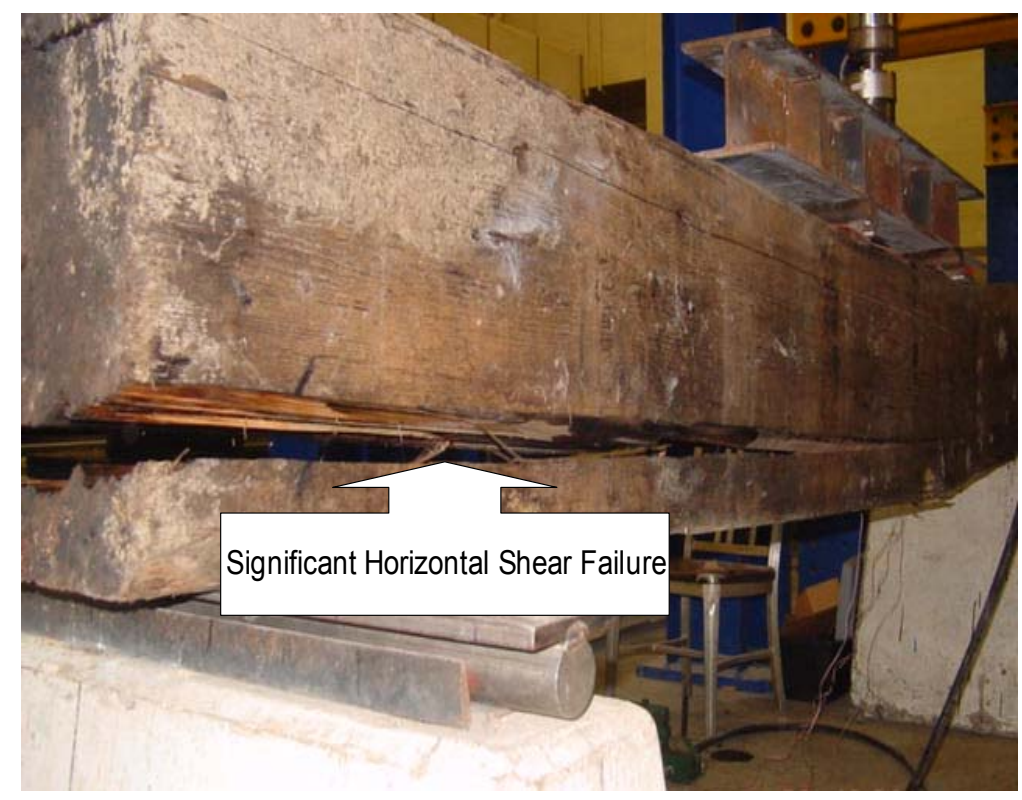

Figure 3.6. Significant Horizontal Shear Failure in Control Beam Two

\subsubsection{Beam Four - Control Specimen (Bending)}

This undamaged and intact specimen ( 8 in $\times 16$ in $\times 12 \mathrm{ft}$ ) was also tested to failure in accordance with ASTM 198. During the initial loading of this beam, no audible checking sounds were heard. When the load reached, 60,000 lb small horizontal cracks became visible near the neutral axis of the beam and began to propagate towards to ends of the beam. The loading continued until the maximum of load of $86,050 \mathrm{lb}$ was reached and sudden failure occurred under the right bearing plate of the load distribution beam. After achieving maximum load level, the load dropped to around 61,500 lb and remained there for the rest of the loading. After failure, it was observed that the horizontal shear crack initiated by a flexural failure, propagated through the entire width of the beam (Figure 3.7). The load versus deflection curve for beam four is shown in Figure 3.8. 


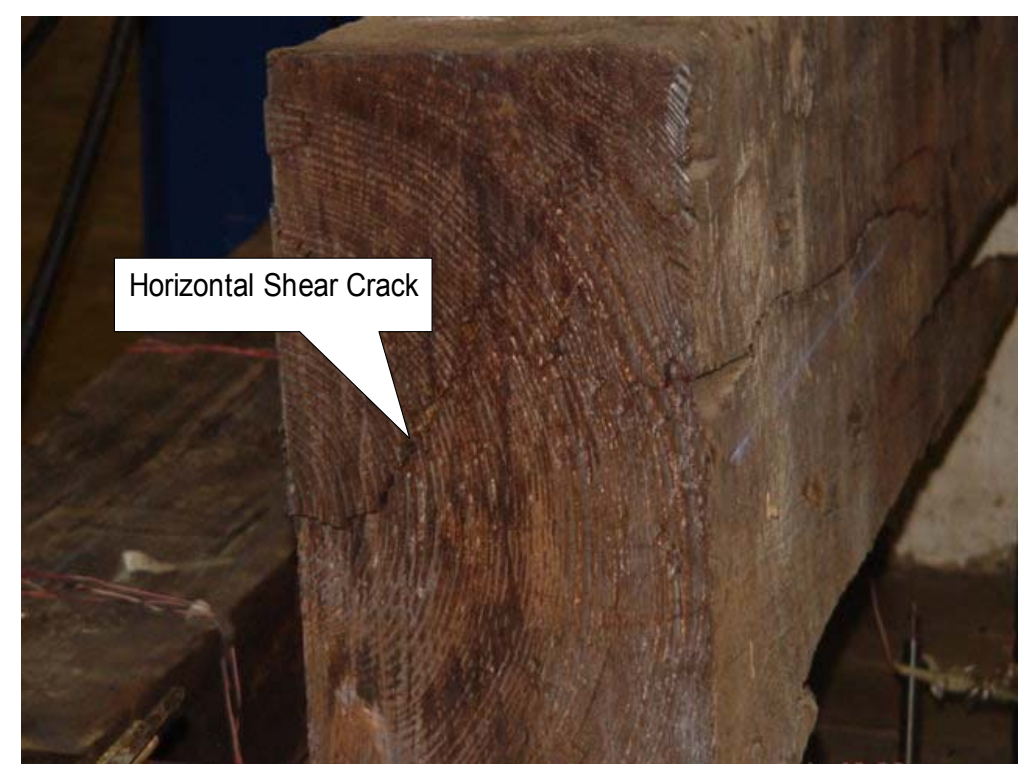

Figure 3.7. Horizontal Shear Crack propagated throughout beam width (Beam 4).

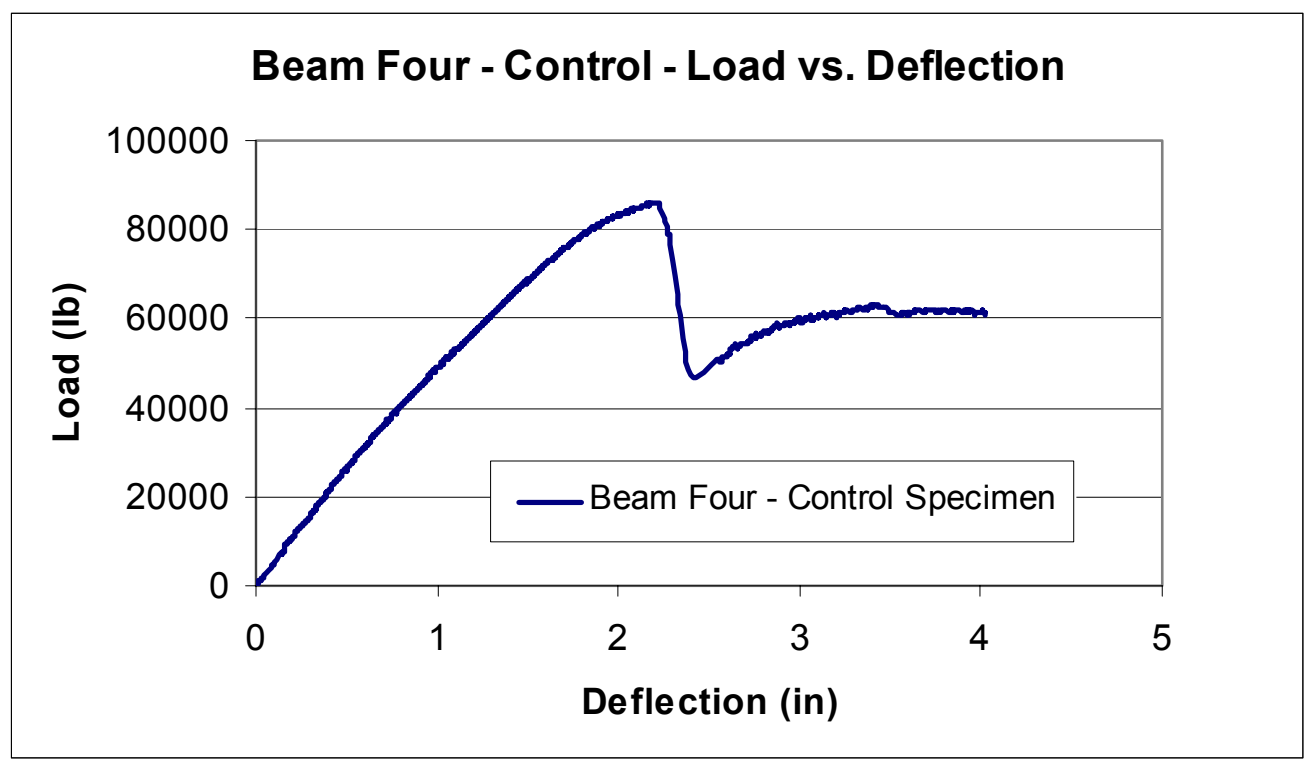

Figure 3.8. Load vs. Deflection for Control Specimen Four

The smell of creosote was also strong throughout the duration of the test and became very intense after the beam failed. The ultimate mode of failure in Beam four was a sudden horizontal shear failure, as shown in Figure 3.9. The strain at failure measured 
from the extreme tension fibers of the beam was $3,834 \mu \varepsilon$; the maximum measured deflection at midspan was 4.50 inches, while the maximum loading was $86,050 \mathrm{lb}$. Beam four was able to sustain a much greater load than beam two.

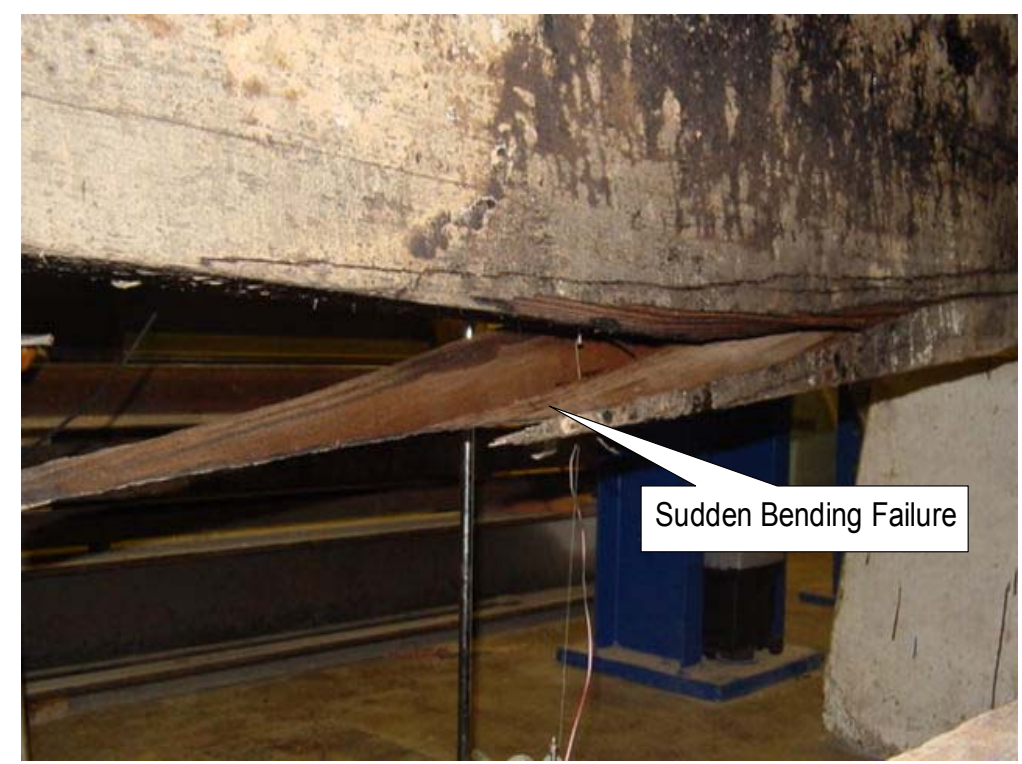

Figure 3.9. Sudden Bending Failure in Beam Four

The maximum load in beam four was almost five (5) times greater than the maximum load in beam two. This is attributed to the higher density of the specimen. The density of beam four was approximately $60 \mathrm{lb} / \mathrm{ft}^{3}$, whereas the density of beam two was approximately $30 \mathrm{lb} / \mathrm{ft}^{3}$.

\subsection{Unreinforced Control Shear Tests}

\subsubsection{Introduction}

As mentioned earlier, two beams were designated as specimens to be tested to induce a shear failure. These beams were assigned as Beam One and Beam Three. The shear specimens retrieved from SBVR were also $50^{+}$year-old creosote-treated Southern Pine at a Moisture Content (MC) between $8-9 \%$, similar to the bending specimens. 


\subsubsection{Test Procedure and Descriptions}

Shear tests were performed as per ASTM 198 in four-point bending, as shown in

Figure 3.10. The shear span to depth ratio $(\mathrm{a} / \mathrm{h})$ for the shear specimens was 1.875 . According to ASTM 198, $\mathrm{a} / \mathrm{h} \leq 5$ will induce shear failure. Due to the large depth of these specimens an $\mathrm{a} / \mathrm{h} \leq 5$ was easily attained, as to ensure a shear failure. All test specimens were instrumented with electrical strain gages placed at midspan on the tension side. Specimens were also instrumented with a rosette strain gage. The rosettes were placed at the neutral axis of the beam; they allowed the collection of maximum principal strain, and minimum principal strain. Shear strain was calculated by the "Strain smart" data acquisition software. Deflection was measured using an LVDT placed at midspan. The load was monitored using a load cell. A data acquisition system was used to collect data, utilizing Strain Smart software. The beams were tested to failure: Load vs. deflection, stress/strain, and load vs. shear strain curves were developed and the modes of failure were identified.

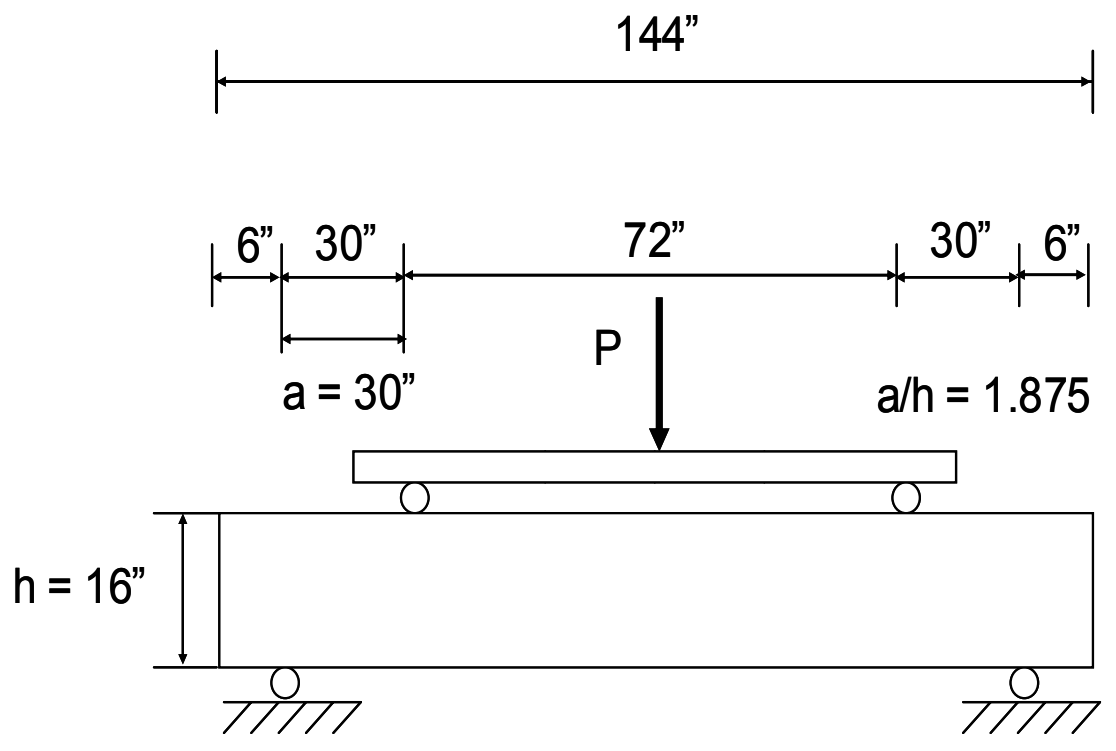

Figure 3.10. Shear Test Setup

\subsubsection{Beam One - Control Specimen (Shear)}

Beam one (undamaged and intact) was tested to failure under four-point bending as per ASTM 198, with an a/h $<5$, to ensure shear failure. From the initial onset of 
loading, small checking noises were audible. These checking sounds grew louder as the load continued to increase. As the load reached $37,000 \mathrm{lb}$ a loud pop was accompanied by a small drop in load, thus indicating an initial failure. The specimen continued to take additional load until the load reached 47,963 lb when a sudden horizontal shear failure occurred along the midsection of the beam. After the maximum load level was reached, the load declined and stabilized at 36,000 lb. The specimen ultimately failed in a horizontal shear failure (Figure 3.11), due to the low a/h ratio. The load versus shear strain curve for beam one can be seen in Figure 3.12. The maximum shear strain measured at the neutral axis of the specimen was $5178 \mu$. A high shear strain value indicates lower shear stiffness, for this beam the computed shear stiffness $(G)$ was 60 , $484 \mathrm{psi}$. The maximum bending strain measured at the extreme tension fiber of the specimen was $843 \mu \varepsilon$. This is attributed to the low a/h ratio. The beam was loaded in shear producing a lower tensile stress at the bottom of the beam. The maximum measured deflection at the midspan of the specimen was 1.93 inches. The maximum load was 47, $963 \mathrm{lb}$.

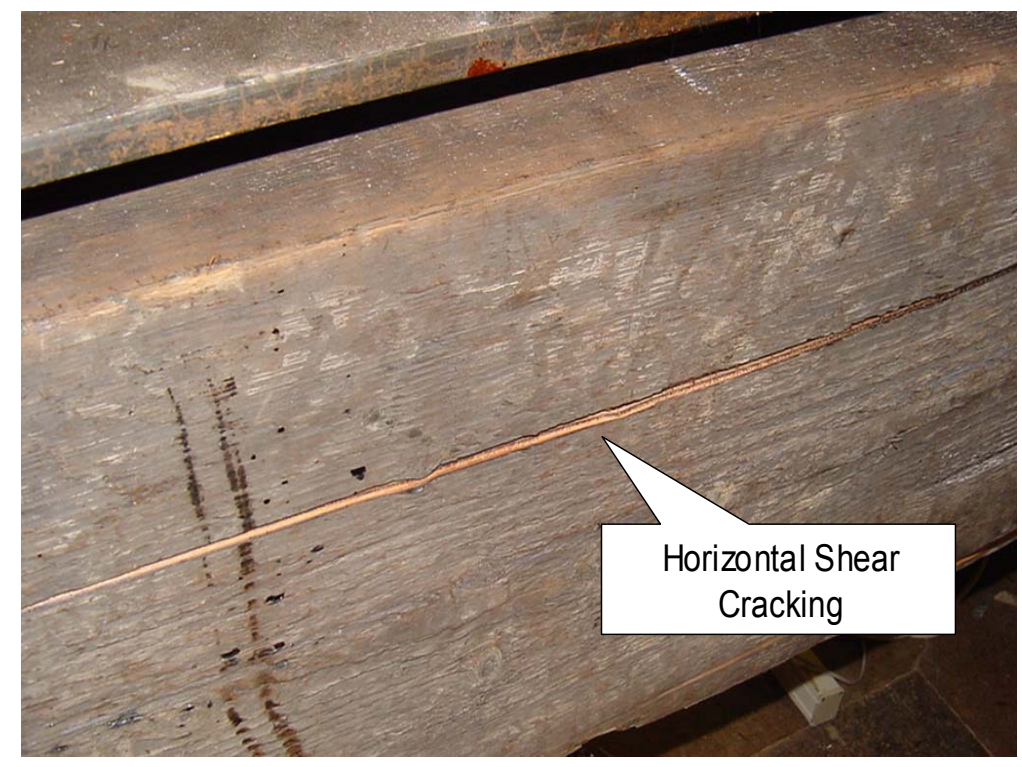

Figure 3.11. Beam One Horizontal Shear Cracking 


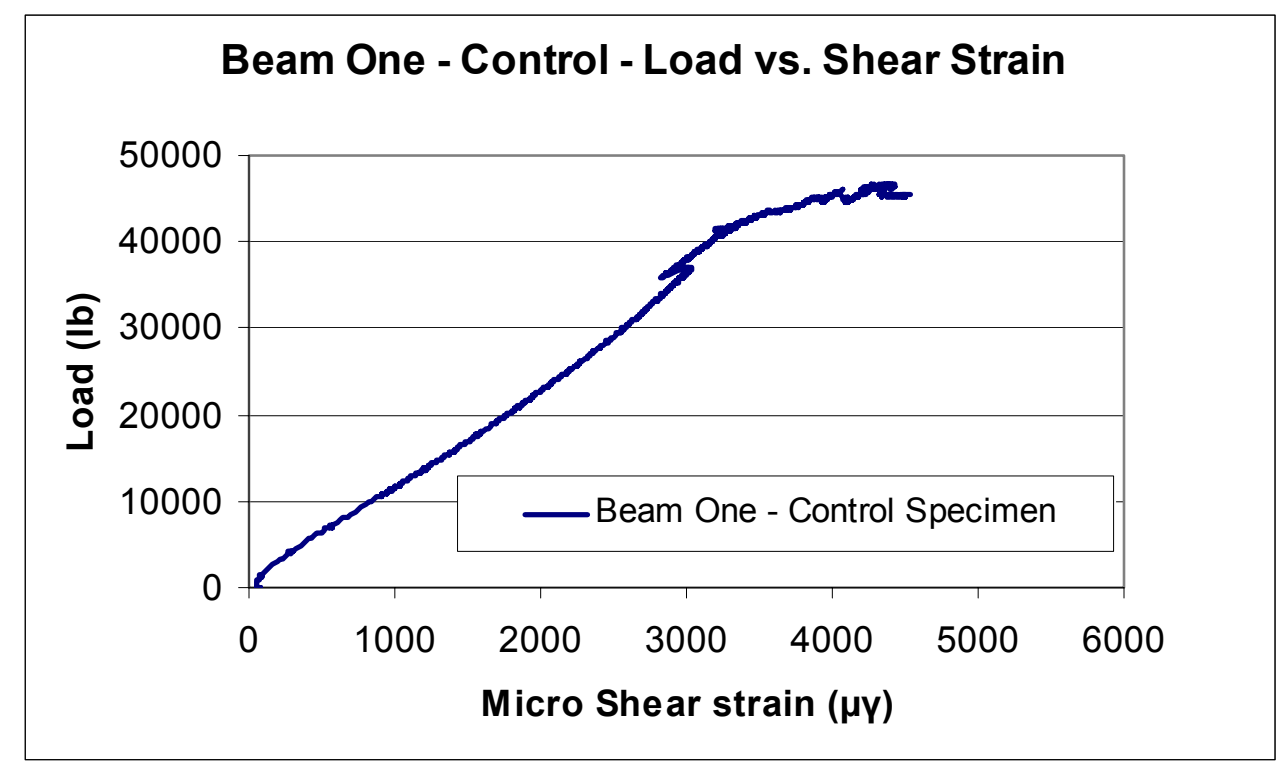

Figure 3.12. Load vs. Shear Strain for Control Specimen One

\subsubsection{Beam Three - Control Specimen (Shear)}

Beam three, also undamaged and intact, was failed under four-point loading according to ASTM 198 with an $\mathrm{a} / \mathrm{h}<5$ to induce shear failure. Small checking sounds were heard at a load of 45,000 $\mathrm{lb}$ and continued throughout the remainder of the test. The load continued linearly until the initial failure at 101,000 lb. After the initial failure, the load continued to climb until again until sudden ultimate failure occurred at 106, $550 \mathrm{lb}$. The ultimate failure mode of the specimen was sudden horizontal shear failure induced by the low a/h ratio. The maximum shear strain measured at the neutral axis of the specimen was $1415 \mu \gamma$. The maximum measured deflection at the midspan of the specimen was 2.56 inches and the maximum loading was 106,550 lb. Due to a malfunction of the uniaxial strain gage, the strain readings were not used for further analysis. Load versus shear strain curve is shown in Figure 3.13. Beam Threes' ability to achieve a loading of 106, $550 \mathrm{lb}$ is attributed to its high density. 


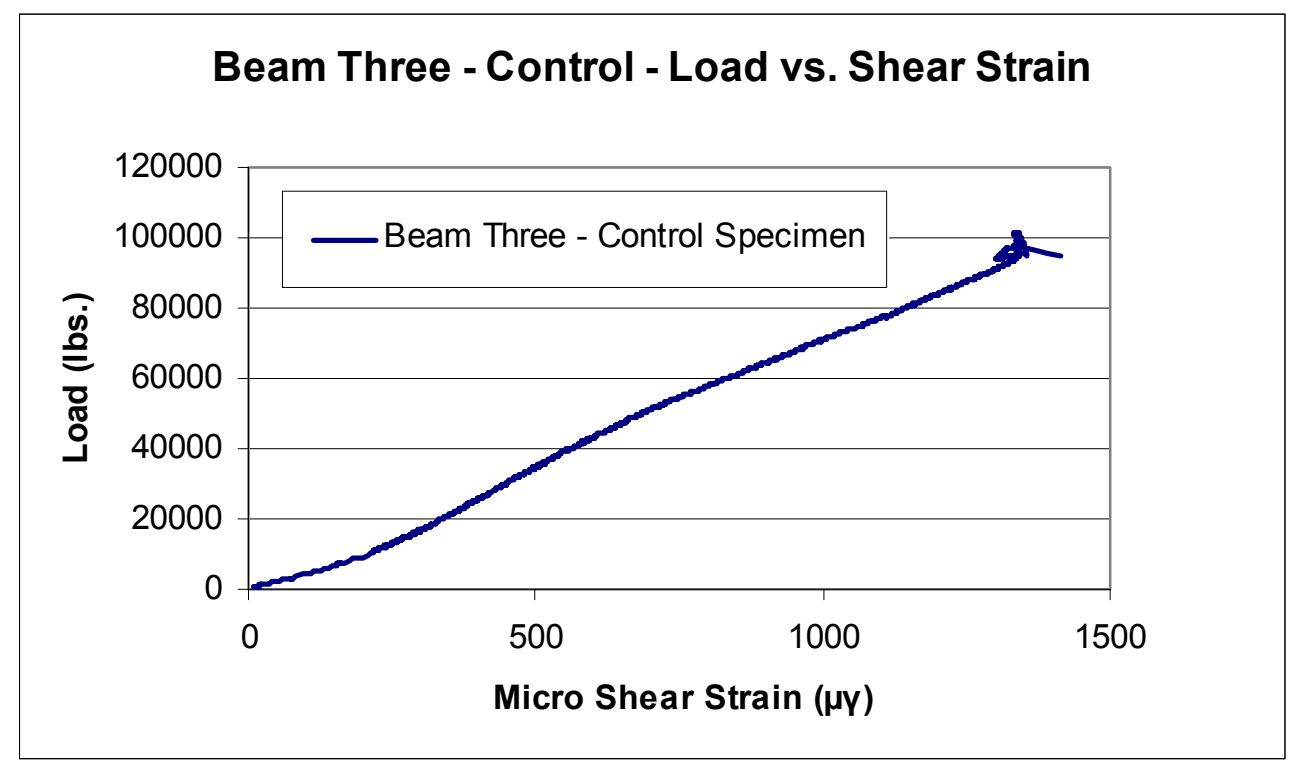

Figure 3.13. Load vs. Shear Strain for Control Specimen Three

The differences in load carrying capacity between beam one and three, is attributed to the large difference in the density of the beams. Beam Three had a density of $60 \mathrm{lb} / \mathrm{ft}^{3}$, while Beam One's density was $30 \mathrm{lb} / \mathrm{ft}^{3}$.

\subsection{Properties of Undamaged Intact Specimens}

Table 3.2 presents the material properties of each beam determined through the testing, described Section 3.3 of this report. These material properties include Shear Modulus (G), Modulus of Elasticity (E), and Density.

Table 3.2 Summary of Tests of Control Specimens

\begin{tabular}{|c|c|c|c|c|}
\hline \multirow{2}{*}{ Property } & \multicolumn{2}{|c|}{ Shear Tests } & \multicolumn{2}{c|}{ Bending Tests } \\
\cline { 2 - 5 } & Beam One & Beam Three & Beam Two & Beam Four \\
\hline Density $\left(\mathrm{lb} / \mathrm{ft}^{3}\right)$ & 30 & 60 & 30 & 60 \\
\hline E, Modulus of Elasticity (psi) & N/A & N/A & 348,958 & 710,121 \\
\hline G, Shear Modulus (psi) & 60,484 & 383,036 & N/A & N/A \\
\hline
\end{tabular}


The modulus of elasticity and shear modulus values were obtained from the linear part of the load/deflection and load/shear strain curves, respectively. These relationships are presented in the Sections $3.7 \& 3.8$, respectively. From Table 3.2, it is shown that the specimens of heavier density display increased mechanical properties when compared to the lighter beams. For example, Beam Four was found to have a much higher modulus of elasticity than Beam Two, and Beam Three achieved a higher modulus of rigidity than Beam One. In addition, several references have reported shear moduli values (for Pine) as a function of modulus of elasticity in the range of $\mathrm{E} / 16$ to $\mathrm{E} / 18$ (Gurfinkel, 1981; Bodig and Jayne, 1993), while others have reported average values of shear moduli expressed as ratios with respect to $E$ in the range of $0.05-0.1$ (FPL, 1999). However, Lang (2004) suggested that values for shear moduli for Pine less than 500,000 psi are reasonable. Usually strength and stiffness values increase with higher specific gravity and density. However, the values of these specimens are much lower than values typically observed for southern pine beams of this size. According to a study performed by the U. S. Department of Agriculture, Forest Product Laboratory, the density of pine range in value between $36-52 \mathrm{lb} / \mathrm{ft}^{3}$ dependent upon moisture content (Alden, 1997). The moisture content of the specimen was between $8-9 \%$. The specimens were also creosote treated, which might have affected the density.

In addition, a laboratory test was conducted to evaluate variations of shear stiffness values along the span at mid-depth. A 6"x 8" yellow poplar specimen at $10.7 \%$ moisture content, was tested under bending in a three-point and four-point bending configuration in the linear range. Three rosette strain gages were placed at mid-depth of the beam to measure shear strain. One rosette was placed nine inches from the support, one at the center line of the beam, and one at mid shear span of the beam. Figure 3.13(a) and 3.13(b) show the load vs. shear strain for the two test configurations. 


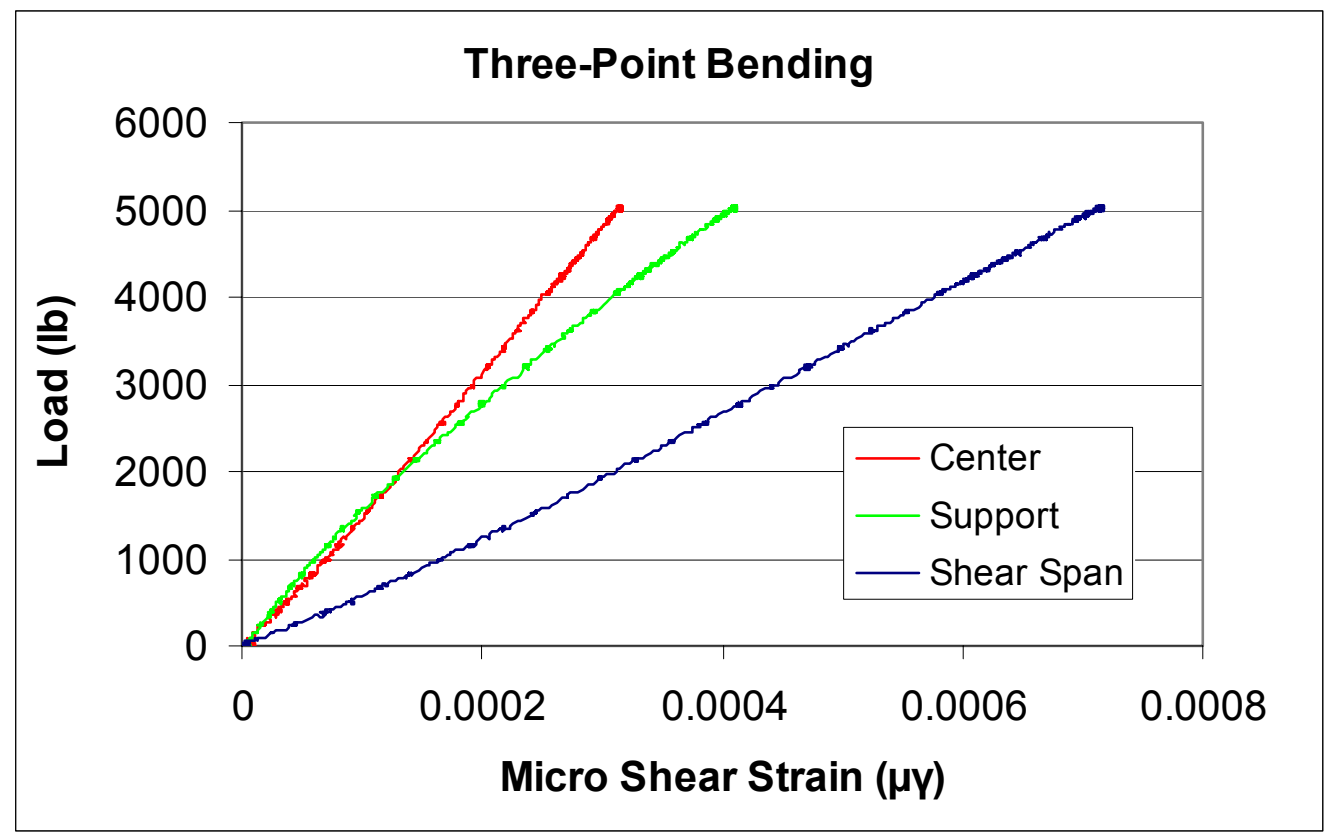

Figure 3.13(a). Load vs. Micro Shear Strain for Three-Point Bending

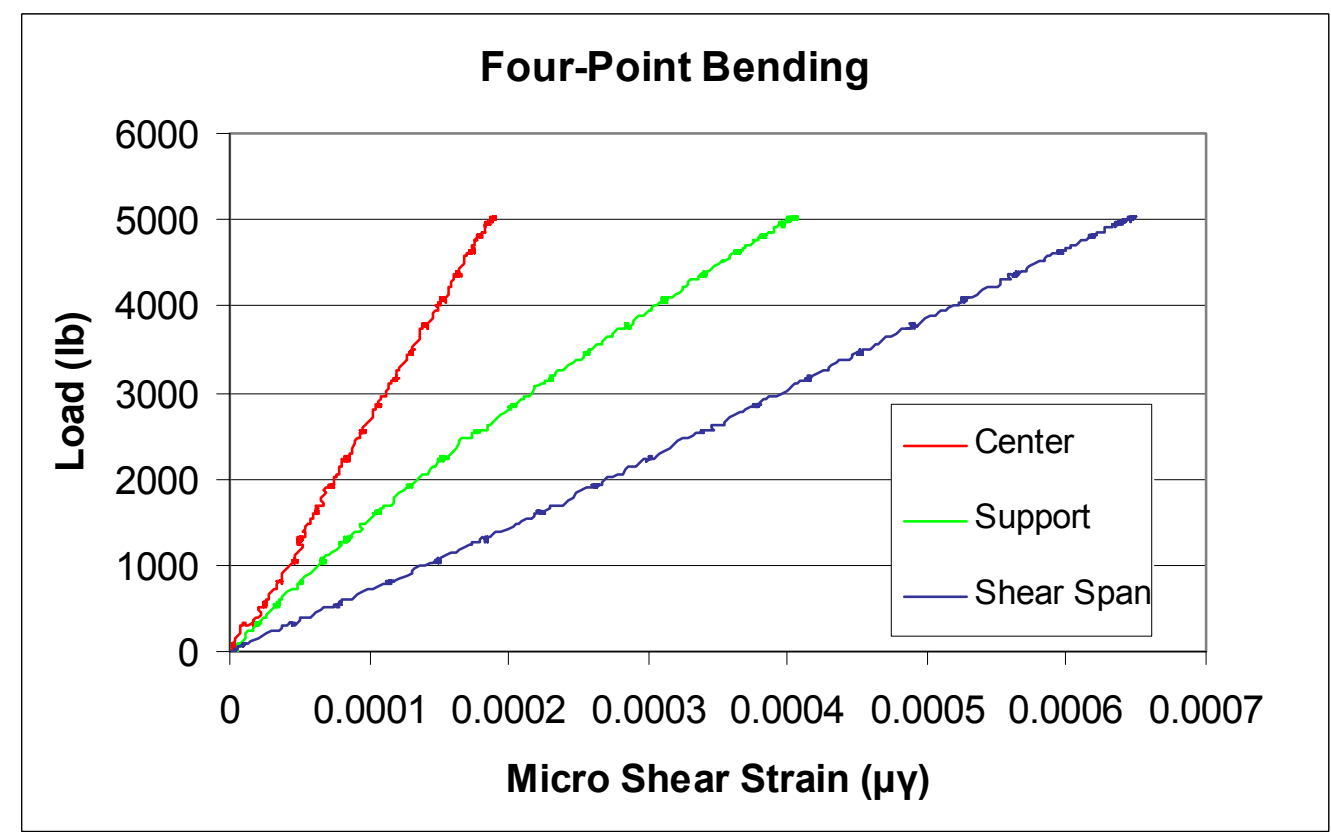

Figure 13.3(b). Load vs. Micro Shear Strain for Four-Point Bending

As shown, the slope of the load vs. micro shear strain plot is the highest for the center of the beam and lowest in the shear span of the beam. Furthermore, the highest shear stiffness is at the center of the beam and the lowest shear stiffness is in the shear 
span of the beam. For design purposes, the lowest shear stiffness value is used, since it results in a more conservative approach. The value obtained from this test for the shear stiffness $(\mathrm{G})$ from the shear span location is approximately $150,000 \mathrm{psi}$. It is interesting to note that the shear stiffness value from a torsion test also resulted in a value approximately equal to 153,000 psi.

\subsection{Repaired Beam Tests (Bending)}

\subsubsection{Introduction}

In order to demonstrate the effectiveness of the GFRP composite wrapping system in restoring damaged or failed wood members in the field, beam two and beam four were repaired and retested. Each beam was repaired using a $U$-shaped GFRP composite wrap at the location of maximum moment between the two concentrated loads. The $U$-shaped composite system was selected because repairs made on in-situ beams usually do not allow access to the top surface of the beam. Therefore, to simulate field conditions it was assumed that access to the top of each beam was not readily available.

\subsubsection{Repair Procedure \& Test Setup}

Before application of the GFRP fabric all exposed edges of the beam were rounded using a hand held sander to make the fabric bend smoothly around the corners and not break due to stress concentration under loading. All areas of the beam being treated with the GFRP wrap were then coated with a primer (phenolic resin) to enhance the durability of the bond between GFRP wrap and substrate. This primer was left to cure for 24 hours before placing of the wrap.

Three layers of GFRP composite fabric soaked with phenolic resin were determined as appropriate for this type of repair as developed by CFC researchers (Laosiriphong, 2000). A Phenolic based adhesive in combination with the GFRP composite wrap was used for the rehabilitation because it was found to be compatible with the creosote treated wood substrate and provided adequate chemical cross-linking (a.k.a., bond) between the GFRP wrap and the wood substrate. The fabric used in this 
study is E-glass, based on its advantage over other fabrics in terms of cost. The density of the GFRP fabric is $28 \mathrm{oz} / \mathrm{sq} . \mathrm{yd}$. It is saturated with the resin during the wet hand-lay up wrapping process.

The Phenolic adhesive G 1131-A, and formaldehyde hardener G 1131-B were purchased from the Borden Chemical Company. Schematics of the rehabilitation areas on Bending is shown in Figure 3.14.

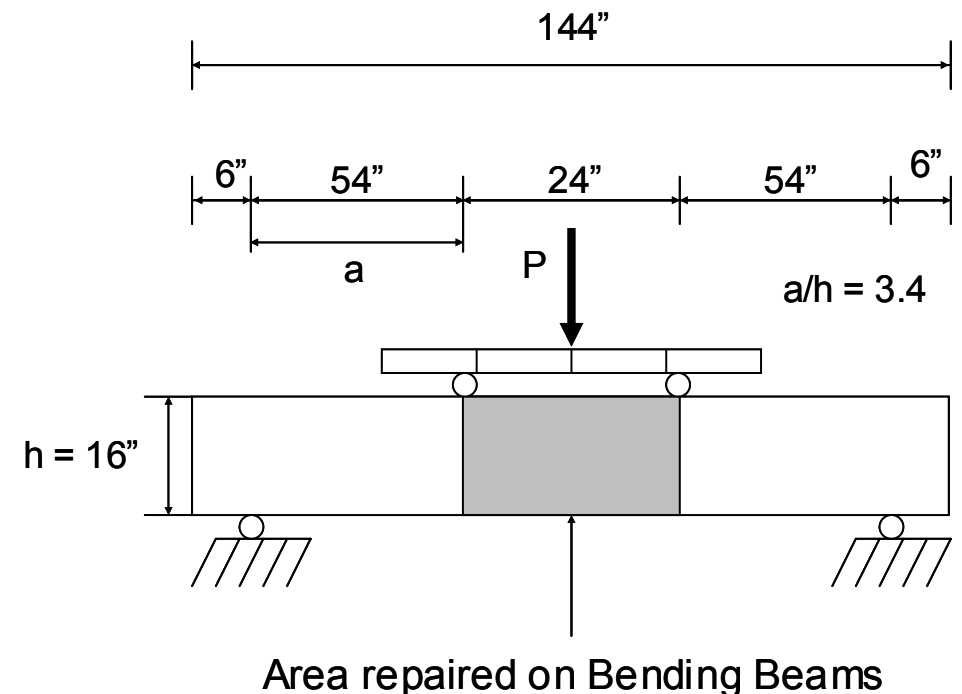

Figure 3.14. Typical of Bending GFRP wrapped Area.

By rehabilitating the bending specimens in the maximum moment zones, the area of GRFP wrap was minimized, while maximizing the regain of strength within the specimen. Approximately, $18 \%$ of the span was covered using GFRP composite materials.

The GFRP composite fabric was soaked in the phenolic formaldehyde adhesive and a manual "hand-wringer" was then used to remove excess resin from the fabric. After the excess resin had been squeezed-out, the GFRP fabric was applied to the beam by hand-lay up and a small amount of resin was applied by hand to "seal" the edges of the fabric. An air powered staple gun was used to secure each piece of GFRP fabric to the specimen. This allowed each piece to be pulled tightly, driving out any entrapped air voids between the layers of wrap. Three layers of GFRP wrap was applied to the specimen. Each layer consisted of two pieces of seventeen-inch wide fabric with an overlap of ten inches. This length of overlap was selected to maximize the fabric to 
substrate bond area while providing sufficient bond between the individual pieces of composite wrap. Once the wrap was sufficiently secured on the specimen, wax paper was layered to completely cover the surface of the GFRP wrap. The wax paper is applied to prevent the plywood from sticking to the wood substrate. After the wax paper was in place, pressure was applied to the wrap to attain a complete bond between all layers of wrap and the substrate. This pressure took the form of plywood cut to fit the dimensions of the beam being wrapped with fabric. The plywood was attached to the specimen using the air powered staple gun. This provided uniform pressure throughout the entire area of the wrap. This uniform pressure allows a more complete bond to form between not only the layers of wrap, but also the wrap and the wood. The plywood was left in-place throughout the drying/curing process (the manufacturers recommended curing time is 24 hours).

Once curing was complete, the plywood was removed from the specimen and any hardened excess GFRP wrap was removed using a hand grinder and a diamond bladed circular saw specifically designed to cut GFRP. This provides smooth edges on all surfaces of the specimen. In field rehabilitation, this would prevent water entrapment and bond degradation. Once the rough edges of the beam had been removed, the final step in the wrapping process was to seal the edges with phenolic-based adhesives as discussed previously. When used in field applications the sealing of edges prevents water infiltration and moisture collection, thus preventing the weakening of the bond between the layers of the GFRP.

Once the rehabilitation process was completed, the test specimens were instrumented with electrical strain gages placed at midspan on the tension side on the surface of the GFRP wrap. Specimens were also instrumented with a rosette strain gage on the surface of the GFRP wrap. This data will be used for comparative analysis with the unreinforced control specimens. The rosette was placed at the neutral axis of the beam; it allowed the collection of shear strain, maximum principal strain, and minimum principal strain. Deflection was measured using an LVDT placed at midspan. The load was monitored using a load cell. A data acquisition system was used to collect data, utilizing Strain Smart software. The repaired beams were tested to failure: Load vs. deflection, load vs. shear strain curves were developed, and the modes of failure were 
identified. All tests were completed in four point bending as per ASTM 198, with and $\mathrm{a} / \mathrm{h}$ ratio of 3.4.

\subsubsection{Beam Two - Repaired Bending Test}

To evaluate the structural response of the repair procedure, the repaired specimen was tested to failure in four-point bending in accordance with ASTM 198. Small checking sounds were heard upon the initial loading of the beam. These checking sounds became gradually louder until they were accompanied by a large popping noise at 4,425 lb. The loading had increased linearly until that point, but continued in a nonlinear manner. This behavior is shown in the load vs. deflection curve, Figure 3.15.

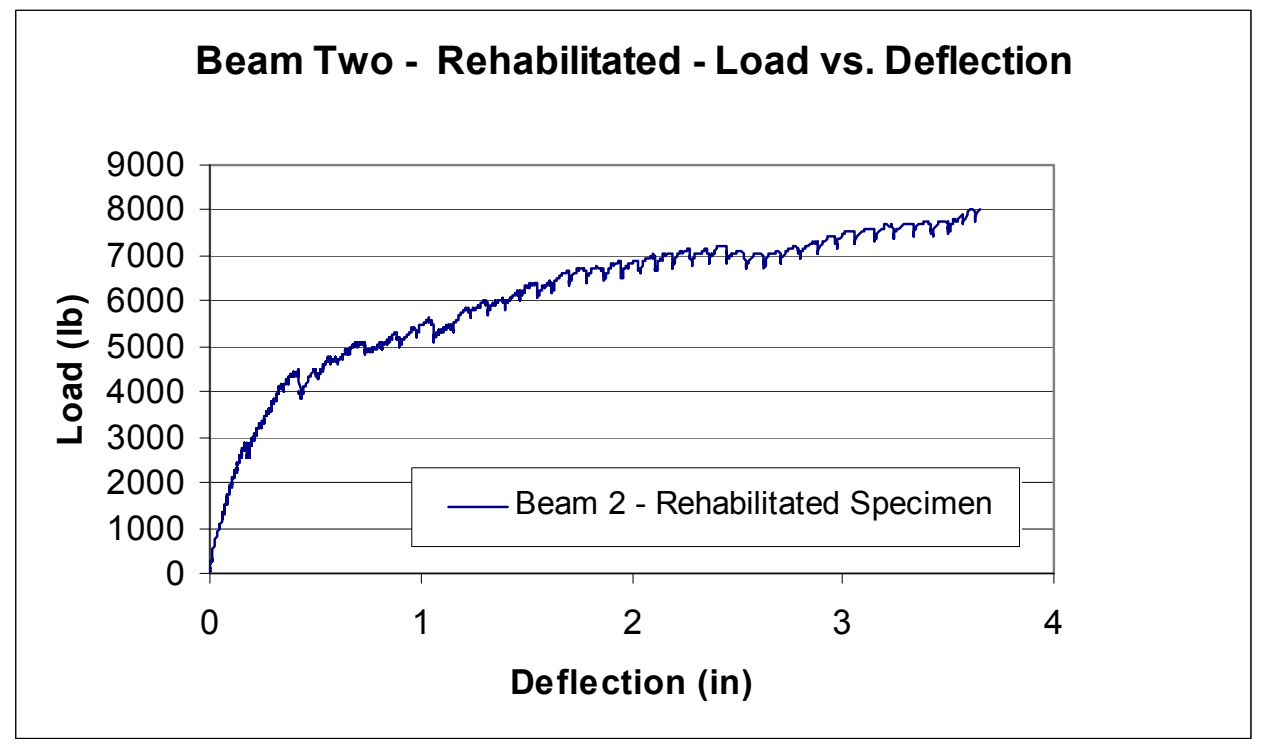

Figure 3.15 Load vs. Deflection Rehabilitated Specimen Beam Two

As the load reached 5,700 $\mathrm{lb}$ the GFRP wrap began to separate along the sides of the beam. This separation continued until total separation at approximately $8,300 \mathrm{lb}$. After inspection of the separation, it was observed that $50 \%$ of the failure occurred within the fibers of the wood, i.e., the wood fibers ripped apart while maintaining a bond between the GFRP wrap and the wood. This separation can be seen in Figure 3.16. Although the GFRP wrap separated completely, the beam continued to take load. This is attributed to the fact that there was no separation of the GFRP wrap from the wood on the bottom of the beam (Figure 3.17). This separation of the side panels of GFRP wrap is caused by torsion in the specimen during loading. This is important because the beam was failing in bending. The load continued to increase until a sudden bending failure 
occurred at a maximum load of 10,775 lb. After failure, the loading decreased to around $6,700 \mathrm{lb}$ and remained there until the completion of the test. The ultimate mode of failure was sudden bending failure under the left bear plate of the load distribution beam, accompanied by horizontal shear failure. The horizontal shear failure is evident from the crack that propagated throughout the midsection of the beam as shown in Figure 3.18.

The maximum strain measured at the extreme tension fibers of the GFRP wrap was 2,851 $\mu \varepsilon$. The maximum measured deflection of the specimen was 3.73 inches while the maximum load was $10,775 \mathrm{lb}$.

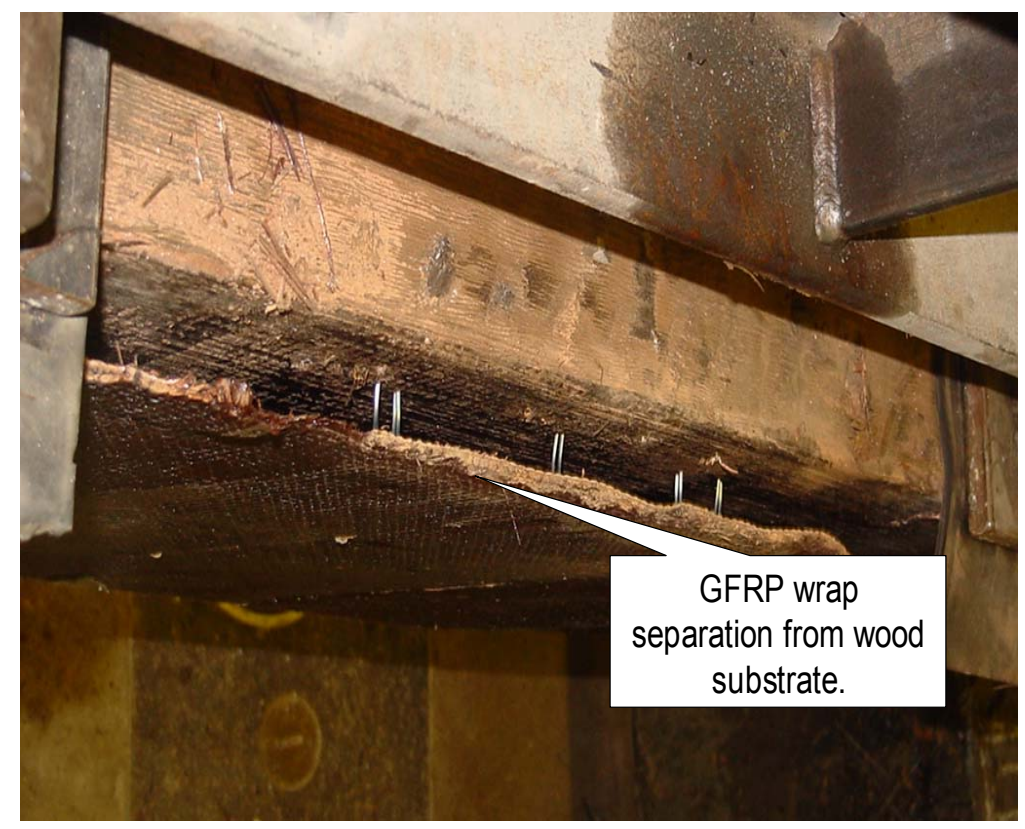

Figure 3.16. Separation of GFRP wrap from wood substrate (view from above). 


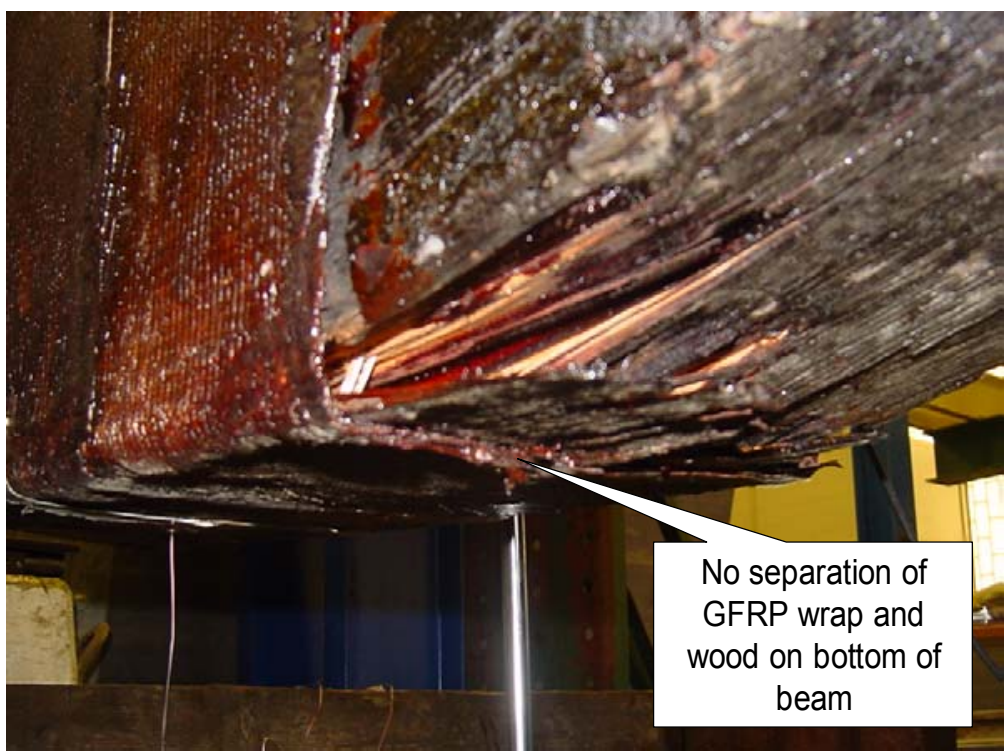

Figure 3.17. No separation of GFRP wrap and wood.

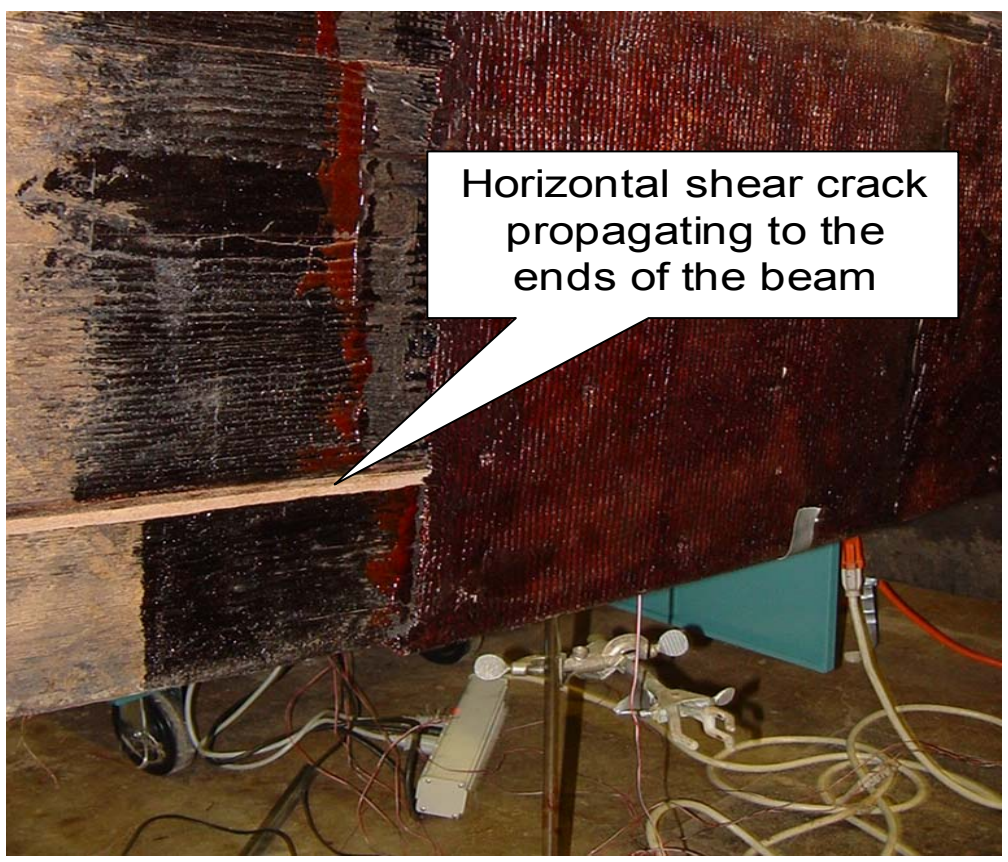

Figure 3.18. Horizontal Shear Crack Propagating Outward

\subsubsection{Beam Four - Repaired Bending Test}

The repaired specimen was tested to failure in four point bending in accordance with ASTM 198 with an $\mathrm{a} / \mathrm{h}<5$ to induce bending failure. Small checking noises were heard when the load reached approximately 7,500 $\mathrm{lb}$. This cracking gradually became 
louder until the load reached 20,000 lb. At this loading, a large pop was accompanied by the intense smell of creosote. At a load of 32,000 lb there was a loud pop accompanied by an initial separation of the GFRP wrap. The load vs. deflection curve is shown in Figure 3.19 .

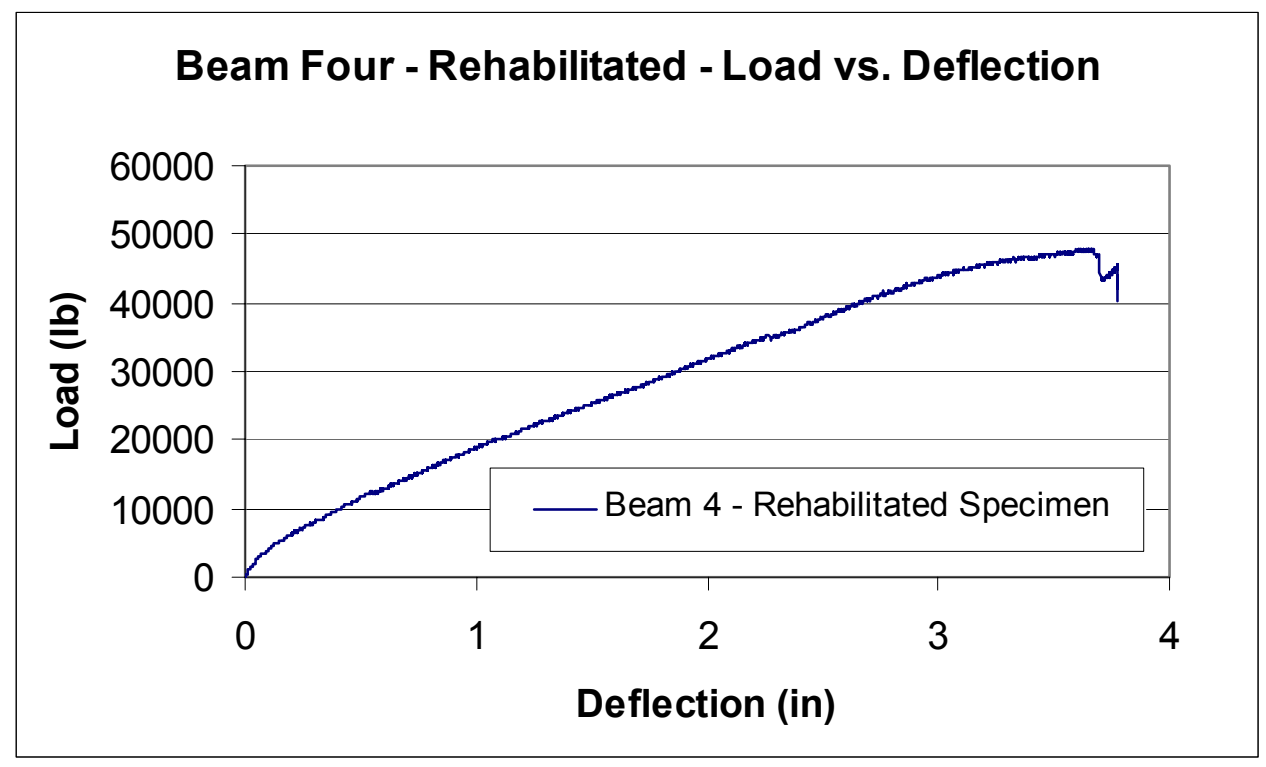

Figure 3.19. Load vs. Deflection for Beam Four Rehabilitated Specimen

As shown in Figure 3.20, this separation was caused by a large crack along the bottom of the beam. The bottom of specimen four was not square, due to damage received during the control test, hence a small amount of twist due to eccentric loading may have been induced. This twist caused a torsional loading, initiating the crack. This crack propagated throughout the entire repaired section (i.e. the entire bending zone). 


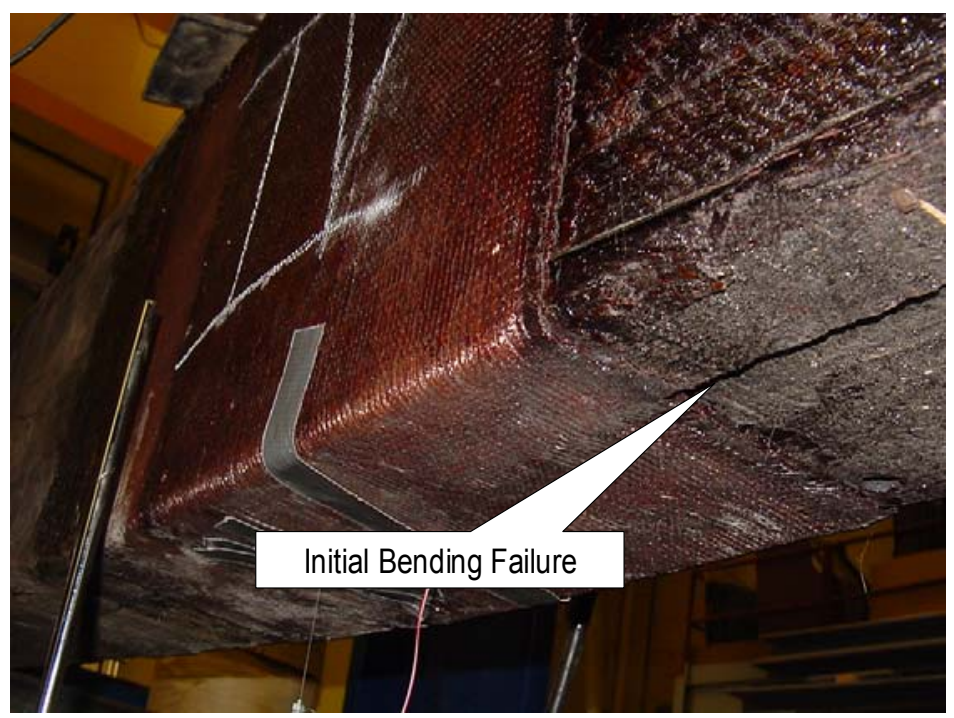

Figure 3.20. Initial Bending Failure

When the load reached 34,000 lb there was a complete separation of the GFRP wrap along the side of the beam. This separation was caused by the failure of the bond between the wood fibers located along the edge of the repaired section. Loading increased until a sudden bending failure occurred at a load of 47, $925 \mathrm{lb}$. The bending failure was accompanied by horizontal shear failure along the length of the beam as shown in Figure 3.21. After reaching the maximum load, the load decreased until reaching a load of approximately $44,000 \mathrm{lb}$ and remained there for the remainder of the test. The maximum measured deflection of the specimen was 3.78 inches. A maximum strain value was not recorded due to a malfunction in the uniaxial strain gage. The maximum shear strain measured at the outer fibers of the GFRP wrap on the neutral axis was $1252 \mu \gamma$. The maximum load was measured as 47, $925 \mathrm{lb}$ 


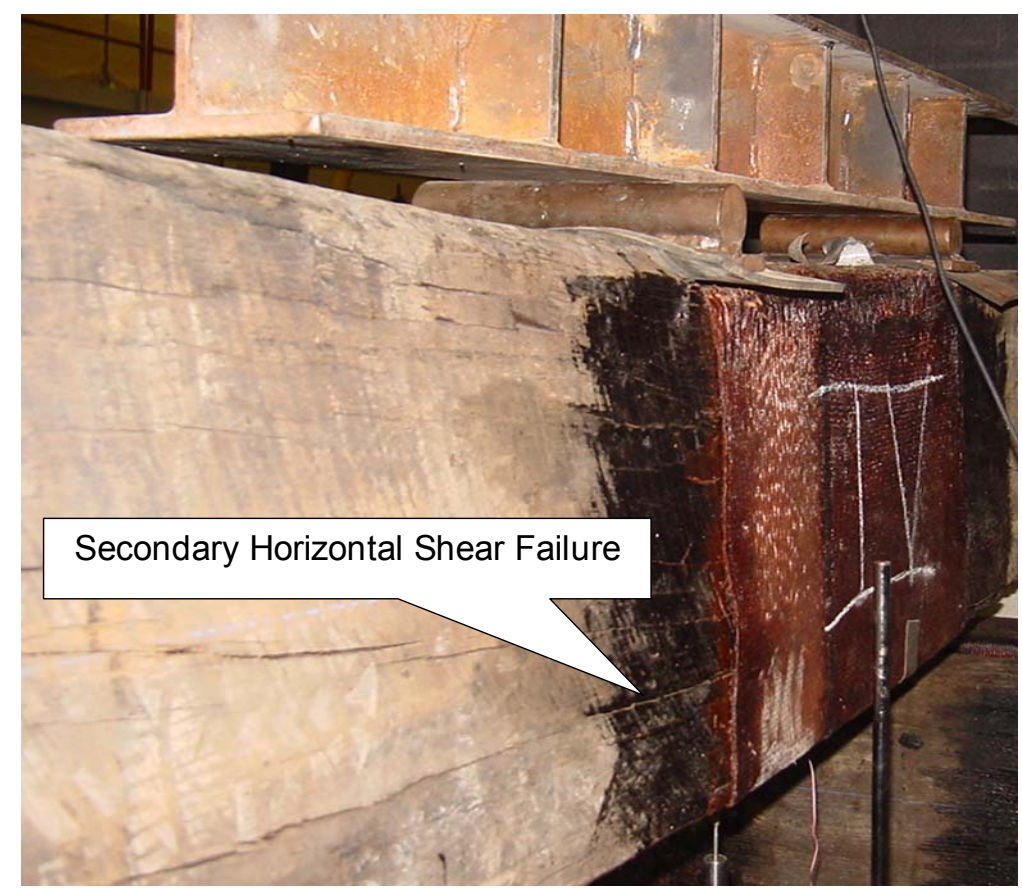

Figure 3.21. Secondary Horizontal Shear Failure

\subsection{Repaired Beam Tests (Shear)}

\subsubsection{Introduction}

After the initial shear failure of both the unreinforced control specimens (Beam One and Beam Three), they were repaired by using three (3) layers of GFRP composite wraps $U$-shaped throughout the length of the cross section on the beam's shear span. The $U$-shaped wrap was selected because repairs made on in-situ beams do not allow access to the top surface of the beam. Therefore, to simulate field conditions it was assumed that access to the top of each beam was not readily available.

\subsubsection{Repair Procedure \& Test Setup}

The repairing of the damaged or failed shear specimens was essentially the same process as described for the Bending Tests. The major difference being that the wrapping of the shear beams involved wrapping of two areas on each specimen. The repaired areas were selected based on the occurrence of the maximum shear (beam's shear span) at the end of the specimen (Figure 3.22). 

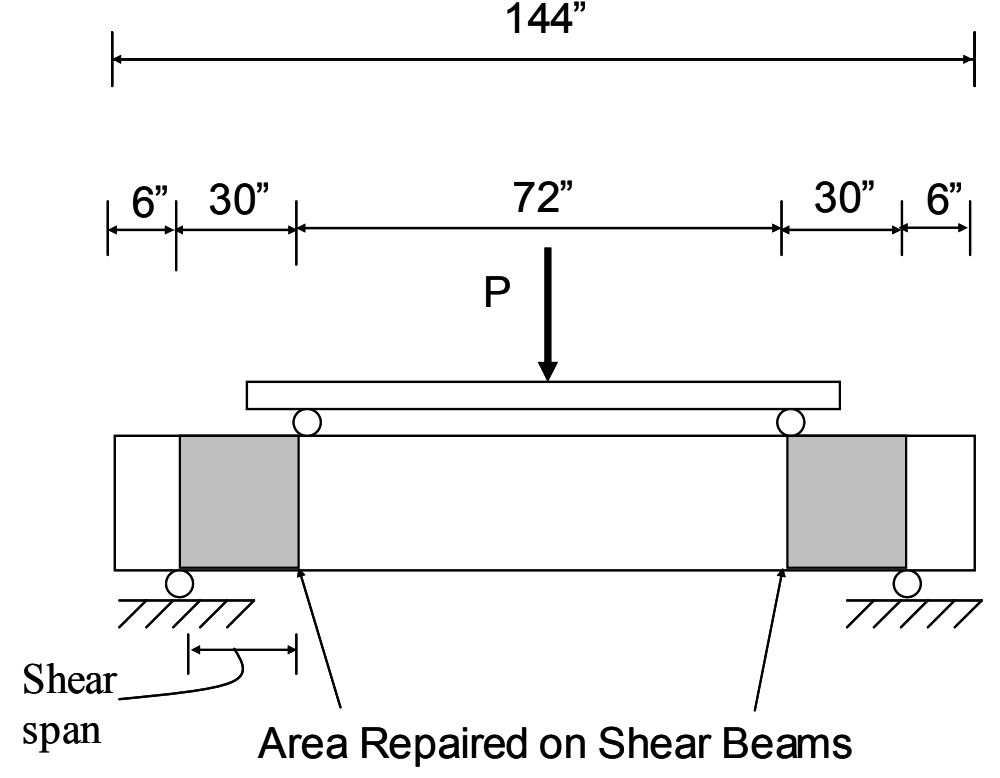

Figure 3.22. Typical of GFRP shear wrapped area

By rehabilitating the shear specimens in the areas of maximum shear force, the area of GRFP wrap was minimized, while maximizing the regain of shear strength within the specimen. Approximately, $45 \%$ of the span was covered using GFRP composite materials.

\subsubsection{Beam One - Repaired Beam}

The repaired specimen was tested to failure in four-point bending, in accordance with ASTM 198. The specimen was tested with an $\mathrm{a} / \mathrm{h}=1.875$ to induce shear failure. Checking sounds began immediately upon loading of the specimen. The checking was accompanied by large horizontal shear cracks that began to propagate outward from the center of the beam at approximately $13,700 \mathrm{lb}$. Horizontal shear cracks began to propagate throughout the length of the beam as the loading increased. Crushing at the end of the specimen was caused by crushing of the wood under the bearing plate on the left side of the beam (Figure 3.23). 


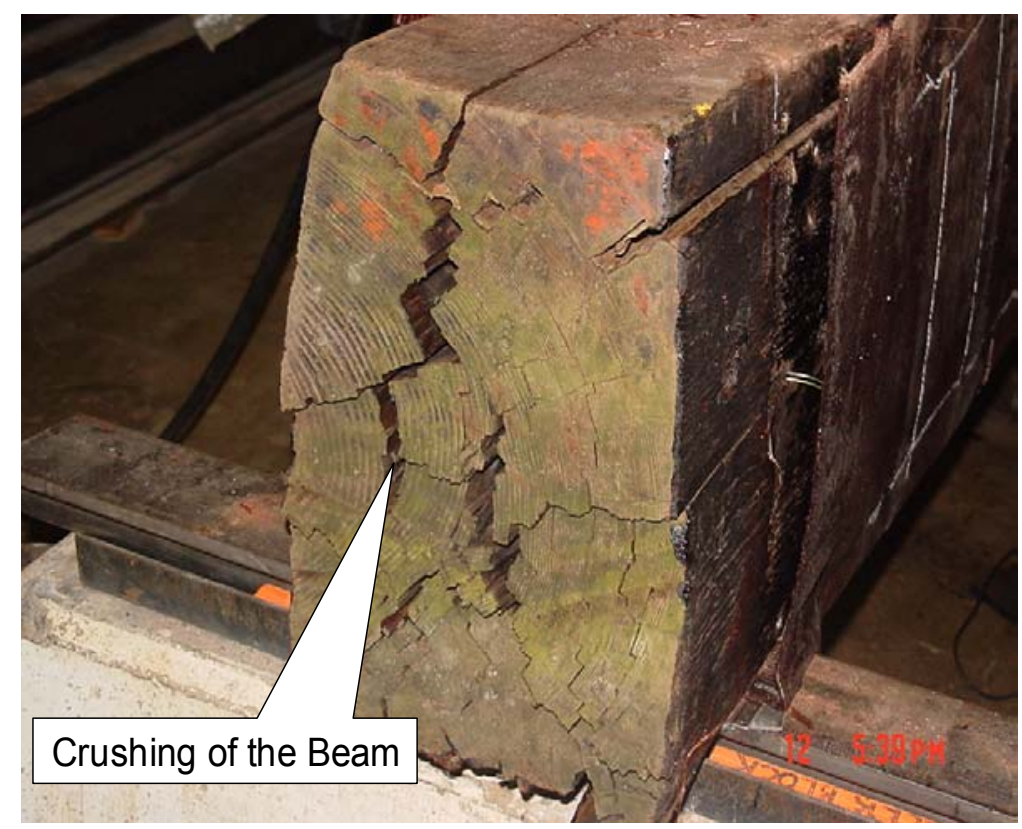

Figure 3.23. Crushing of Beam One

Loading continued linearly until the load reached $39,700 \mathrm{lb}$. At this load, an initial failure occurred causing the load to drop to 37,000 lb. The GFRP wrap began to separate from the beam along the sides of the beam (see Figure 3.24). Loading continued nonlinearly until the specimen underwent sudden horizontal shear failure, at a maximum load of 51,175 lb, as shown in Figure 3.25. The load then decreased to 44, $800 \mathrm{lb}$. The beam began to take load after failure; a plateau was reached at approximately 48,000 lb. The "load stepping" behavior is due to the additional load carrying capabilities supplied by the GFRP wrap. The application of the GFRP wrap provides added ductility of the beam prior to failure. The unreinforced beams did not provide this ductility and were likely to fail suddenly. The ultimate mode of failure was sudden horizontal shear failure. The maximum strain measured at the extreme tension fibers of the GFRP wrap was 1279 $\mu \varepsilon$. The maximum shear strain measured at the neutral axis of the beam was $2568 \mu \gamma$. The load vs. shear strain plot is shown in Figure 3.26. This is due to the shear loading and is attributed to the low a/h ratio. The maximum measured deflection was 3.96 inches and the maximum load was $51,175 \mathrm{lb}$. 


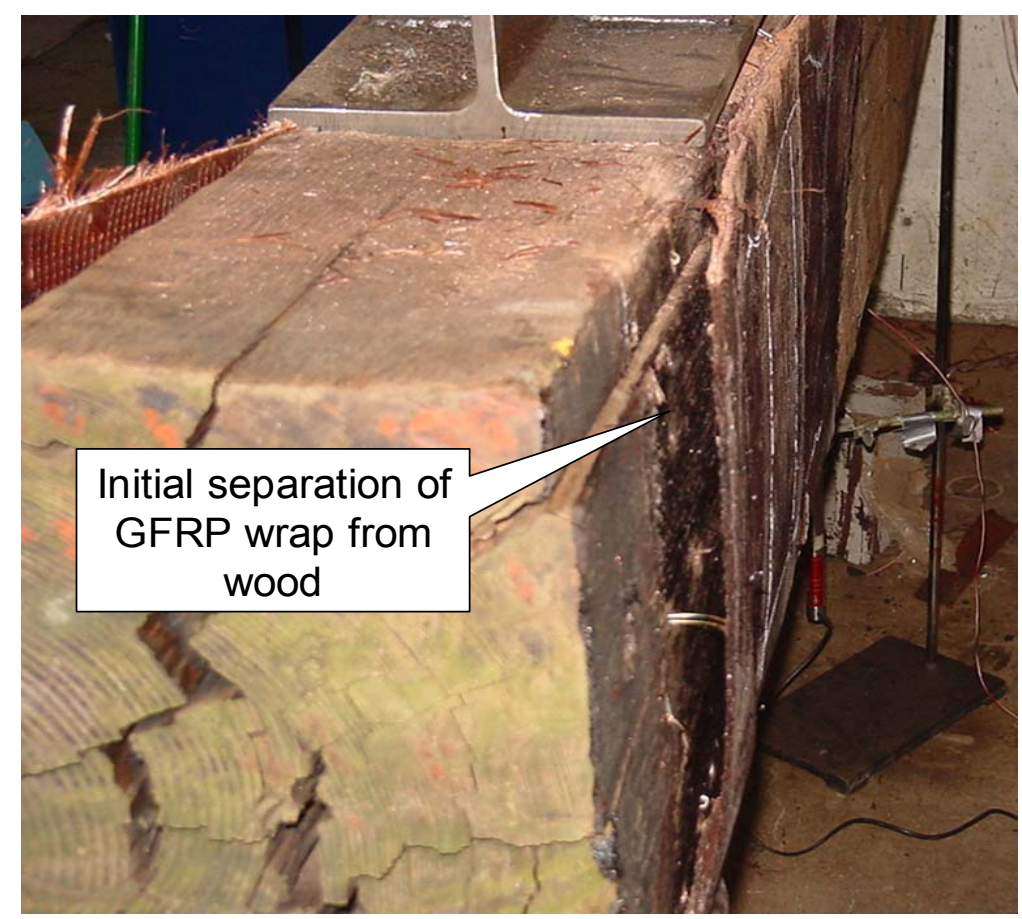

Figure 3.24. Initial separation of GFRP wrap and wood

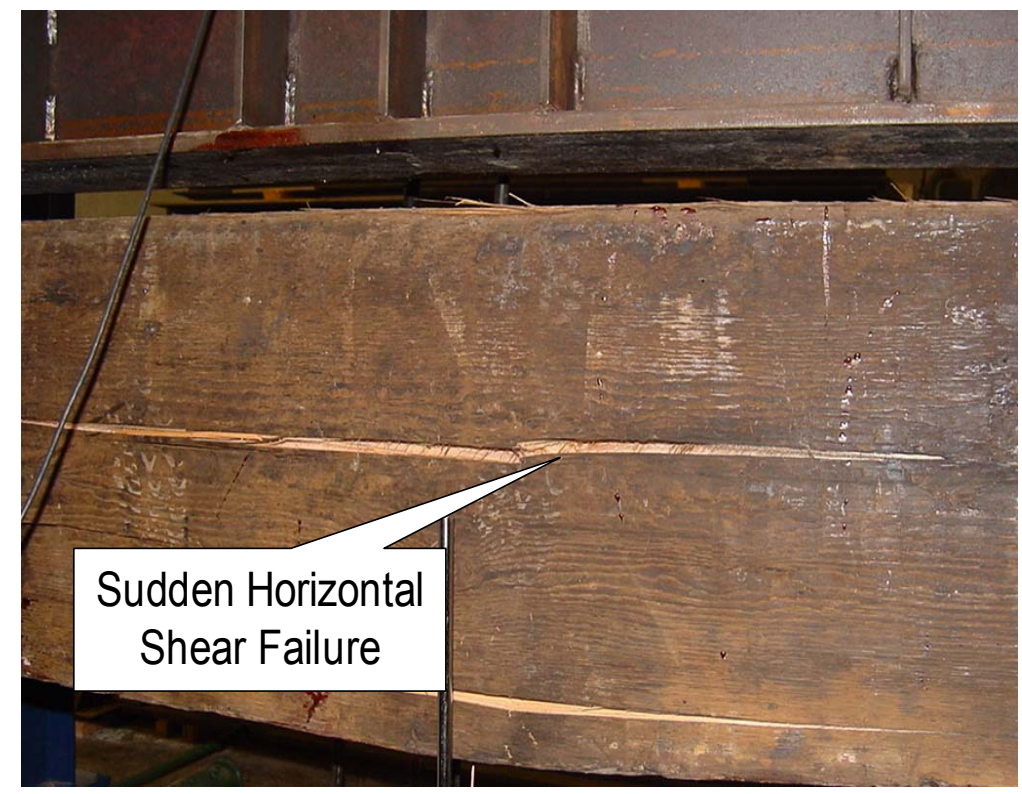

Figure 3.25. Horizontal Shear Failure (Beam One) 


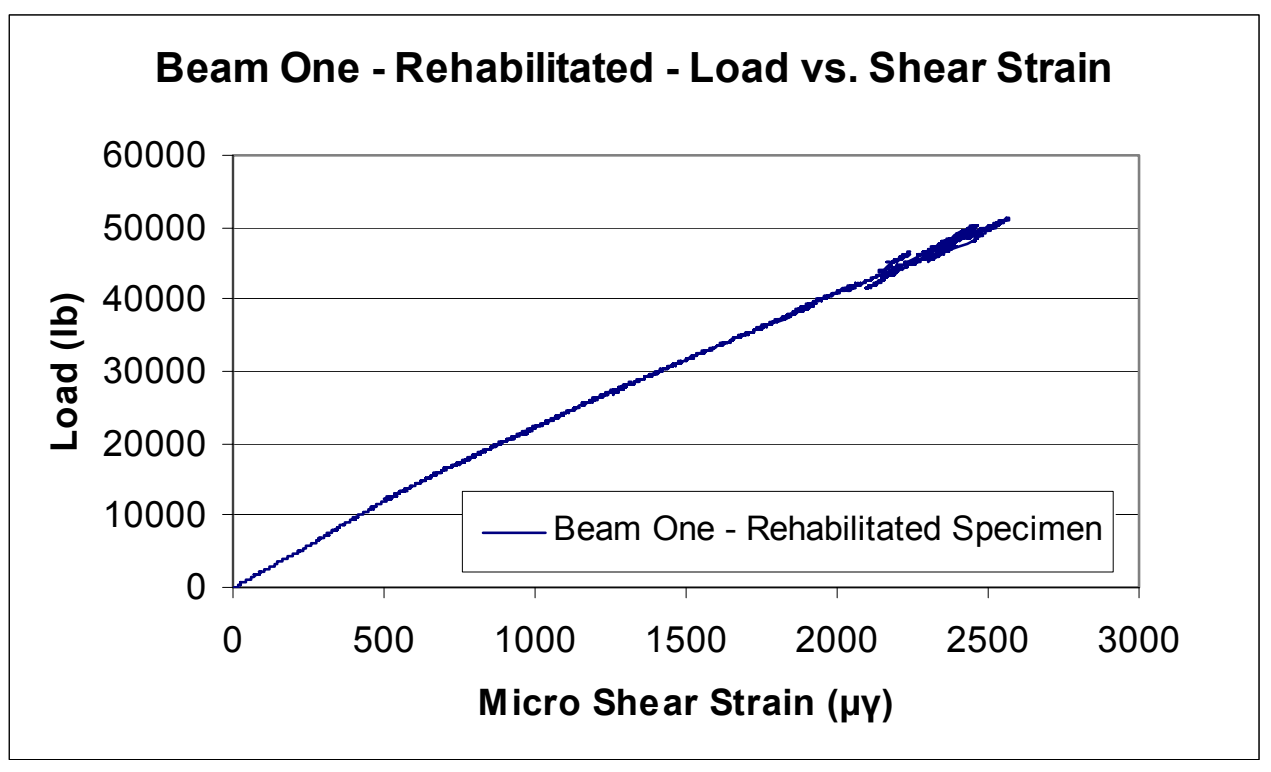

Figure 3.26. Load vs. Shear Strain of Rehabilitated Beam One

\subsubsection{Beam Three - Repaired Beam}

The second repaired specimen (Beam Three) was tested in four-point bending, in accordance with ASTM 198. The specimen was tested with an $\mathrm{a} / \mathrm{h}=1.875$ to induce shear failure. Beam three experienced crushing above the left support (see Figure 3.27), causing instability while loading. For safety purposes, the beam was not tested to failure. 


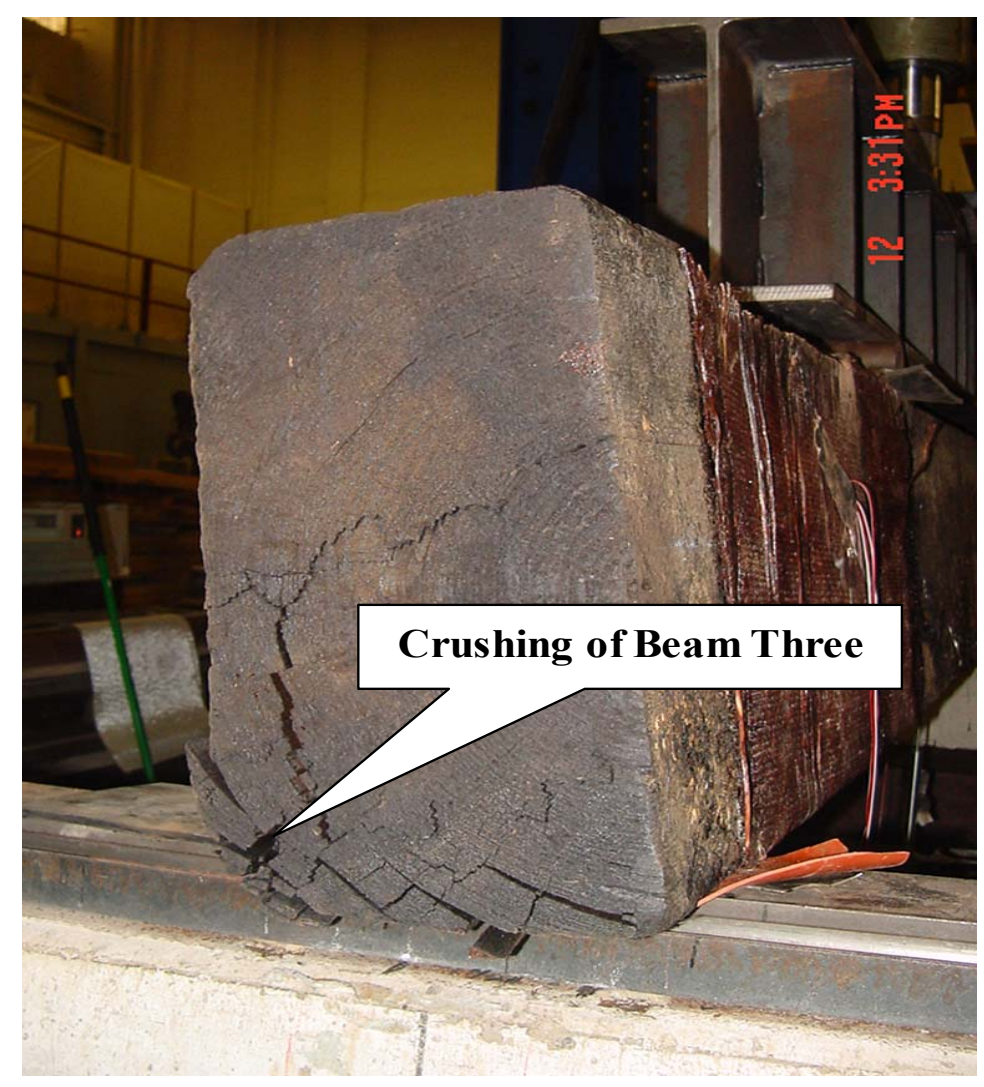

Figure 3.27. Crushing of Beam Three

Because the specimen itself was crushing at the supports, it was determined that lateral bracings would not improve the quality of the test. A load of approximately $30,600 \mathrm{lb}$ was applied, to allow for the collection of shear strain and deflection data in the linear range. Once enough data were collected for comparative analysis purposes, the test was stopped. During the loading no separation of the GFRP wrap from the wood substrate was evident. Several significant popping sounds were heard during testing. The first significant popping noise occurred at $21,550 \mathrm{lb}$. This caused a small drop in the load, but the beam continued to take load in linear fashion. The next pop was heard at 26,275 lb Loading continued linearly therefore this was also not an initial failure. The maximum load of 30,625 $\mathrm{lb}$ was reached without ultimate failure. The load vs. shear strain plot is shown in Figure 3.28. 


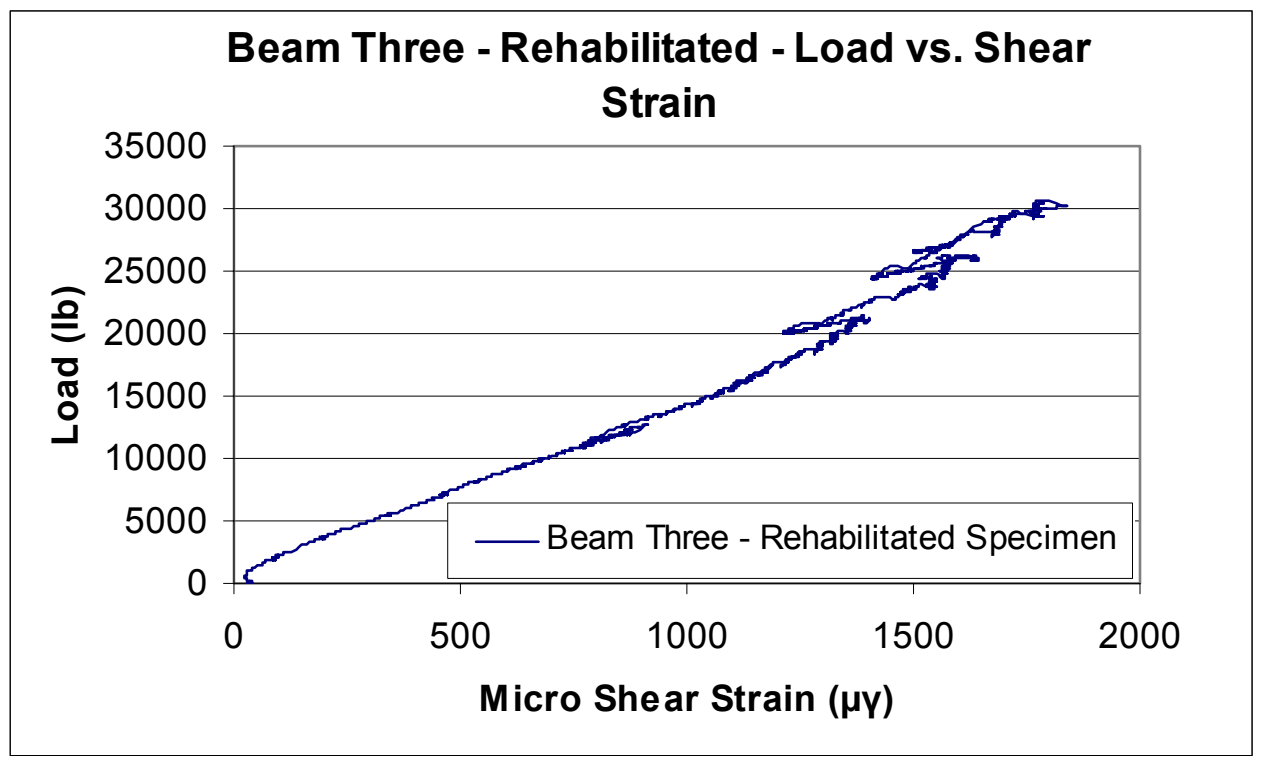

Figure 3.28 Load vs. Shear Strain for Rehabilitated Beam Three

The maximum shear strain measured at the neutral axis of the specimen at the extreme shear fibers of the GFRP wrap was $1837 \mu \gamma$. The maximum strain measured at the extreme tension fibers of the specimen at midspan was $422 \mu \varepsilon$. The maximum deflection measured at the midspan of the specimen was $0.82 \mathrm{in}$. The high shear strain and relatively low uniaxial strain is attributed to the low $\mathrm{a} / \mathrm{h}$ ratio, placing the beam in shear loading, with a low bending moment because of the low value of shear span "a".

\subsection{Results and Discussion}

\subsubsection{Introduction}

In this section, the results of the experimental testing are presented. A comparative analysis and discussion of the results of the unreinforced control specimens and repaired specimens are also presented. Topics discussed include; flexural rigidity differences between control and repaired beams, strength regain (or recovery) of the repaired beams due to the addition of GFRP wrap, and discrepancies between the shear moduli of the unreinforced control specimens and the repaired specimen. 


\subsubsection{Results - Beam Two (Bending)}

The control unreinforced, undamaged and intact, specimen was loaded in fourpoint bending according to ASTM 198, with an a/h ratio of 3.375. The control beam reached a maximum load of $18,070 \mathrm{lb}$ at failure. The ultimate mode of failure was tension failure due to bending in combination with horizontal shear failure. This attributed to the high a/h ratio. The experimental flexural rigidity $\left(\mathrm{EI}_{\mathrm{exp}}\right)$ was computed as $9.33 \times 10^{8} \mathrm{lb}-\mathrm{in}^{2}$ and the ultimate strength or Modulus of Rupture (MOR) was computed as 1452 psi. The load vs. deflection curve is shown in Figure 3.5. The bending flexural rigidity $\left(\mathrm{EI}_{\text {bending }}\right)$ and experimental flexural rigidity $\left(\mathrm{EI}_{\mathrm{exp}}\right)$ the Modulus of Rupture (MOR) were calculated utilizing the following equations:

To calculate the flexural rigidity $\left(\mathrm{EI}_{\mathrm{exp}}\right)$ of the control specimens, the following equations were used:

$$
\begin{gathered}
\Delta_{\max }=\Delta_{\text {bending }}+\Delta_{\text {shear }} \\
\Delta_{\max }=\frac{P a / 2}{24 E I_{\exp }}\left(3 L^{2}-4 a^{2}\right)+\kappa \frac{P a}{2 G A}
\end{gathered}
$$

Rearranging Equation 3.1,

$$
\begin{aligned}
& E I_{\exp }=\frac{P a\left(3 L^{2}-4 a^{2}\right)}{48\left[\Delta_{\max }-\left(\frac{6}{5}\right)\left(\frac{P a}{2 G A}\right)\right]} \\
& E I_{\exp }=\frac{10005 * 54\left(3 * 132^{2}-4 * 54^{2}\right)}{48 *\left[0.4521-\left(\frac{6}{5}\right) *\left(\frac{10005 * 54}{2 * 41667 * 126}\right)\right]} \\
& E I_{\exp }=11.71 \times 10^{8} \mathrm{psi}
\end{aligned}
$$


Where,

$\mathrm{L}=$ Total length of beam between reaction points, in

a = shear span, distance from reaction point to load point, in

$\mathrm{P}=$ Total load, $\mathrm{lb}$

$\kappa=$ constant, equal to $6 / 5$ for rectangular sections

$\Delta_{\max }=$ measured bending and shear deflection at midspan, in

$\mathrm{EI}_{\mathrm{exp}}=$ experimental flexural rigidity, $\mathrm{lb}-\mathrm{in}^{2}$

$\mathrm{P} / \Delta_{\max }=$ slope of load vs. deflection curve

Neglecting shear deformation, Equation 3.1 becomes

$$
E I_{\text {bending }}=\frac{P}{\Delta_{\max }} \frac{a}{48}\left(3 L^{2}-4 a^{2}\right)=\frac{20540 * 54}{48} *\left(3 * 132^{2}-4 * 54^{2}\right)
$$

$$
E I_{\text {bending }}=9.38 \times 10^{8} \mathrm{psi}
$$

Where:

$\mathrm{EI}_{\text {bending }}=$ Flexural rigidity in pure bending, psi

The following equation was used to calculate the Modulus of Rupture (MOR) for the control specimens:

$$
M O R=\frac{P a / 2}{b_{w} d_{w}^{2} / 6}
$$

Where,

$$
\begin{aligned}
\mathrm{MOR} & =\text { modulus of rupture } \\
\mathrm{a} & =\text { shear span, distance from reaction point to load point, in. } \\
\mathrm{P} & =\text { Total load, } \mathrm{lb} \\
\mathrm{b}_{\mathrm{w}} & =\text { width of wood section, in }
\end{aligned}
$$




$$
\mathrm{d}_{\mathrm{w}}=\text { depth of wood section, in }
$$

\subsubsection{Results - Beam Four (Bending)}

The control specimen was loaded in four-point bending according to ASTM 198, with an $\mathrm{a} / \mathrm{h}$ ratio of 3.375 . The control beam reached a maximum load of $86,050 \mathrm{lb}$ at failure. The ultimate mode of failure was tension failure due to bending. Similarly, the experimental flexural rigidity $\left(\mathrm{EI}_{\mathrm{exp}}\right)$ was computed as $11.31 \times 10^{8} \mathrm{lb}$-in ${ }^{2}$ and the ultimate strength or Modulus of Rupture (MOR) was computed as 6502 psi. These values are much higher than that of the calculated values for beam two. This is attributed to the density of beam four, which was $60 \mathrm{lb} / \mathrm{ft}^{3}$, while beam two had a density of $30 \mathrm{lb} / \mathrm{ft}^{3}$. The load vs. deflection curve can be seen in Figure 3.8.

\subsubsection{Results - Beam Two Repaired}

The repaired specimen was loaded in four-point bending according to ASTM 198 with an a/h ratio of 3.375. The repaired beam reached a maximum load of $10,775 \mathrm{lb}$. The ultimate mode of failure was sudden bending failure accompanied by a secondary horizontal shear failure. The maximum measure deflection was 3.73 inches while the maximum strain measured at the extreme tension fibers of the GFRP wrap was 2, $851 \mu \varepsilon$. The fiber volume fraction for the repaired specimen was $4.8 \%$. The load vs. deflection data is shown in Figure 3.15.

Since there are two (2) materials (wood \& GFRP) forming a composite section, its neutral axis (N.A.) is not located at the geometric centroid of the section and its location is determined using the concept of transformed section. A transformed section is a fictitious section in which the cross-sectional area of one material (GFRP) is converted (transformed) into an equivalent area of the other material (wood).

Based on this concept, calculations were performed to find the modulus of rupture (MOR), shear modulus (G), the first moment of area $(\mathrm{Q})$, and the transformed moment of inertia $\left(\mathrm{I}_{\mathrm{xt}}\right)$ for the repaired specimens.

Figure 3.29 shows the transformed and actual sections. A transformed moment of inertia calculation is used to compute MOR values, as well. 


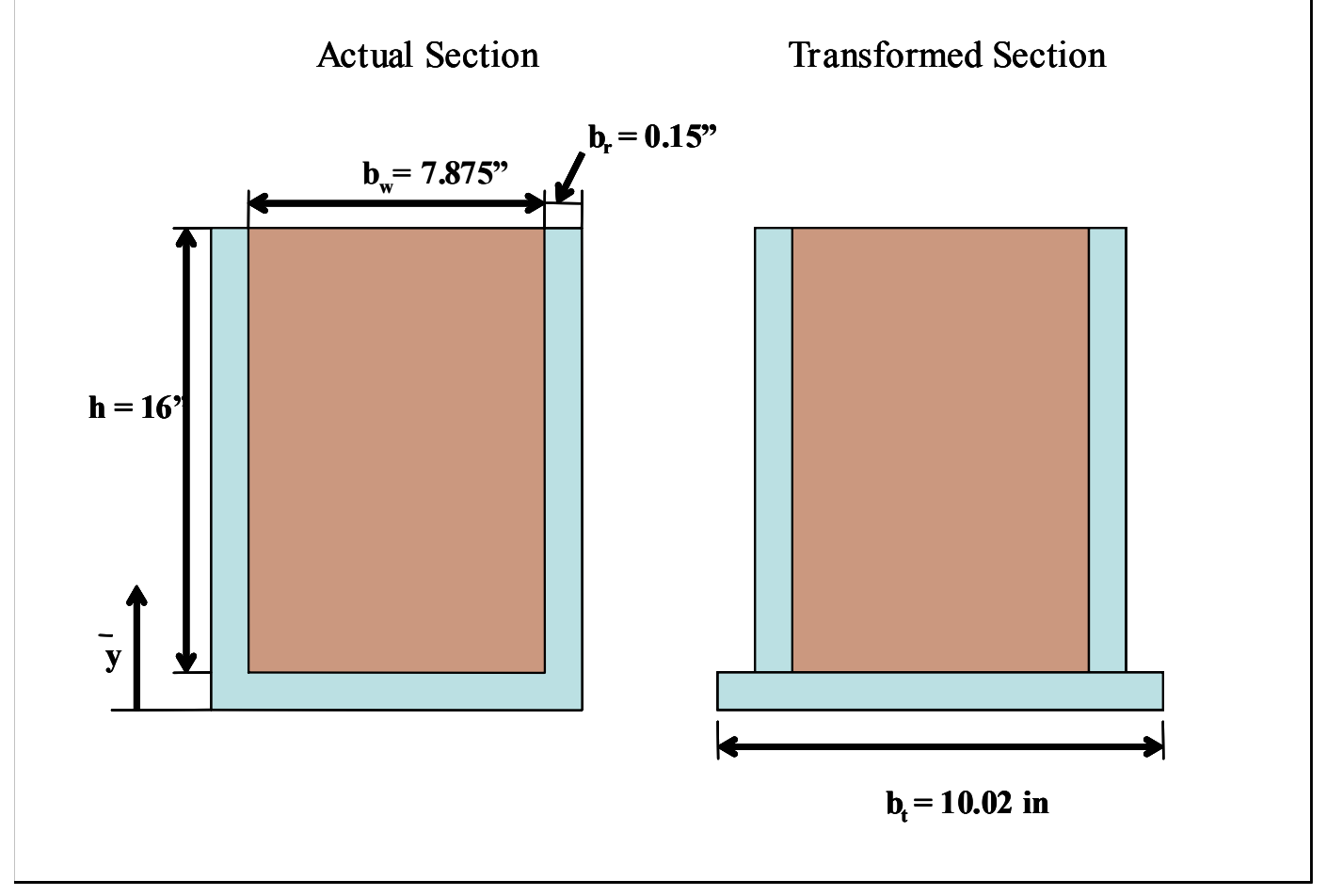

Figure 3.29. Actual and Transformed section of Beam Two

Using the following equations, the neutral axis (N.A.), moment of inertia (I), and the transformed beam width $\left(b_{t}\right)$ were calculated:

$$
\begin{gathered}
\bar{y}_{t}=\frac{\sum \mathrm{y}_{\mathrm{i}} \mathrm{A}_{\mathrm{i}}}{\sum \mathrm{A}_{\mathrm{i}}} \\
I=\sum_{i=1}^{j}\left(\frac{b_{w} h_{i}^{3}}{12}\right) \\
n=\frac{E_{\text {GFRP }}}{E_{\text {Wood }}}=\frac{2.6 \mathrm{msi}}{0.349 \mathrm{msi}}=7.164
\end{gathered}
$$

* $\mathrm{E}_{\mathrm{wood}}$ is an experimental value.

$$
b_{t}=2 n b_{r}+b_{w}
$$




$$
b_{t}=2 *(7.164) *(0.15)+7.875=10.02 \text { in }
$$

Where $\mathrm{y}_{\mathrm{t}}=$ Centroid of the entire beam, in

$\mathrm{y}_{\mathrm{i}}=$ Centroid of each element in beam, in

$\mathrm{A}_{\mathrm{i}}=$ Area of reinforcement element, in $^{2}$

$\mathrm{I}=$ Moment of inertia, in ${ }^{4}$

$\mathrm{I}_{\mathrm{xt}}=$ Cross-sectional transformed moment of inertia, in ${ }^{4}$

$\mathrm{b}_{\mathrm{w}}=$ wood beam width, in

$\mathrm{h}_{\mathrm{i}}=$ Height of each element, in

$\mathrm{d}_{\mathrm{i}}=$ Distance from the Centroid of each element to the neutral axis, in

$\mathrm{n}=$ Modular ratio

$b_{t}=$ Transformed beam width, in

$\mathrm{b}_{\mathrm{r}}=$ Reinforcement thickness, in

The centroid is calculated at $\overline{y_{t}}=7.75$ inches from the bottom of the beam.

The transformed moment of inertia for beam two is computed as:

$$
I_{x t}=\left\{\frac{b_{w} h^{3}}{12}\right\}+2\left\{\frac{n b_{r} h^{3}}{12}+n b_{r} h d_{1}^{2}\right\}+\left\{\frac{n b_{i} b_{r}^{3}}{12}+n b_{w} b_{r} d_{2}^{2}\right\}
$$

Where:

$\mathrm{d}_{1}=$ distance from centroid of the GFRP side sections to the neutral axis of the beam, in $\mathrm{d}_{2}=$ distance from centroid of the GFRP bottom section to the neutral axis of the beam, in

$$
\begin{array}{r}
I_{x t}=\left\{\frac{7.875 * 16^{3}}{12}\right\}+\left\{\frac{7.164 * 0.15 * 16^{3}}{12}+(7.164 * 0.15 * 16)\left(0.4^{2}\right)\right\}+ \\
+\left\{\frac{7.164 * 7.875 * 0.15^{3}}{12}+(7.164 * 7.875 * 0.15)\left(7.6^{2}\right)\right\}
\end{array}
$$




$$
I_{x t}=3925.76 \text { in }^{4}
$$

Taking into account the transformed section, the modulus of rupture (MOR) of the failed and repaired beam is calculated as:

$$
\begin{gathered}
\text { MOR }=\frac{M c}{I_{x t}} \\
\mathrm{MOR}=\frac{(290925 \mathrm{lb}-i n)(7.75 \mathrm{in})}{3925.76 \mathrm{in}^{4}}=571.42 \mathrm{psi} \\
\text { MOR }=\mathbf{5 7 4 . 4 2} \mathbf{~ p s i}
\end{gathered}
$$

Where

$\mathrm{M}=$ maximum moment, $\mathrm{lb}$-in

$\mathrm{c}=$ distance from the extreme fiber to the neutral axis, in

$\mathrm{I}_{\mathrm{xt}}=$ transformed section moment of inertia, in ${ }^{4}$

Due to the condition of the damaged beam, the modulus of rupture (MOR) for the repaired beams was significantly lower than that of the control specimens.

\subsubsection{Results - Beam Four Repaired}

Similarly, the repaired specimen was tested to failure in four-point bending in accordance with ASTM 198 with an a/h of 3.375. A maximum load of 44, $925 \mathrm{lb}$ was reached inducing a bending failure. The load vs. deflection plot is shown in Figure 3.19. The maximum measured deflection was 3.78 inches. The fiber volume fraction for the repaired specimen was $4.6 \%$. The ultimate failure mode was a bending failure, accompanied by a secondary horizontal shear failure. 


\subsubsection{Discussion}

As shown in Figures 3.30 \& 3.31, both repaired beams failed at considerably lower loads than the control specimens. It is important to note that at failure, the control specimens were unable to withstand any further loading; they were completely damaged. By repairing the beams with GFRP wrap, a very reasonable recovery of strength (55 - 60 $\%$ of the control bending strength) and significant improvement in ductility was achieved. The strength regain in Beam Two was $60 \%$ of the original load carrying capacity, while Beam Four regained $55 \%$ of the control load carrying capacity.

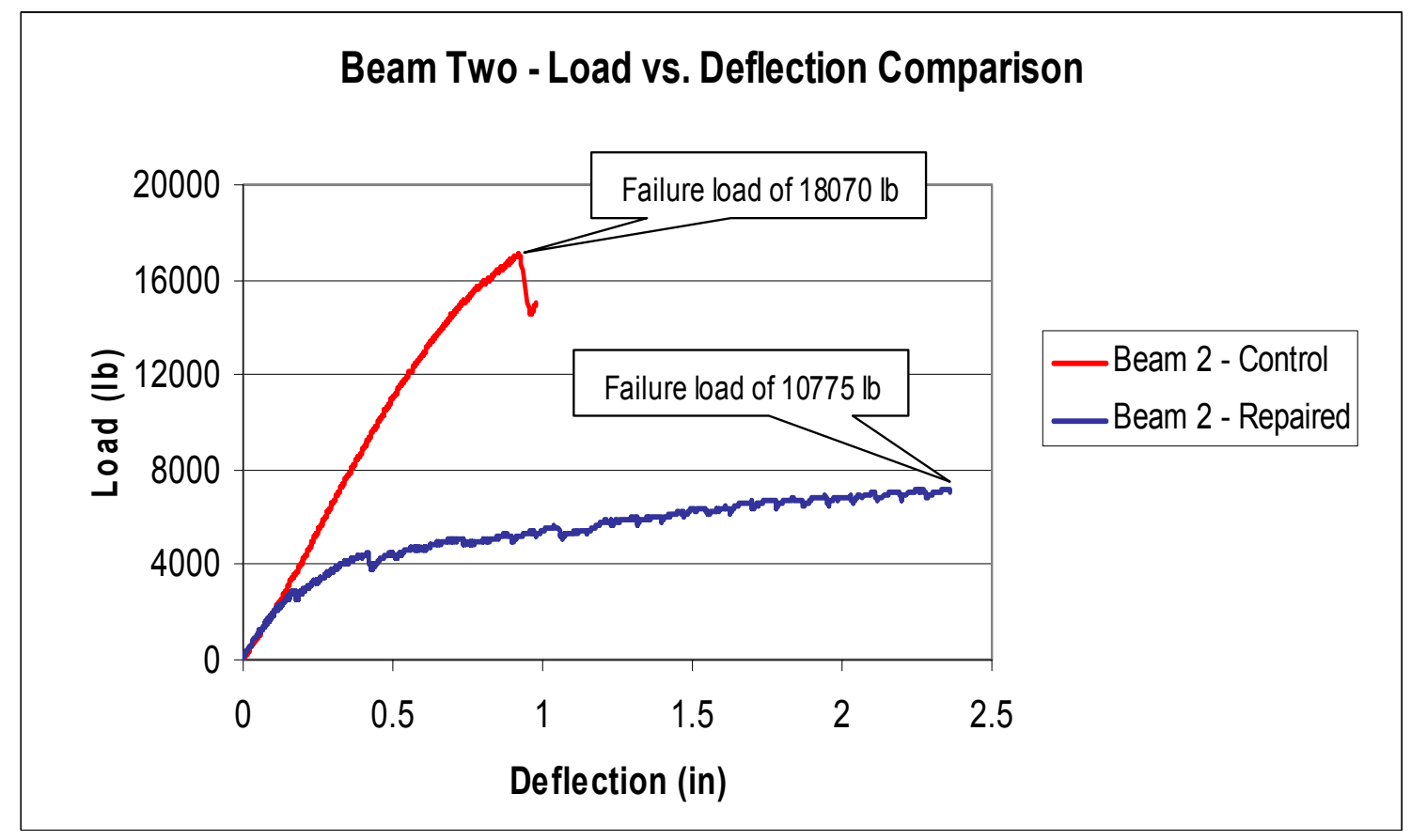

Figure 3.30. Beam Two - Load vs. Deflection Comparison 


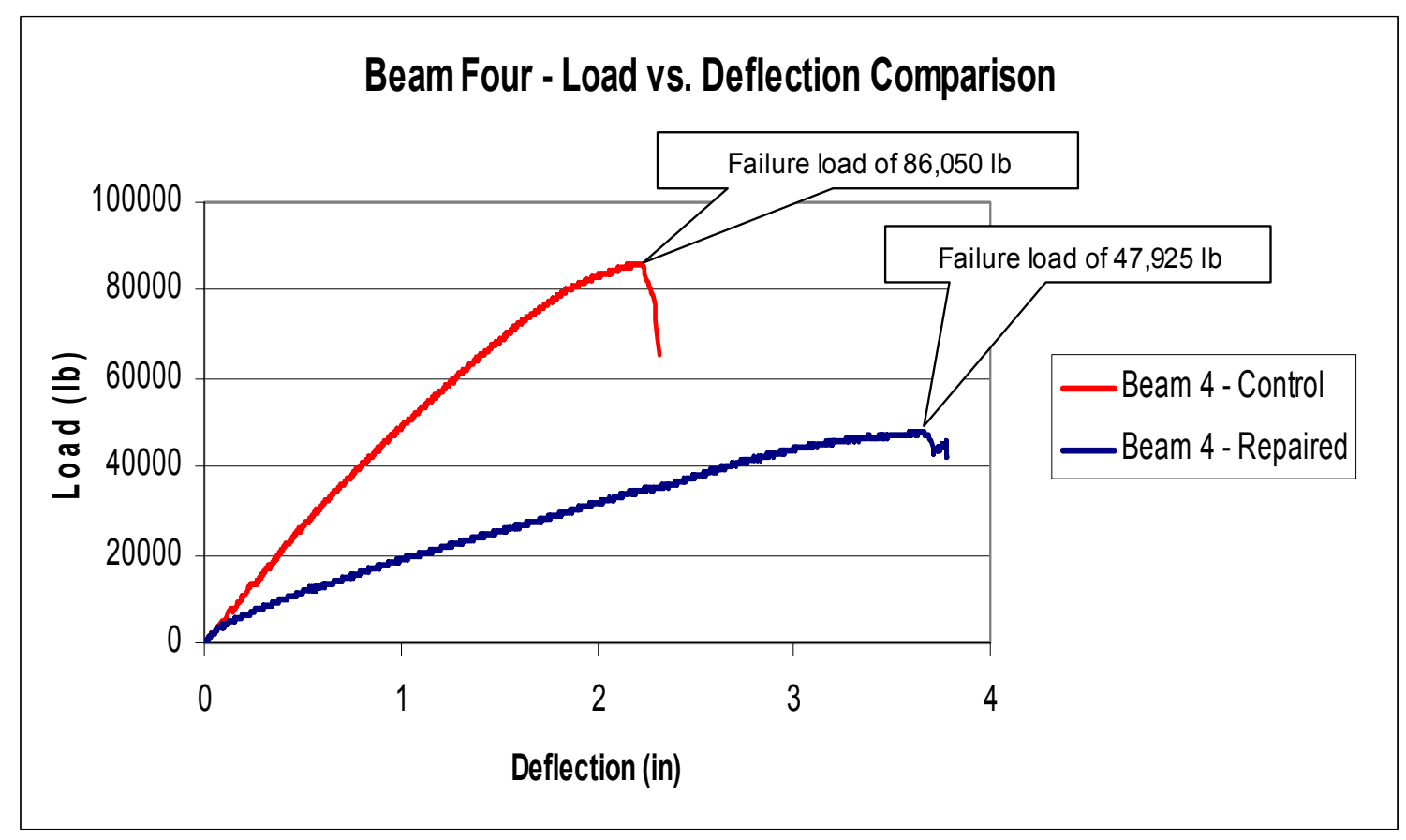

Figure 3.31. Beam Four - Load vs. Deflection Comparison

Table 3.3 presents the maximum load, flexural strength, among other properties of Beams Two and Four. For the purpose of comparison, relative parameter values are computed and presented in a separate column.

Table 3.3. Comparison of Bending Test Results

\begin{tabular}{|c|c|c|c|c|c|c|}
\hline & \multicolumn{3}{|c|}{ Beam 2} & \multicolumn{3}{|c|}{ Beam 4} \\
\hline & $\begin{array}{l}\text { Control } \\
\text { (a) }\end{array}$ & $\begin{array}{l}\text { Repaired } \\
\text { (b) }\end{array}$ & $\begin{array}{c}\text { Relative } \\
\text { Value } \\
\text { (b/a) }\end{array}$ & $\begin{array}{l}\text { Control } \\
\text { (a) }\end{array}$ & $\begin{array}{l}\text { Repaired } \\
\text { (b) }\end{array}$ & $\begin{array}{c}\text { Relative } \\
\text { Value } \\
\text { (b/a) }\end{array}$ \\
\hline Maximum Load (Ib) & 18070 & 10775 & 0.60 & 86050 & 47925 & 0.56 \\
\hline Bending Flexural Rigidity $\left(\mathrm{El}_{\text {bending, }}{\left.\mathrm{Ib} .-\mathrm{in}^{2}\right)}\right)$ & $9.4 \times 10^{8}$ & $5.89 \times 10^{8}$ & 0.63 & $20.30 \times 10^{8}$ & $5.81 \times 10^{8}$ & 0.29 \\
\hline Experimental Flexural Rigidity $\left(\mathrm{El}_{\text {exp }}, \mathrm{lb}-\mathrm{in}^{2}\right)$ & $11.71 \times 10^{8}$ & $9.33 \times 10^{8}$ & 0.80 & $26.11 \times 10^{8}$ & $11.31 \times 10^{8}$ & 0.43 \\
\hline Modulus of Rupture (MOR, psi) & 1452 & 574 & 0.40 & 6502 & 4759 & 0.73 \\
\hline Maximum Deflection $(\Delta$, in) & 3.74 & 3.73 & 1.00 & 4.5 & 3.78 & 0.84 \\
\hline Maximum Strain @ Midspan $\left(\times 10^{-6}\right)$ & 3393 & 2851 & 0.84 & 3834 & 248 & 0.06 \\
\hline $\begin{array}{l}\text { Failure Mode } \\
\end{array}$ & Bending & Bending & NA & Bending & Bending & NA \\
\hline
\end{tabular}

From Table 3.3, it can be seen that the repaired beams experienced a much lower level of strain at the extreme tension fibers. The maximum strain for repaired Beam Four is 
extremely low, which is attributed to the malfunction of the uniaxial strain gage very early in the loading.

\subsection{Shear Test}

\subsubsection{Results - Beam One}

The control undamaged and intact specimen was loaded in four-point bending according to ASTM 198, with an a/h ratio of 1.875 . The control beam reached a maximum load of $47,963 \mathrm{lb}$ at failure. The ultimate mode of failure was horizontal shear failure. The control shear modulus $(\mathrm{G})$ was computed as 60,484 psi and shear strength $\left(\tau_{\max }\right)$ was computed as 290 psi. The load vs. shear strain curve is shown in Figure 3.32. The shear modulus and shear strength $\left(\tau_{\max }\right)$ were computed using the following equations:

$$
\begin{gathered}
\tau_{\max }=\mathrm{G}^{*} \gamma \\
\tau_{\max }=\frac{V Q}{I b} \\
Q=A \bar{y}
\end{gathered}
$$

Where,

$$
\begin{aligned}
& \mathrm{A}=\text { Cross-sectional Area, } \mathrm{in}^{2} \\
& \bar{y}=\text { Distance from centroid of area to neutral axis, in } \\
& \mathrm{V}=\frac{P}{2}, \mathrm{lb} \\
& \mathrm{P}=\text { Maximum Load }, \mathrm{lb}
\end{aligned}
$$

By equating 3.11a \& 3.11b, the Shear Modulus (G) can be calculated by the following equation:

$$
G=\frac{P}{\gamma}\left[\frac{Q}{2 \times I \times b}\right]
$$


Where,

$$
\begin{aligned}
G & =\text { Shear Modulus, psi } \\
\gamma & =\text { shear strain } \\
Q & =\text { First moment of area, in }{ }^{3} \\
I & =\text { Moment of inertia, in }{ }^{4} \\
b_{w} & =\text { width of wood beam, in }
\end{aligned}
$$

where $\mathrm{P} / \gamma$ is the slope of the line from the Load vs. Shear Strain Diagrams (Figure $3.32 \&$ 3.33).

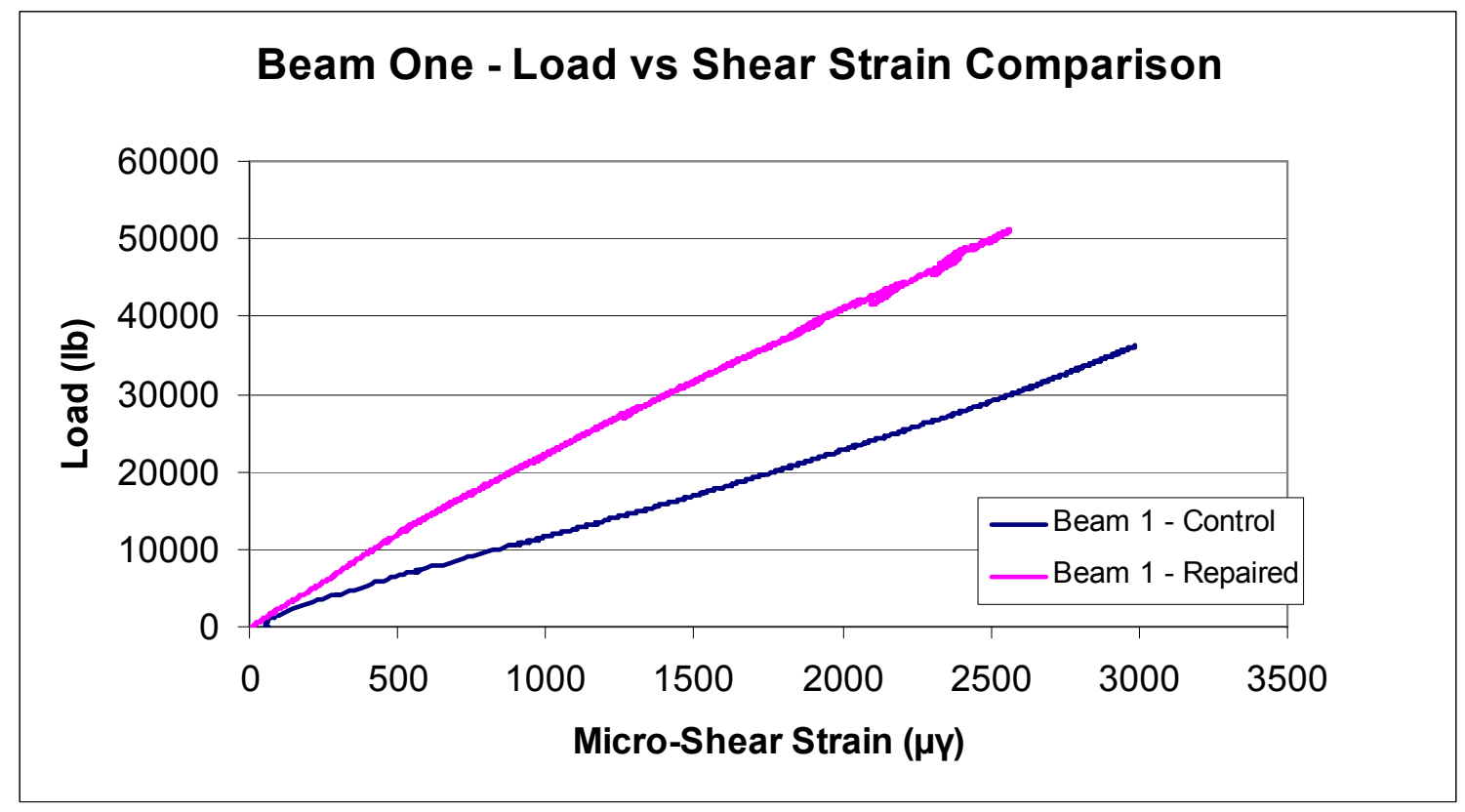

Figure 3.32. Beam One - Load vs. Shear Strain Comparison 


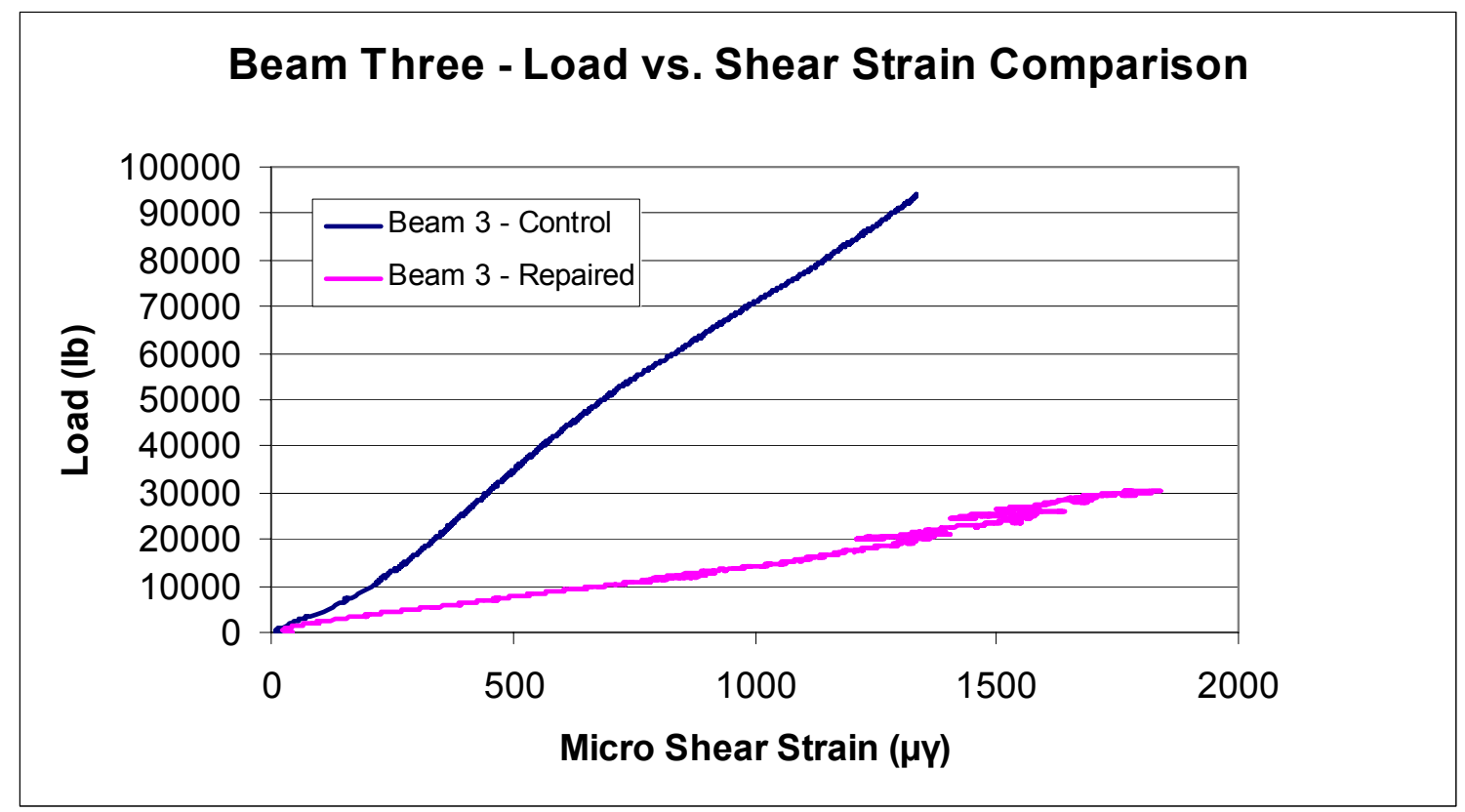

Figure 3.33. Beam Three - Load vs. Shear Strain Comparison

For a rectangular cross-section shear strength is calculated using the formula;

$$
\tau=\frac{V * Q}{I * b}
$$

Where $\tau$ can be reduced to:

$$
\tau=\frac{3}{2} * \frac{V}{b_{w} d_{w}}
$$

Where

$$
\begin{aligned}
& \mathrm{V}=\frac{P}{2}, \mathrm{lb} \\
& \mathrm{P}=\text { maximum load, } \mathrm{lb} \\
& \mathrm{b}_{\mathrm{w}} \mathrm{d}_{\mathrm{w}}=\text { cross-sectional area of wood, } \mathrm{in}^{2}
\end{aligned}
$$




\subsubsection{Results - Beam Three}

The control undamaged and intact specimen was loaded in four-point bending according to ASTM 198, with an a/h ratio of 1.875 . The control beam reached a maximum load of $106,550 \mathrm{lb}$ at failure. The ultimate mode of failure was sudden horizontal shear failure. Similarly, the control shear modulus (G) was computed as $383,037 \mathrm{psi}$ and the ultimate shear strength $\left(\tau_{\max }\right)$ was computed as $583 \mathrm{psi}$. The load vs. shear strain curve can be seen in Figure 3.13.

\subsubsection{Results - Beam One Repaired}

The repaired specimen was tested to failure in four-point bending in accordance with ASTM 198 and an a/h of 1.875. A maximum load of 51,175 lb was achieved. The maximum measured deflection was 3.96 inches. A maximum shear strain of $2568 \mu \gamma$ was recorded at the neutral axis. A shear modulus $\left(\mathrm{G}_{\mathrm{r}}\right)$ of $85,178 \mathrm{psi}$ and shear strength $\left(\tau_{\max }\right)$ of $217 \mathrm{psi}$ was calculated. The ultimate failure mode was sudden horizontal shear failure. The fiber volume fraction for the repaired specimen was $4.76 \%$. The load vs. shear strain plot is shown in Figure 3.26.

To evaluate the restored shear modulus $(\mathrm{G})$ and shear strength $\left(\tau_{\max }\right)$ using the concept of transformed sections, the transformed moment of inertia for the shear test specimens are calculated. Based on those calculations, a transformed first moment of inertia $\left(\mathrm{Q}_{\mathrm{t}}\right)$ and a repaired shear modulus $\left(\mathrm{G}_{\mathrm{r}}\right)$ are also calculated using the following equations. As an example, the calculations for the repaired Beam One are as follows:

$$
\begin{gathered}
G_{r}=\frac{P}{\gamma}\left[\frac{Q_{t}}{2 * I_{x t} * b_{t}}\right] \\
Q_{t}=\left\{\left(h_{i}-\bar{y}\right) b_{i}\left(\frac{h_{i}-\bar{y}}{2}\right)+2\left[\left(b_{t}\left(h_{i}-\bar{y}\right)\left(\frac{h_{i}-\bar{y}}{2}\right)\right)\right]\right\} \\
Q_{t}=\left\{(15.5-7.4)(8)\left(\frac{15.65-7.4}{2}\right)\right\}+2\left\{(9.54)(0.15)(15.5-7.4)\left(\frac{15.5-7.4}{2}\right)\right\}
\end{gathered}
$$




$$
Q_{t}=370 \text { in. }^{3}
$$

Using the first moment of inertia, the transformed shear modulus $\left(G_{r}\right)$ can then be calculated using:

$$
\begin{gathered}
G_{r}=2 * 10^{7}\left[\frac{370 \text { in. }^{3}}{(2)\left(3996.08 \text { in. }^{4}\right)(10.86 \text { in. })}\right] \\
\mathbf{G}_{\mathbf{r}}=\mathbf{8 5 , 1 7 8 ~ p s i .}
\end{gathered}
$$

The shear strength $\left(\tau_{\max }\right)$ is computed using:

$$
\tau_{\max }=\frac{V * Q_{t}}{I_{x t} * b_{t}}
$$

From equation 3.18, the maximum shear strength of a wood beam rehabilitated using composite wraps is calculated with the following equation:

$$
\tau_{\max }=\frac{P * Q_{t}}{2 * I_{x t} * b_{t}}
$$

Where

$$
Q_{t}=370 \text { in }^{3} \quad \text { and } \quad G_{r}=85,178 \text { psi }
$$

\subsubsection{Results - Beam Three Repaired}

The repaired specimen was tested in four-point bending in accordance with ASTM 198 and an a/h of 1.875. The maximum load achieved was 30,625 lb without ultimate failure. Due to instability while loading, the specimen did not reach ultimate failure. The shear modulus $\left(\mathrm{G}_{\mathrm{r}}\right)$ was calculated to be 73,946 psi. The fiber volume fraction for the repaired specimen was $4.6 \%$. The maximum shear strength $\left(\tau_{\max }\right)$ was 
calculated as 113 psi. Because failure load was not reached, these values are low relative to the other specimen. There was no failure mode due to the instability of the loading.

\subsubsection{Discussion}

Table 3.4 shows an increase in the repaired shear modulus of Beam One and a decrease in the shear modulus of Beam Three. Repaired Beam One was able to sustain a greater load than the control specimen. One explanation for this behavior is the existence of a "near perfect" bond between the GFRP wrap and the wood substrate. It is believed that the repaired beam (Beam One) with the GFRP composite wrap restored enough shear capacity to the failed beam to allow it to sustain greater loads and experience ductility. Beam One failed in horizontal shear, i.e. a horizontal shear split formed at mid-depth an propagated towards the end of the beam. Beam One was repaired using $\mathrm{U}$-shaped three layer GFRP fabric reinforcement strategically placed in the shear zone areas. This beam was retested and the U-shaped reinforcement performed well, by providing a confinement zone, thereby, repairing the failed section. Further, the presence of the reinforcement at that location allowed the redistribution of the shear strain upon retesting. Hence, an increase in the shear load attained. Note also, that although there was an increase in load during the repaired Beam One test that the maximum shear strength $\left(\tau_{\max }\right)$ dropped. This is could be attributed to the fact that the maximum shear strength may not occur at the maximum shear strain.

However, the shear stiffness (modulus) of repaired Beam Three dropped considerably more than the control specimen. This could indicate a possible premature debonding of the GFRP wrap from the wood substrate and no confinement, as would be provided if the GFRP wrap went completely around the section instead of U-Shaped. Another explanation could be that various levels of damage occurred while testing the control specimen. Therefore, when beam three was repaired and retested a significant improvement in the shear modulus $(\mathrm{G})$ could not e attained. 
Table 3.4. Summary of Shear Test Results

\begin{tabular}{|c|c|c|c|c|c|c|}
\cline { 2 - 7 } & \multicolumn{3}{|c|}{ Beam One } & \multicolumn{3}{c|}{ Beam Three } \\
\cline { 2 - 7 } & $\begin{array}{c}\text { Control } \\
(\mathrm{a})\end{array}$ & $\begin{array}{c}\text { Repaired } \\
(\mathrm{b})\end{array}$ & $\begin{array}{c}\text { Relative } \\
\text { Value } \\
(\mathrm{b} / \mathrm{a})\end{array}$ & $\begin{array}{c}\text { Control } \\
(\mathrm{a})\end{array}$ & $\begin{array}{c}\text { Repaired } \\
(\mathrm{b})\end{array}$ & $\begin{array}{c}\text { Relative } \\
\text { Value } \\
(\mathrm{b} / \mathrm{a})\end{array}$ \\
\hline Maximum Load $(\mathrm{Ib})$ & 47,963 & 51,175 & 1.07 & 106,550 & 30,625 & 0.29 \\
\hline Deflection $($ in) & 1.926 & 3.964 & 2.06 & 2.558 & 1.817 & 0.71 \\
\hline Maximum Shear Strain $\left(\times 10^{-6}\right)$ & 5178 & 2567 & 0.50 & 1415 & 1837 & 1.30 \\
\hline Shear Modulus $(\mathrm{G}) \mathrm{psi}$ & 60,484 & 85,178 & 1.41 & 383037 & 73946 & 0.19 \\
\hline Shear Strength $\left(\tau_{\max }\right) \mathrm{psi}$ & 290 & 217 & 0.75 & 583 & 113 & 0.19 \\
\hline
\end{tabular}

Based on the experimental results, it is evident that repairing creosote treated beams using GFRP composite fabrics in combination with phenolic resins and formaldehyde adhesives performed well, providing reasonable shear and bending strength regain in all beams tested to failure. The repairing scheme of timber beams is critical in the maintenance of in service timber bridges. Repairing superstructure and substructure members in the field can provide an alternative to bridge replacement. 


\section{Chapter 4. In-situ Rehabilitation and Field Testing}

\subsection{Introduction}

As a part of Phase II of this research project, field load tests were conducted in July of 2002 and August of 2003, respectively, on two 50-year-old open-deck timber railroad bridges located in Moorefield, WV. The two test sites selected contained rehabilitated members using GFRP composite wraps. The rehabilitation was performed under Phase I of this research program. This chapter describes the static and dynamic testing performed to evaluate the dynamic response, load distribution, and condition of the bridges that have been rehabilitated and provide a baseline for future testing. This chapter also describes the "step-by-step" in-situ rehabilitation procedure for a "pile cap/pile" joint and pile repairs for a in-service timber railroad bridge. The results of these tests are presented in Chapter 5.

\subsection{Description of Bridges}

Two sites were selected because of their close proximity to each other, accessibility, and low profile making it easy for instrumentation purposes.

The two bridges are located on the South Branch Valley Railroad (or SBVR). The SBVR is a state owned section of railroad track that contains several timber bridges constructed in the early 1900's (Figure 4.1). Bridges 570 and 568 are subject to flooding on a yearly basis. The open-deck bridge spans measured approximately 12 feet center to center of supports and contained two main chords, each consisting of three sawn timber stringers placed in a staggered fashion. Chords are supported by pile bents at approximately 12 feet apart. Each pile bent consisted of one pile cap and four piles. 


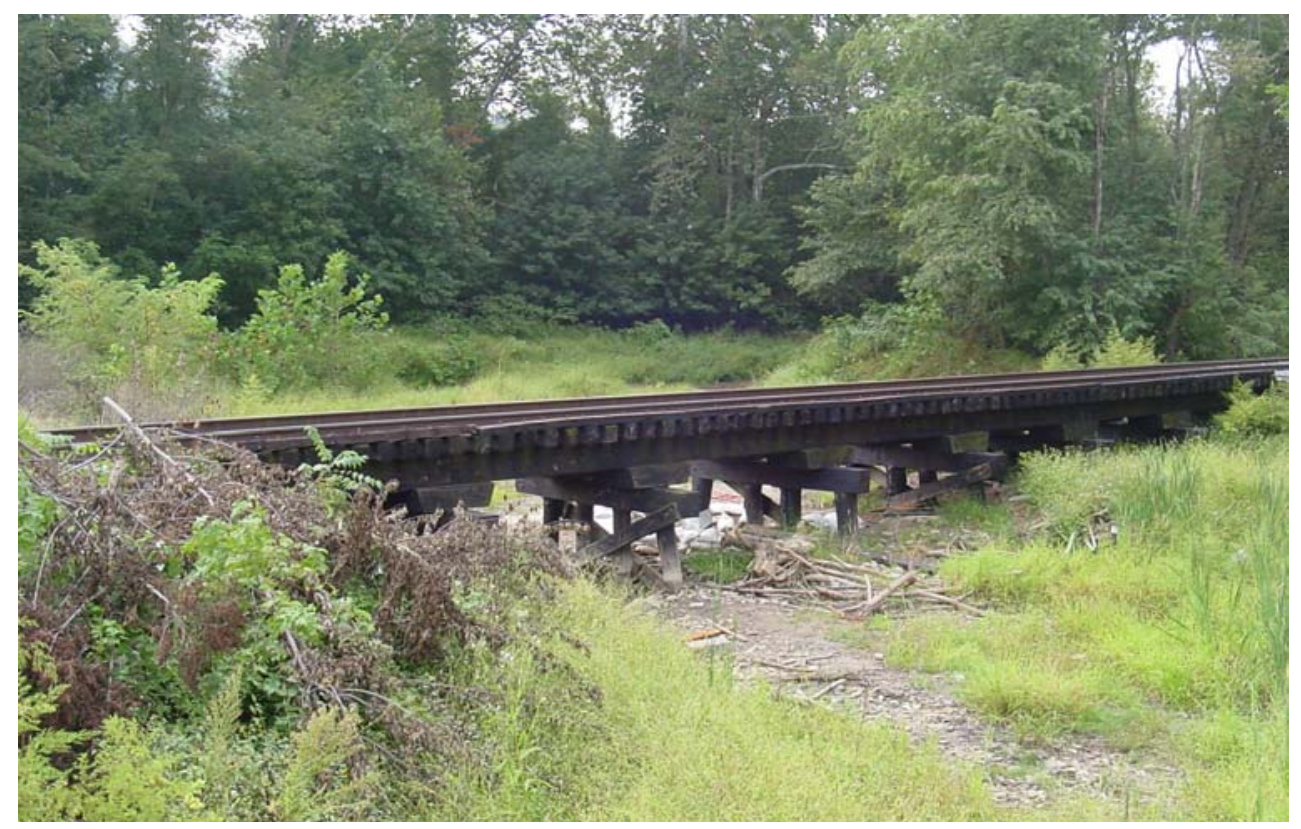

Figure 4.1. Bridge 568 Summer 2002

\subsection{Description of Field Load Testing}

The Fourth Span from the west end of Bridge 568 was selected to be instrumented with uniaxial strain gages, accelerometers, and LVDT's. This particular Span was selected because it had rehabilitated members and it also had a decayed joint needing rehabilitation and strengthening. Strain gages were placed at four locations on the top and bottom of the selected pile cap, and on each of the four piles. Strain gages were also mounted at midspan on the tension side on all the stringers for both chords. Two LVDTs were used to monitor the static and dynamic deflections of both chords of the Fourth Span. One LVDT was placed on the center stringer of each chord, which consists of three stringers. Two accelerometers were also placed on the center stringer of each chord to measure accelerations of the test span at various speeds. All data were collected using a data acquisition system. See Figure 4.2 for instrumentation lay-out diagram. 


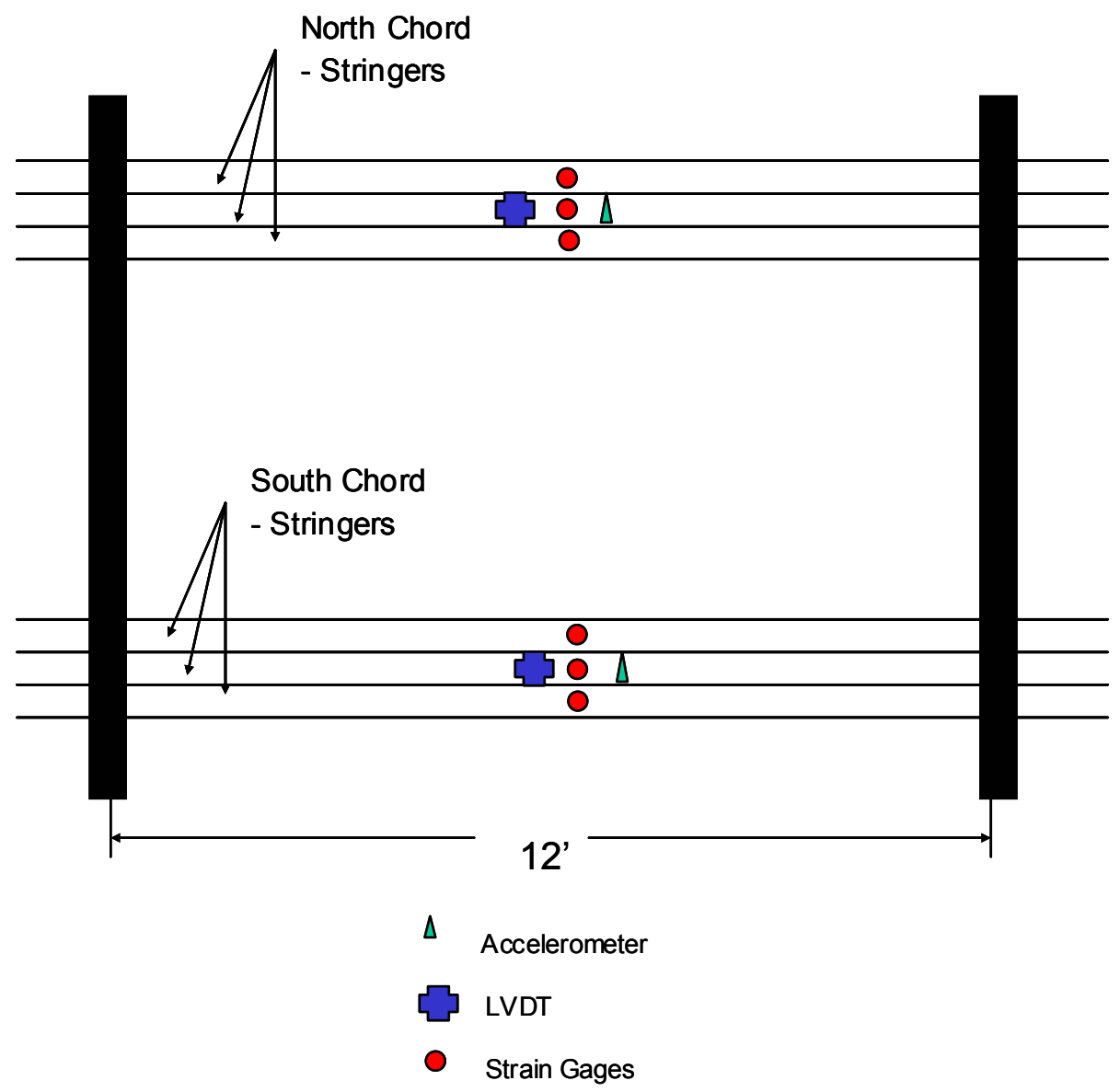

Figure 4.2. Instrumentation lay-out of the Fourth Span

\subsubsection{Test Procedure \& Loading}

The Fourth Span from the west end of Bridge 568 was load tested using a General Electric 80-ton locomotive provided by SBVR (Figure 4.3). To assess the dynamic response of bridges, tests were performed using the locomotive at three different speeds: $5 \mathrm{mph}, 10 \mathrm{mph}$, and $15 \mathrm{mph}$. These speeds were selected so that the dynamic response of the bridge could be evaluated under the same load conditions. 


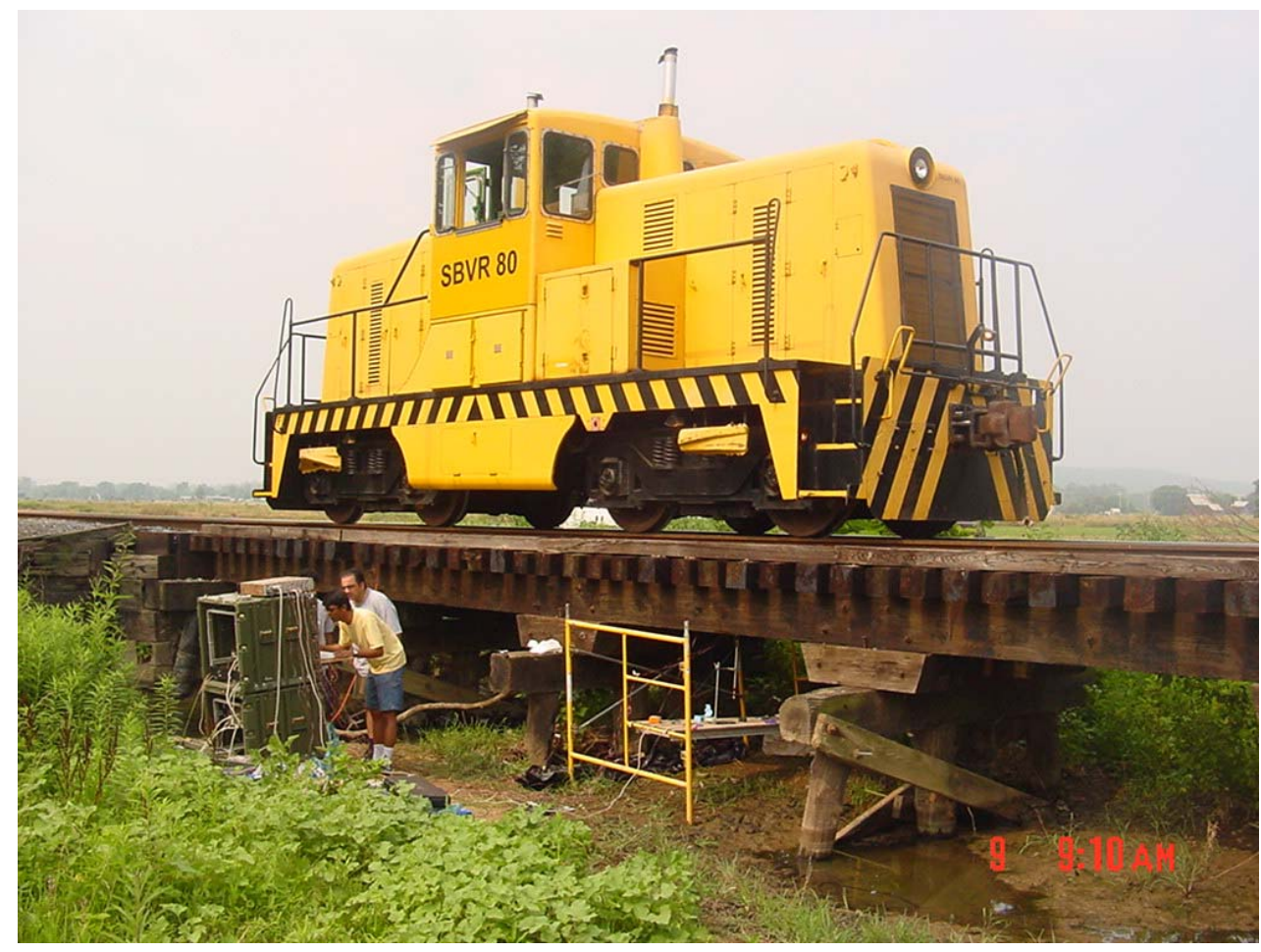

Figure 4.3. 80-TON SBVR Locomotive on Bridge 570 in Moorefield, WV

Static loading was achieved by positioning the test locomotive at specific positions with reference to the bridge span being tested. Specifically, one truck of the locomotive was positioned on the center line of the span being tested.

\subsubsection{Condition Assessment}

Prior to load testing, Bridges 570 and Bridge 568 were subjected to a complete condition assessment survey. This consisted of bridge configuration measurements, visual inspection, and photographic documentation. Several bridge members were found to be in a deteriorated state. Both bridges having been subject to flooding, a substantial amount of damage caused by debris and decay, especially to the above ground piles was observed. Bridge 568 (Span 4) was selected for rehabilitation and testing. 


\subsection{Rehabilitation}

\subsubsection{Introduction}

In cooperation with the South Branch Valley Railroad (SBVR) in Moorefield, West Virginia, Bridge 568, a seven-span open deck trestle built in 1954 was visually inspected and it was determined that the fifth pile bent from the west end of Bridge 568 showed signs of deterioration at several locations. Polyurethane sheeting had been placed around the pile cap - pile joint. Moisture collected within this cover, caused severe decay around the joint (See Figure 4.4).

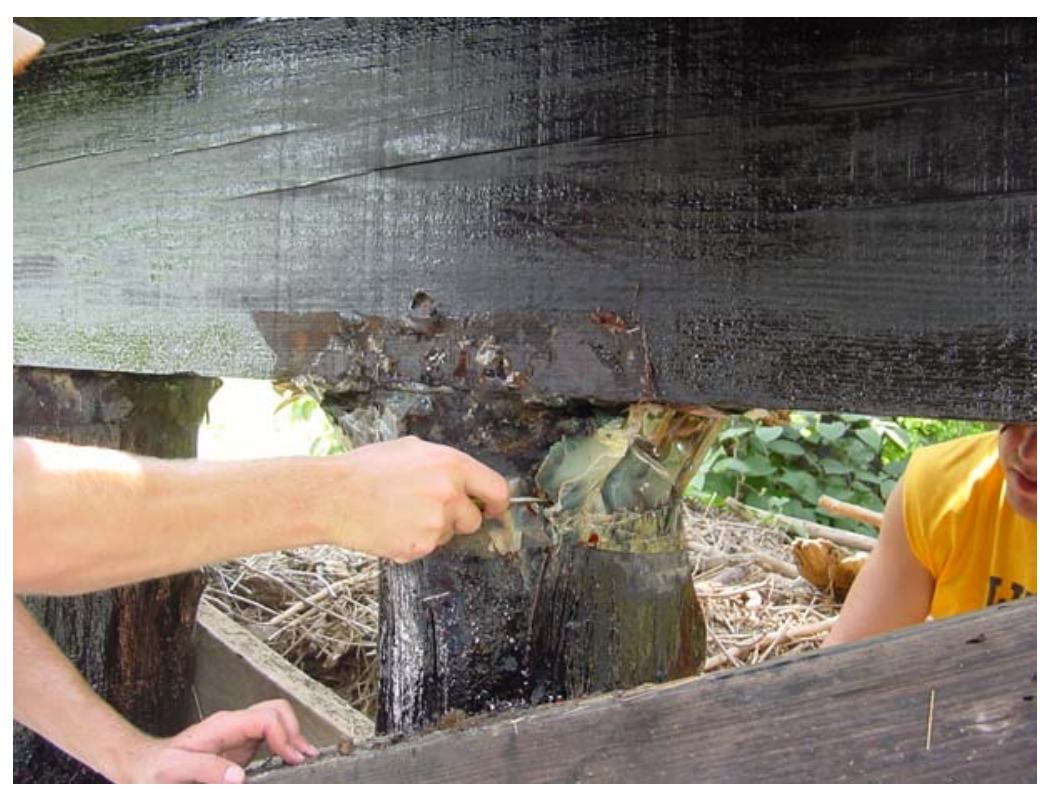

Figure 4.4. Areas of decay contained in the fifth pile bent

A third party (company) had previously repaired the decaying pile/pile cap connection by surrounding it with polyurethane sheeting and injecting an epoxy resin that surrounded the connection. This repair was unsuccessful and eventually caused extensive decay when the plastic sheeting pooled water around the joint. As shown in Figure 4.5, the extent of damage was not realized until the material surrounding the joint was completely removed. Similarly, the pile selected for rehabilitation on the sixth pile bent from the west end of Bridge 568 had a previous rehabilitation attempt, which had been placed on the pile (See Figure 4.6). 


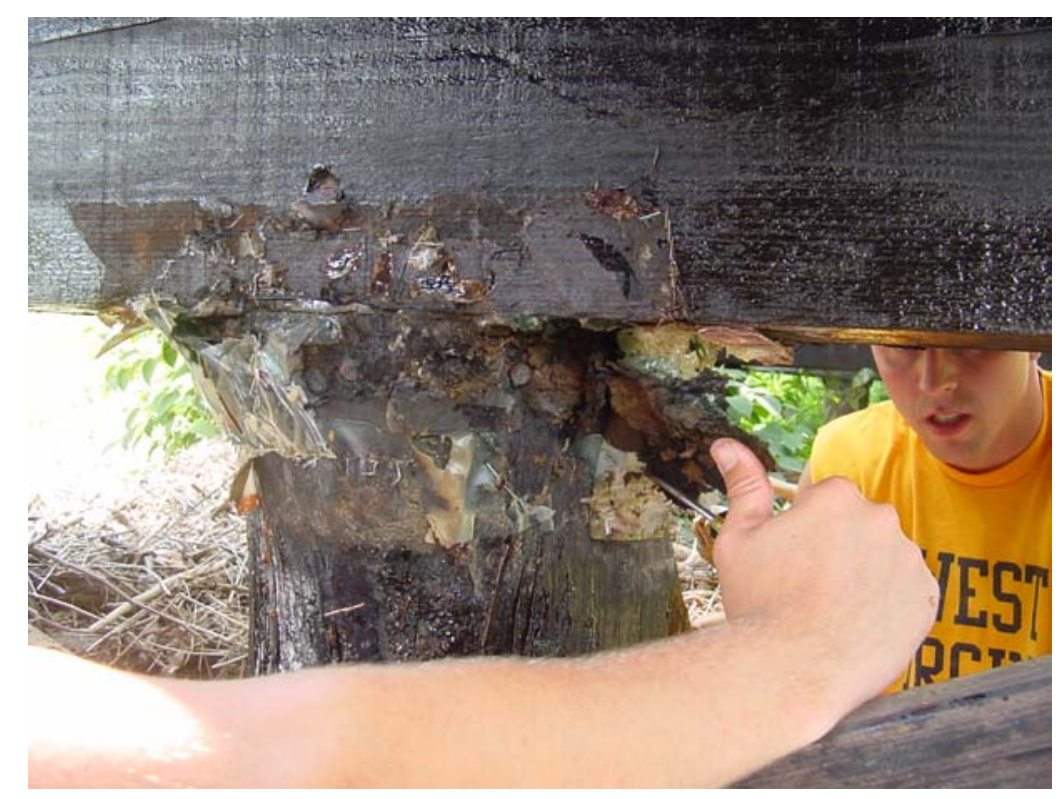

Figure 4.5. Removal of decay from "pile cap/pile" joint

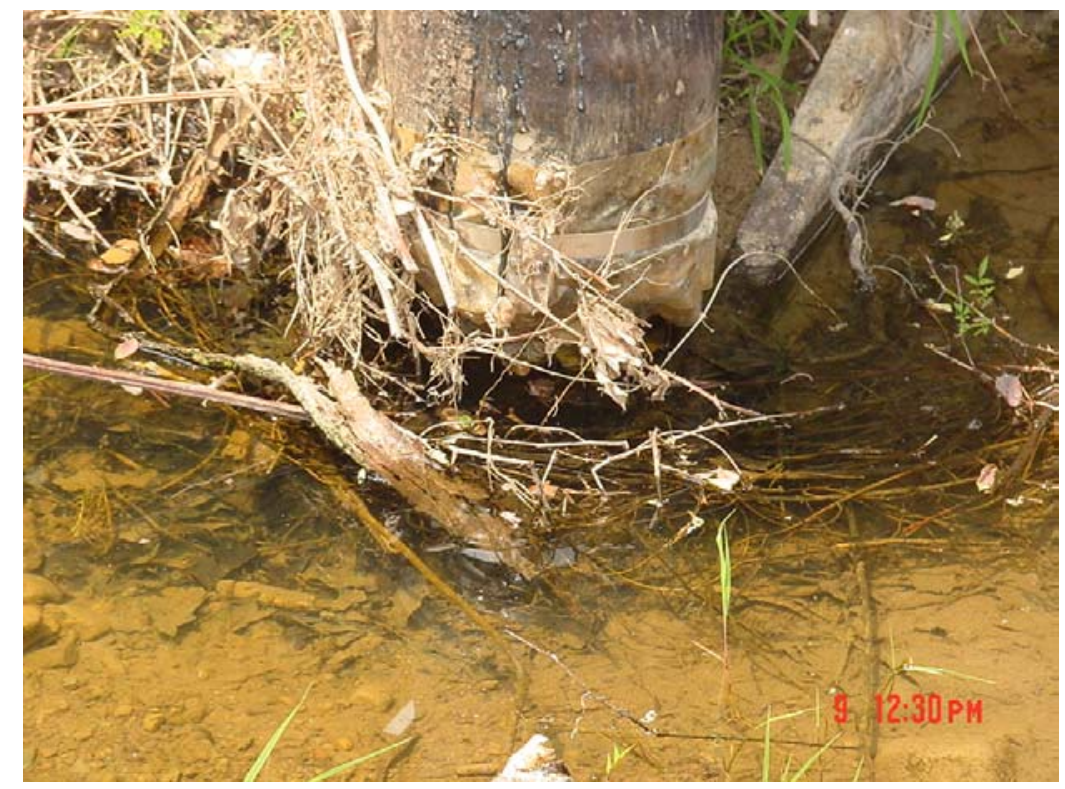

Figure 4.6. Previous pile rehabilitation attempt

A smaller pile diameter pile (i.e., 6“) supported a larger (i.e., 12" diameter) pile. This caused severe reduction in the load bearing area of the pile as seen in Figure 4.6. Stress concentrations at the point of lower pile diameter may eventually cause failure of the pile. 


\subsubsection{Joint Repair Technique}

\subsubsection{Materials}

Glass Fiber Reinforced Polymer (GFRP) fabrics in combination with Phenolicbased adhesives were used to repair the pile bent. The phenolic resin was mixed with a formaldehyde hardener at a 5:1 ratio by weight. The GFRP composite wrap was then coated with the adhesive. This is performed to provide sufficient bond between the GFRP and the substrate. This combination of GFRP composite fabric and phenolic adhesive was used successfully on the phase I rehabilitation performed during Summer 2000 (King \& GangaRao, 2001).

A phenolic-based adhesive in combination with the GFRP composite wrap was used because it was found to be compatible with the creosote treated wood substrate and provided adequate chemical cross-linking (a.k.a., bond) between the GFRP wrap and the wood substrate. The composite fabric used in this rehabilitation and strengthening is Eglass because of its cost advantage over other composite fabrics (e.g., carbon) and the sizing characteristics make it compatible with the adhesive. The density of the GFRP fabric is $28 \mathrm{oz} / \mathrm{sq} . \mathrm{yd}$.

To improve durability and enhance the performance of the bonded surfaces, a phenolic primer was also used on the treated wood surfaces. The Phenolic adhesive $G$ 1131-A, and formaldehyde hardener G 1131-B were purchased from the Borden Chemical Company.

\subsubsection{Step-by-Step Rehabilitation}

\subsubsection{Introduction}

To demonstrate the viability of GFRP composite materials as a non-intrusive, fast retrofit technique for timber bridge rehabilitation, a decayed pile cap/pile joint was selected for repair. While there is extensive information on design and analysis of GFRP-reinforced members, the installation and quality control have been the responsibility of manufacturers, and typically required experimentation and observation. The following step-by-step procedure describes how to install GFRP composite wraps 
and avoid problems, such as air entrapment and fabric wrinkling associated with wet layup systems that usually lead to deficient bond and premature failure.

\subsubsection{Removal of Decay}

For successful rehabilitation, the GFRP wrap must be applied to the original structure. Thus any prior failed repair must be completely removed. After prior defective repairs have been removed, then any damage or decay existing on the pile bent is removed, and GFRP wrap is placed. The removal of previous rehabilitation attempts and existing decay is shown in Figure 4.5.

\subsubsection{Rounding and Sanding}

After the removal of the decayed material, the area in which the GFRP wrap is to be placed was sanded to smooth and round corners of the surface to allow uniform application of the GFRP fabric and provide a better bond between the wood and the wrap.

Upon completion of the sanding, the square edges of the bent were also smoothed using a hand held edger. These edges must be smoothed to diminish stress concentrations along the edge of the beams. If the edges were left square, then stress concentrations in the GFRP would develop, causing ripping of GFRP and a decrease in the load carrying capacity of the wrap. Smoothing of the edges is shown in Figure 4.7. 


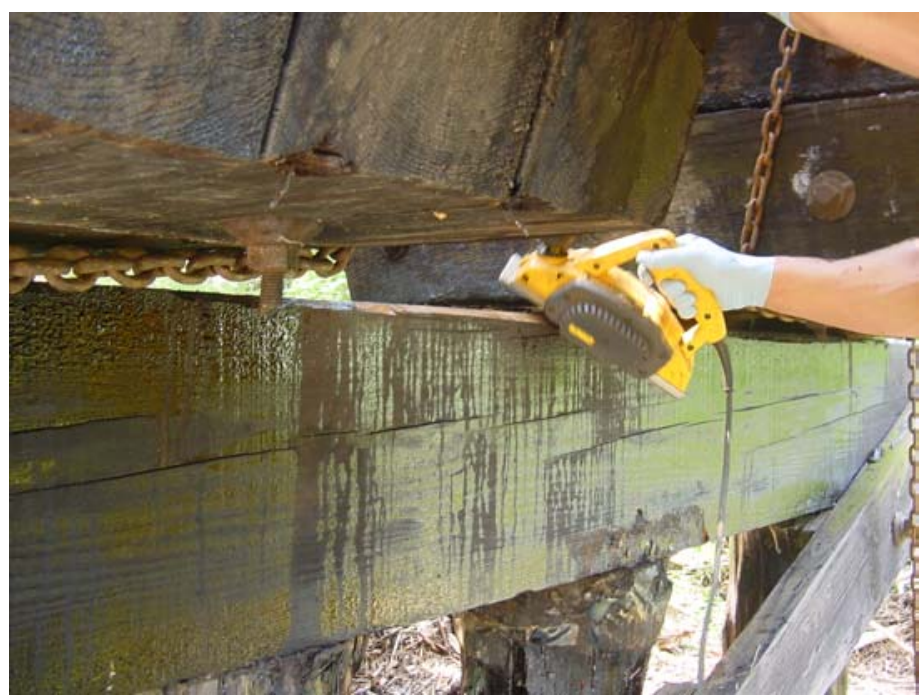

Figure 4.7. Smoothing of the edges

\subsubsection{Priming of the Surface}

Once the edges of the beam have been smoothed, the area in which the GFRP wrap will be applied is pre-coated with a primer to improve and enhance the durability of the bond. The phenolic-based primer, which is crucial in the bonding of the GFRP wrap and the structure, was left to cure for a period of 24 hours.

\subsubsection{Coating of GFRP Fabric with Resin}

After the primer has cured, the structure (pile cap) is ready for the application of the GFRP wrap. Before the wrap is applied it must be coated (soaked) with the phenolic formaldehyde adhesive. To uniformly and completely coat the wrap with adhesive efficiently, a method was developed using a hand wringer attached to a large basin. By filling the basin with the adhesive and then soaking the wrap in the adhesive, a large piece of GFRP can be covered very quickly. Excess resin was quickly removed by passing the fabric through the "manual-wringer". This method of soaking and removing excess resin from the fabric worked well in a field application and reduced the possibility of developing voids or delaminations. Without using the hand wringer, the excess resin must be scraped off by hand. This method of removal is very time consuming and requires at least three individuals. This is illustrated in Figure 4.8(a). By first soaking the 
resin and immediately running it through the wringer (Figure 4.8b), the speed of applying layers of GFRP wrap increased and the number of individuals needed decreased.

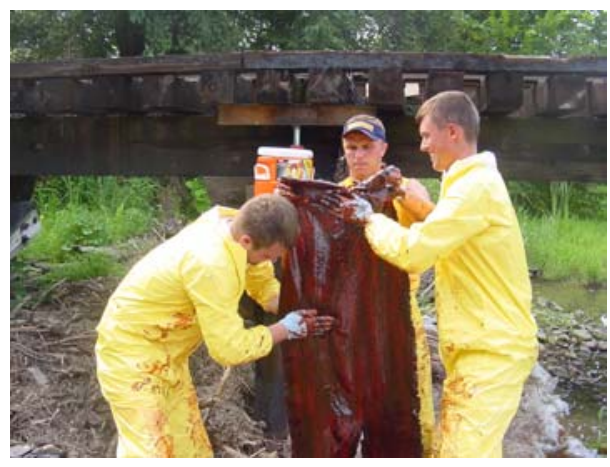

(a)

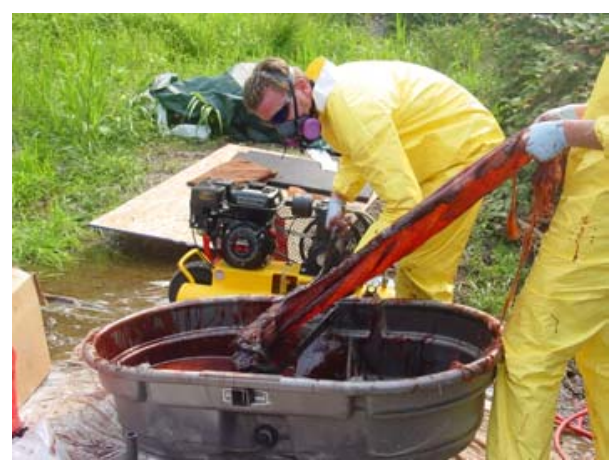

(b)

Hand-removal of excess resin

Hand-wringer removal of excess resin

Figure 4.8. Removal of Resin by hand and "hand - wringer"

\subsubsection{Continuous \& Discontinuous Application of GFRP Fabric}

Once the GFRP wrap has been coated with the phenolic formaldehyde adhesive using the hand wringer-basin system, it is ready to be applied to the pile bent structure. Based on several laboratory trials to wrap "beam column" or "beam-pile" joints with GFRP fabric, two alternative methods of wrapping were considered. To avoid fiber wrinkling, one method uses a continuous piece of cloth approximately 20 feet long with width being nearly equal to the half the beam depth. Another method uses discontinuous pieces of fabric that are approximately 5 feet long and placed in a particular sequence. From the laboratory trials, the discontinuous method of wrapping a joint proved to be more successful in terms of avoiding fiber or fabric wrinkling and minimizing voids. However, since we did not conduct any strength experiments to fully evaluate these techniques, we can not at this time recommend one or the other. From a viewpoint of workability and quality control of "joint wrapping", it appears that the discontinuous approach is better suited for this in-situ rehabilitation and strengthening application. As seen in Figure 4.9, two interior joints of the pile bent were selected for rehabilitation using GFRP wrap. Based on the dimensions of the pile caps used on Bridge 568 span 4 
and the discontinuous method of joint wrapping, a length of 5 feet and a width of 20 " (which is the width of the GFRP fabric roll) were selected for each individual piece of GFRP wrap applied to the joint.

The step-by-step wrapping sequence, as shown in Figure 4.10, is described as follows: The first piece of GFRP wrap at a $90^{\circ}$ angle around the pile cap (completely encompassing the cap). The second piece is placed on the opposite side of the pile cap/pile joint, also at a $90^{\circ}$ angle, in the same manner as the first piece of GFRP wrap. The third piece of wrap is placed at a $45^{\circ}$ angle around the pile cap directly over the pile cap/pile joint. The ends of this piece were cut at $45^{\circ}$ angles, the cutting of these ends made it possible to wrap one section of GFRP around the under side of the pile cap and one section of wrap around the pile. The fourth piece of wrap is placed at a $45^{\circ}$ angle on the pile cap, but is oriented in the opposite direction as piece three. Pieces three and four of GFRP fabric overlapped pieces one and two on the ends. Piece five is placed directly over the pile cap/pile joint and overlapping pieces three and four at their intersect. This piece was cut at $90^{\circ}$ on each corner so that it was possible to connect the pile and pile cap. Piece six is placed directly below the pile cap/pile joint parallel, sealing the exposed edges of pieces three and four. Piece seven is placed at a $90^{\circ}$ angle directly over piece one and overlapping pieces three and four. This piece was used to seal any exposed edges of GFRP fabric. This will ensure more efficient load transfer from member to member. The final piece is placed directly over piece two at an angle of $90^{\circ}$, overlapping with pieces three and four. Figure 4.10 presents an illustration of the wrapping sequence. 


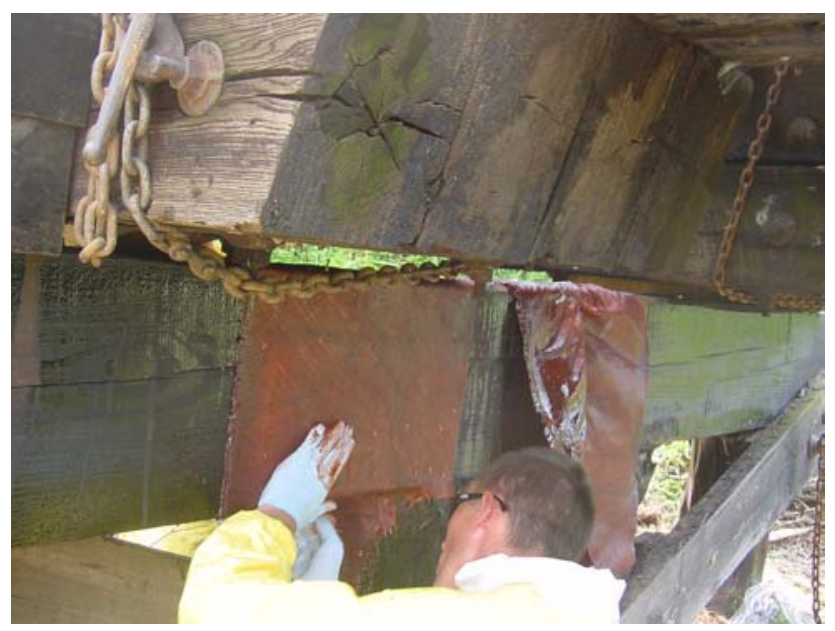

Figure 4.9. Wet hand lay-up application of GFRP to pile cap

During the wrapping process, all individual pieces of wrap were initially attached to the pile bent using an air powered staple gun. This allowed the crew to pull tightly on the pieces and drive out any entrapped air voids around the pile bent. Also during this process, a marginal amount of adhesive was distributed evenly by hand on each piece of GFRP placed on the pile bent. This small amount of adhesive rubbed on the pieces helped to provide a stronger bond in between the pieces as they were applied (See Figure 4.9 illustrating the application of resin by hand). 


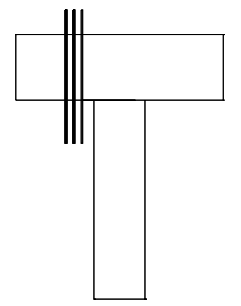

Step 1

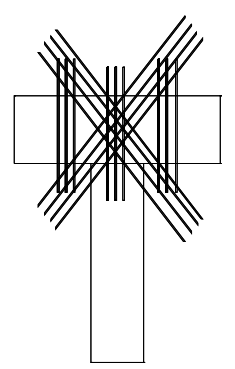

Step 5

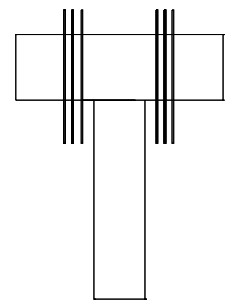

Step 2

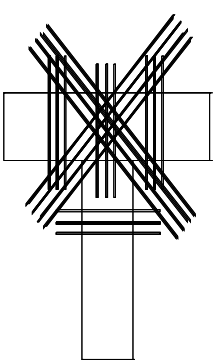

Step 6

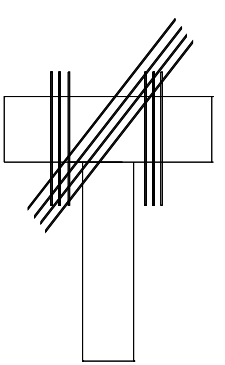

Step 3

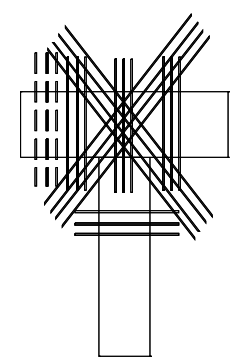

Step 7

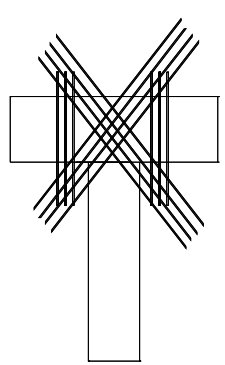

Step 4

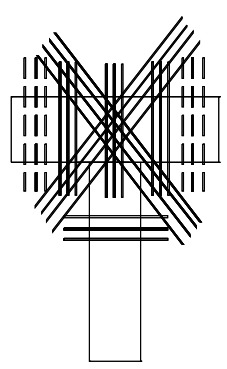

Step 8

Figure 4.10. Steps $1-8$ of the wrapping sequence of a pile cap/pile joint

Through laboratory experimentation and experience, it was determined that three layers of GFRP wrap is the optimum thickness for the rehabilitation of wood members. The method developed by the Constructed Facilities Center (CFC) described above provides three layers of GFRP wrap covering the area of the pile bent selected for rehabilitation.

\subsubsection{Application of Wax Paper}

After the GFRP wrap was applied to the pile bent, any excess resin was removed from the top layers of wrap. Then a layer of wax paper was placed on all surfaces of the GFRP wrap to avoid bonding to the plywood (see Section 4.4.3.8)

\subsubsection{Application of Plywood}

Once the wax paper has been applied, plywood was clamped on the areas that received GFRP wrap. This plywood applies pressure evenly throughout the entire surface. By applying even pressure, a more complete bond between not only the layers 
of GFRP, but also between GFRP and the wood is achieved. This plywood was left inplace throughout the drying/curing process. Figure 4.11 shows the application of plywood to the wrapped pile bent. Also, rubber banding was applied to the pile. This provided uniform pressure on piles.

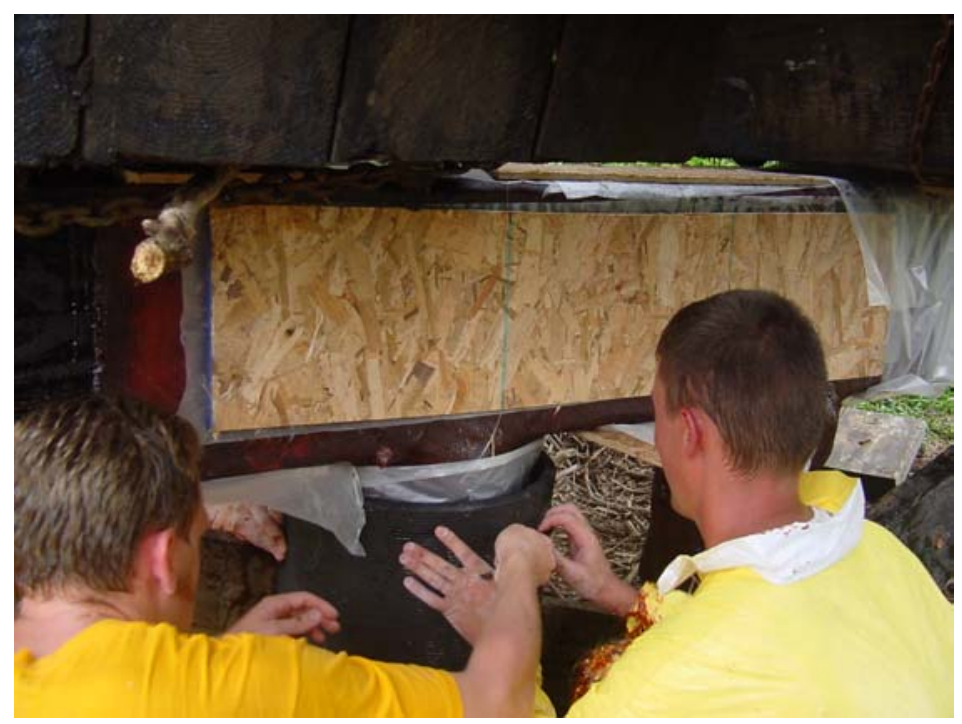

Figure 4.11. Showing plywood being clamped

\subsubsection{Finishing Sanding}

After the GFRP has been given time to sufficiently cure, the plywood was removed from the pile bent. A hand held sander was then used to smooth out any rough edges on the GFRP wrap, to prevent water entrapment and bond degradation, (Figure 4.12). 


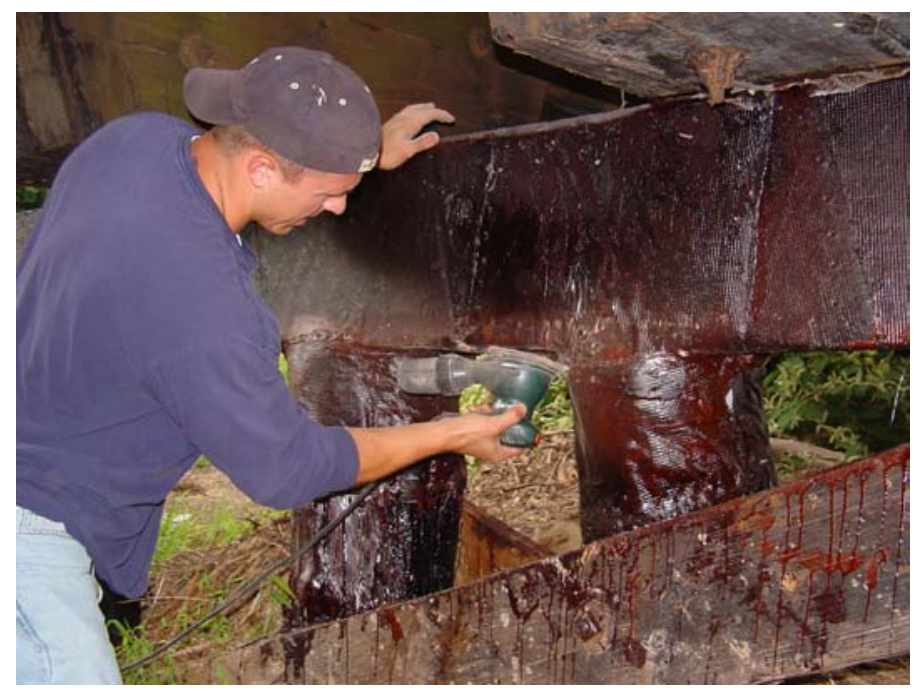

Figure 4.12. Sanding

\subsubsection{Sealing with Phenolic}

The final step in the wrapping process is the sealing of rough edges using the same phenolic-based adhesives. By using the adhesive described previously to seal around the layers of GFRP and prevent any ingress of water or moisture accumulation, thus weakening the GFRP bond between the layers to the timber (Figure 4.13).

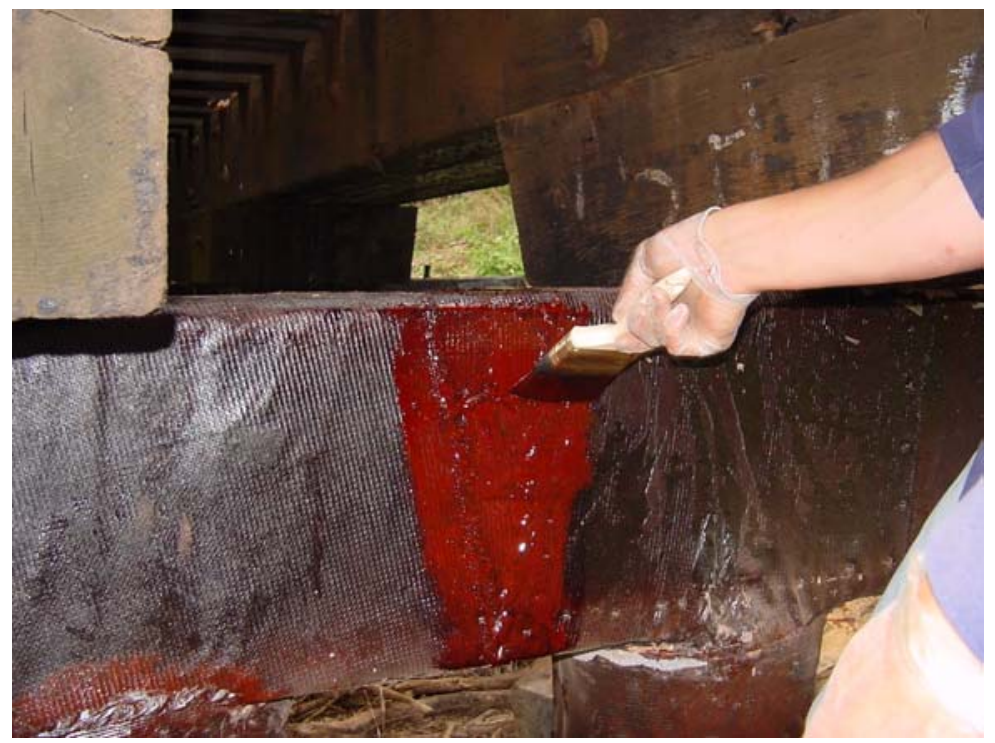

Figure 4.13. Sealing 


\subsection{Pile Repair Technique}

\subsubsection{Materials}

Similar to the joint rehabilitation, GFRP composite fabrics in combination with phenolic-based adhesives were used to repair decayed pile sections. The GFRP wrap and phenolic-based adhesives used in this procedure are the same as those described previously in the pile bent repair.

Also used in the rehabilitation of the pile was a bulk filler material, consisting of the phenolic-based adhesive mixed sawdust. Proper consistency of this material was developed through laboratory experimentation and trials.

\subsubsection{Pile Rehabilitation}

\subsubsection{Site Preparation}

Prior to the rehabilitation of the pile, a coffer dam was constructed around the pile and the stream water was pumped out to provide a dry work area. Plastic tarps were placed above the work area to ensure that the bulk filler material, GFRP wrap, plastic sheeting, and rubber banding remained free of moisture.

\subsubsection{Removal of Decay}

Prior unsuccessful repair attempts were completely removed, and any decaying matter existing on the pile must also be removed before any GFRP wrap can be placed. The removal of previous rehabilitation attempts and existing decay can be seen in Figure 4.14 . 


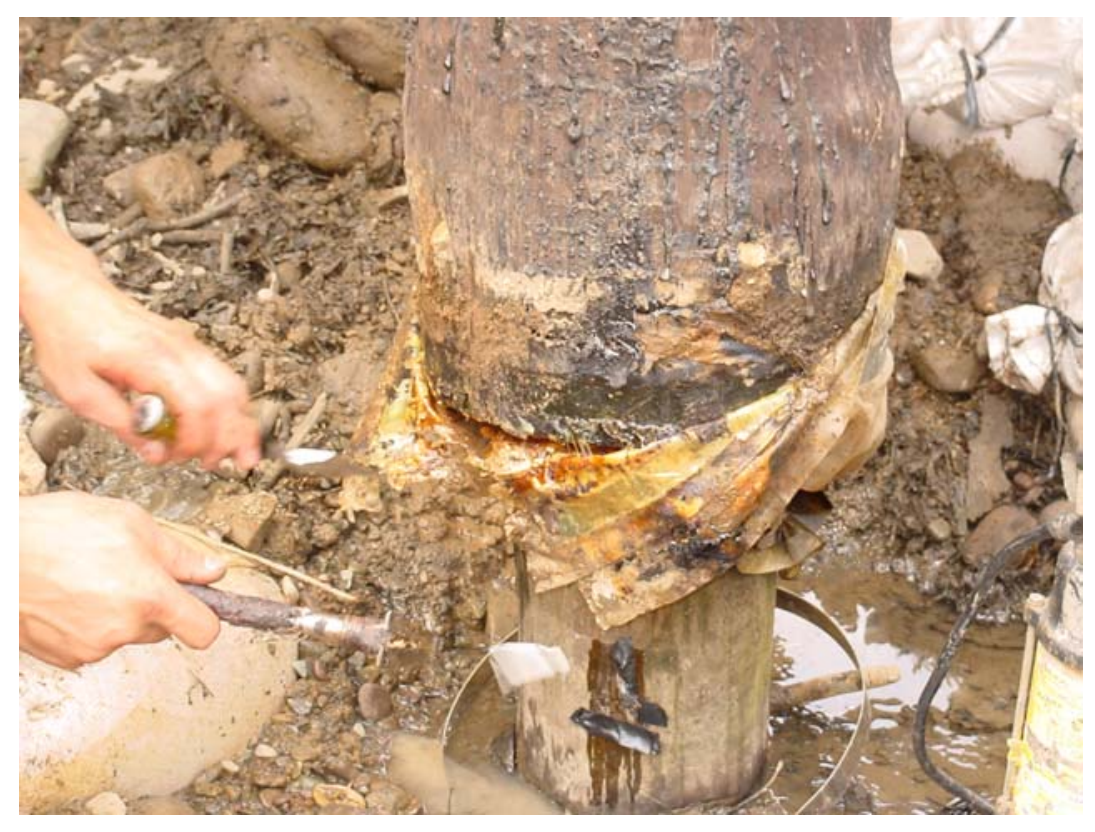

Figure 4.14. Existing Pile (12" and 6" Diameters, respectively)

\subsubsection{Construction of Molding}

To repair the damaged pile, a cone shaped mold using pliable plastic sheeting around the area of the pile that was in need of repair. This mold provided a way to shape the bulk filler material, as Figure 4.15 shows a picture of the mold. 


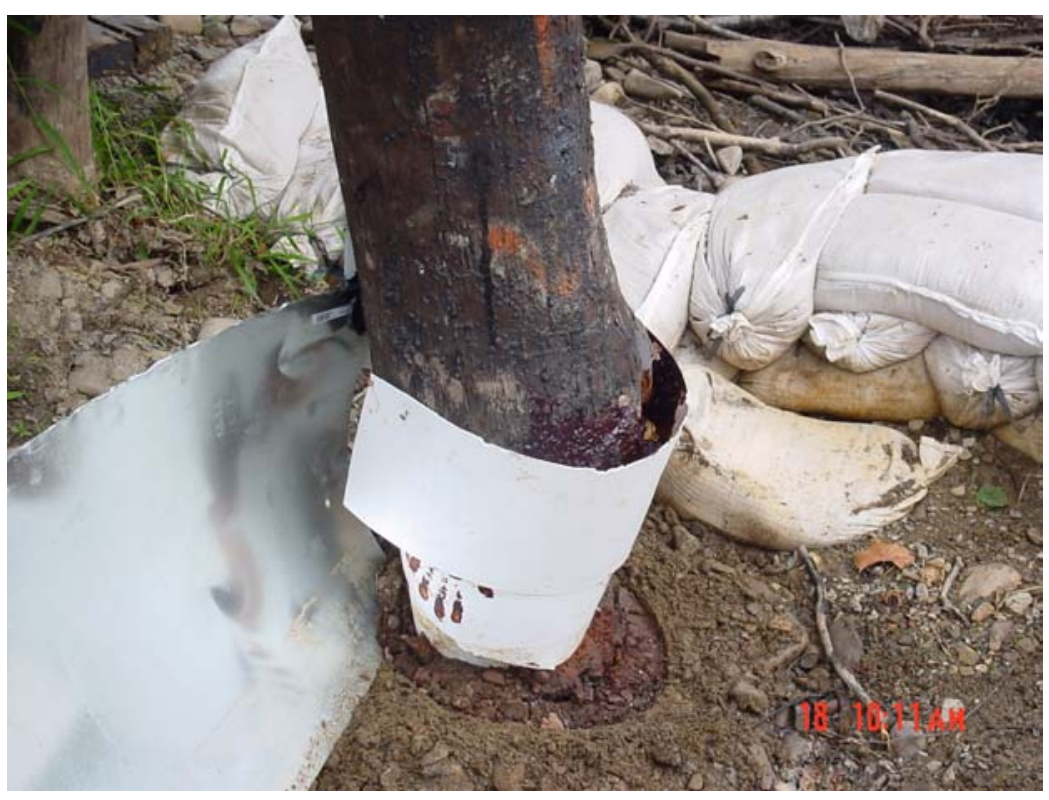

Figure 4.15. Mold around Pile

\subsubsection{Placing of Bulk Filler}

After the mold was placed around the pile, the bulk filler material was placed inside that mold. By placing the bulk filler inside the mold and allowing it to dry and cure, a smooth transition in diameter from the top pile to the smaller pile (embedded in the ground) was provided. This smooth transition will allow a more efficient load transfer within the pile and will reduce the risk of pile failure under transverse loading conditions. Figure 4.16 shows the filling of the mold with bulk filler material. 


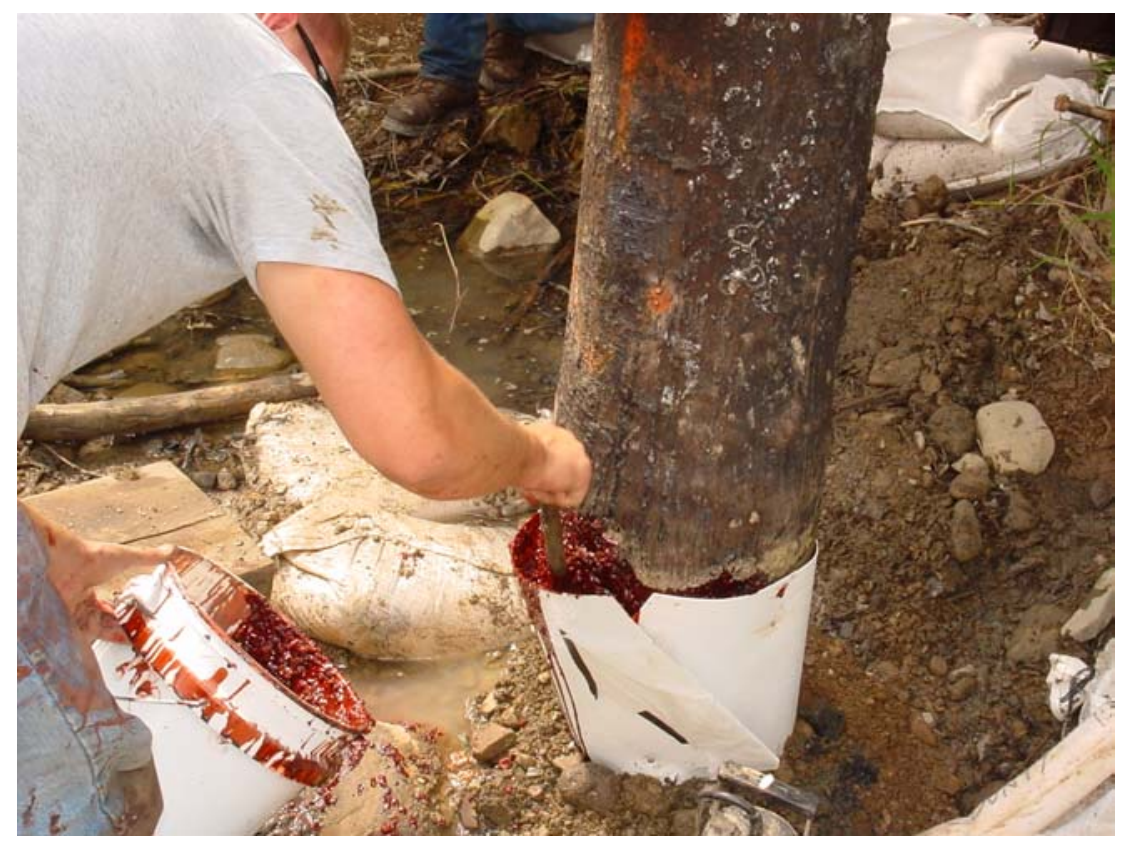

Figure 4.16. Filling of mold with bulk filler material

\subsubsection{Sanding}

Once the bulk filler material has been allowed to dry and the mold is removed, the sharp edges were sanded down. This sanding prepares the bulk filler for placement of the GFRP wrap which will provide the reinforcement necessary to transfer load from the larger diameter pile to the smaller one. Once sanding was completed then, the phenolicbased adhesive was used to prime the pile and the bulk filler, and was cured for 24 hours. This primer ensures a better quality bond between the wood and the GFRP.

\subsubsection{GFRP Fabric Application}

Because the pile is round and the GFRP was being placed on a cone shaped structure, GFRP wrap pieces were cut 5" x 5'. This size piece of GFRP minimized bunching and wrinkling caused by the natural tendencies of the fabric when placed around a cone shape. The wrap was soaked and pulled using the hand wringer method (Figure 4.17(a)) discussed previously. Beginning below the bulk filler on the lower pile, GFRP wrap was placed vertically onto the upper pile approximately one foot above the 
top of the bulk filler material (see Figure 4.17(b)). This GFRP helped to ensure a smooth load transition throughout the rehabilitated section of the pile.

During the wrapping of the pile, the wrap was initially stapled to the pile using an air powered staple gun. This allowed the crew to pull tightly on the wrap and drive out any air voids. Also during this process, a marginal amount of adhesive was distributed evenly by hand on the GFRP placed on the pile (See Figure 4.18).

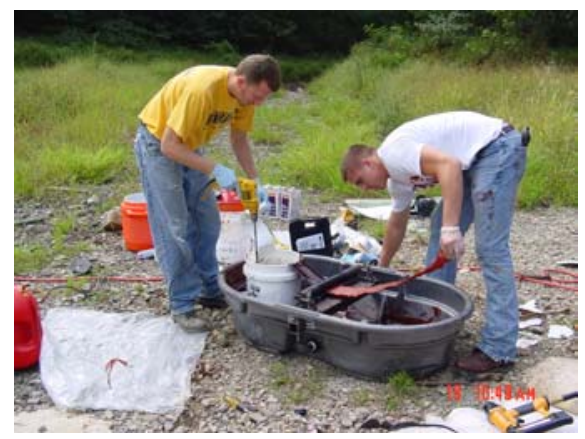

(a)

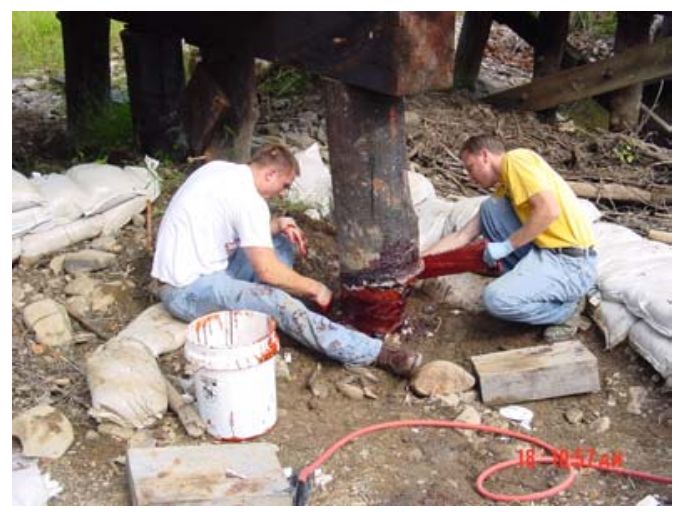
Figure 4.17. Hand wringer method (a) and placement of wrap (b) around pile

(b) 


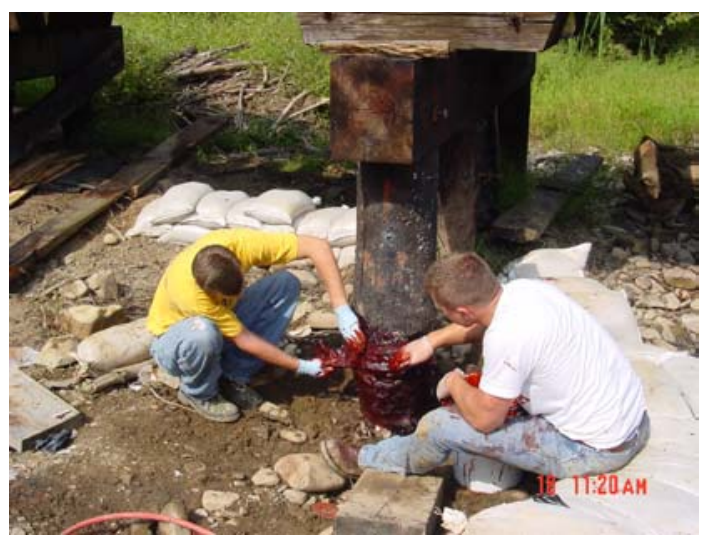

Figure 4.18. Smoothing of wrap with adhesive

\subsubsection{Applying Pressure}

After placing the GFRP wrap, uniform clamping pressure was applied to develop adequate bond between all layers of GFRP and the wooden pile. To apply pressure to the pile a thin and workable plastic sheeting was used. This sheeting was held to the pile by rubber banding (Figure 4.19).

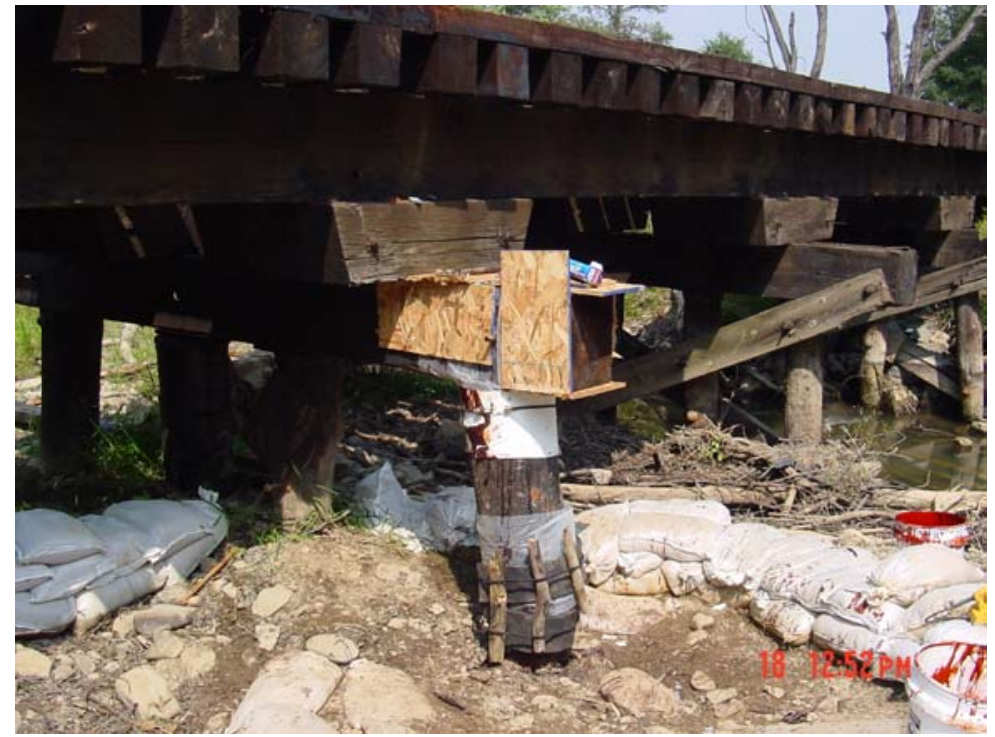

Figure 4.19. Rubber banding around pile 


\subsubsection{Sanding}

After the GFRP has been given time to sufficiently dry and cure, the rubber banding and sheeting were removed from the pile. A hand held sander was then used to smooth out any rough edges on the GFRP wrap. This prevents water entrapment and bond degradation.

\subsubsection{Sealing}

The final step in the wrapping process is the sealing of rough edges using phenolic-based adhesives, to seal around the layers of GFRP and prevent any ingress of moisture and protect the bond between the layers of GFRP.

\subsection{Field Testing After Rehabilitation}

\subsubsection{Introduction}

Dynamic testing was performed on Bridge 568 prior to rehabilitation to provide a baseline for comparison with the dynamic tests performed after application of the GFRP composite materials. Post rehabilitation field testing was conducted on the fourth span from the west of Bridge 568 to evaluate the effects of GFRP composite material on an inservice railroad bridge.

\subsubsection{Description of Bridge 568}

Bridge 568 is located in Moorefield, WV along the South Branch Valley Railroad. It was constructed in 1954, after severe damage to the superstructure of the bridge due to flooding as mentioned in Section 3 of this chapter. There are seven spans within Bridge 568, containing eight pile bents. Each span measures 12 feet center-to-center of supports and contained two main chords, each consisting of three sawn timber stringers placed in a staggered fashion. Chords are supported by pile bents approximately 12 feet apart. Each pile bent consisted of one pile cap and four piles. Figure 4.20 shows a layout view of Bridge 568 and indicated which pile bent was selected for rehabilitation. 


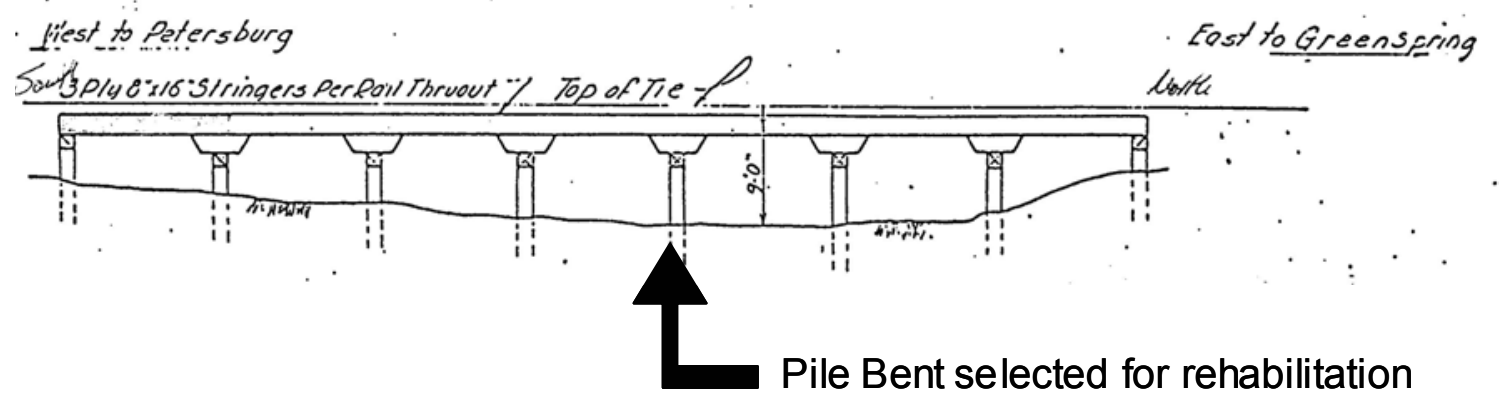

Figure 4.20. Elevation view of Bridge 568

\subsubsection{Description of Strengthening}

The fifth pile bent from the west end of Bridge 568 was strengthened using GFRP composite fabric coated with a phenolic formaldehyde adhesive. The rehabilitation focused on the joint connecting the pile cap and pile. Several of the piles had undergone serious decay at these joints and previous attempts at rehabilitation had proved ineffective. Under normal weather conditions this joint had experienced little or no stress due to debris. However, during periods of unusually heavy rain, this joint becomes critical in the function of the pile bent. Deterioration can weaken the joint and cause a pile separation from the pile cap. The strengthening performed provides a strong bond between the pile cap and pile.

\subsection{Field Load Testing}

The Fourth Span from the west end of Bridge 568 was again selected to be instrumented with uniaxial strain gages and LVDT's. This particular span had been tested previously to establish a baseline for comparative purposes with post rehabilitation dynamic test results. Because the strengthening involved pile bents, joint and piles, strain gages were placed on the surface of the GFRP composite material on each of the four piles. Strain gages were also mounted at midspan on the tension side on all the stringers for both chords. Two LVDTs were used to monitor the static and dynamic deflection of both chords of the Fourth Span. One LVDT was placed on the center stringer of each 
chord. All data was collected using a data acquisition system. See Figure 4.21(a \& b) for instrumentation lay-out diagram.

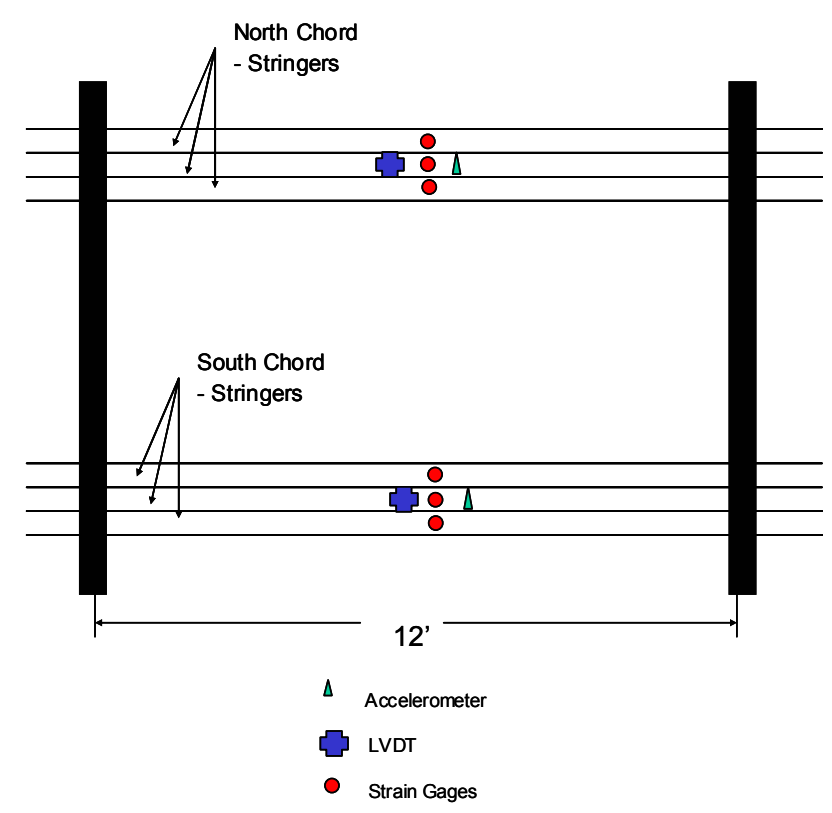

(a) Instrumentation lay-out post-rehabilitation

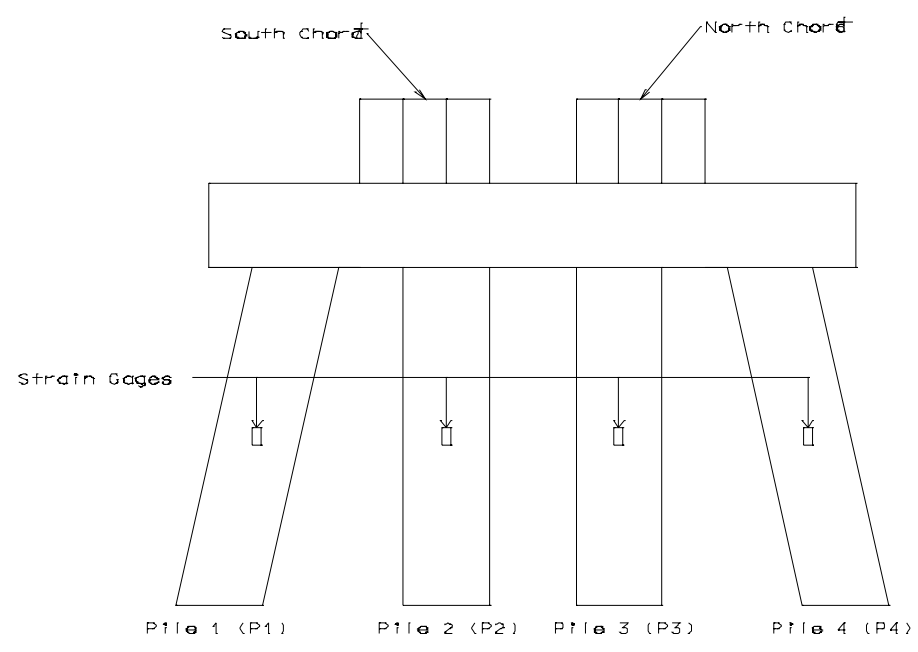

(b)Pile bent instrumentation layout

Figure 4.21. (a) Fourth Span \& (b) Pile bent instrumentation layout for postrehabilitation test 


\subsubsection{Test Procedure \& Loading}

The Fourth Span from the west end of Bridge 568 was load tested using a General Electric 80-ton locomotive provided by SBVR (Figure 4.3). Similar to the first field test, tests were performed using the locomotive at four different speeds: $3 \mathrm{mph}, 5 \mathrm{mph}, 10$ $\mathrm{mph}$, and $15 \mathrm{mph}$. These speeds were selected so that the dynamic response of the bridge could be evaluated under the same load conditions. Static loading was achieved by positioning the test locomotive at specific positions with reference to the bridge being tested (see Figure 4.22). Specifically, one truck (i.e. train axle) of the locomotive was positioned on the center line of the span being tested.

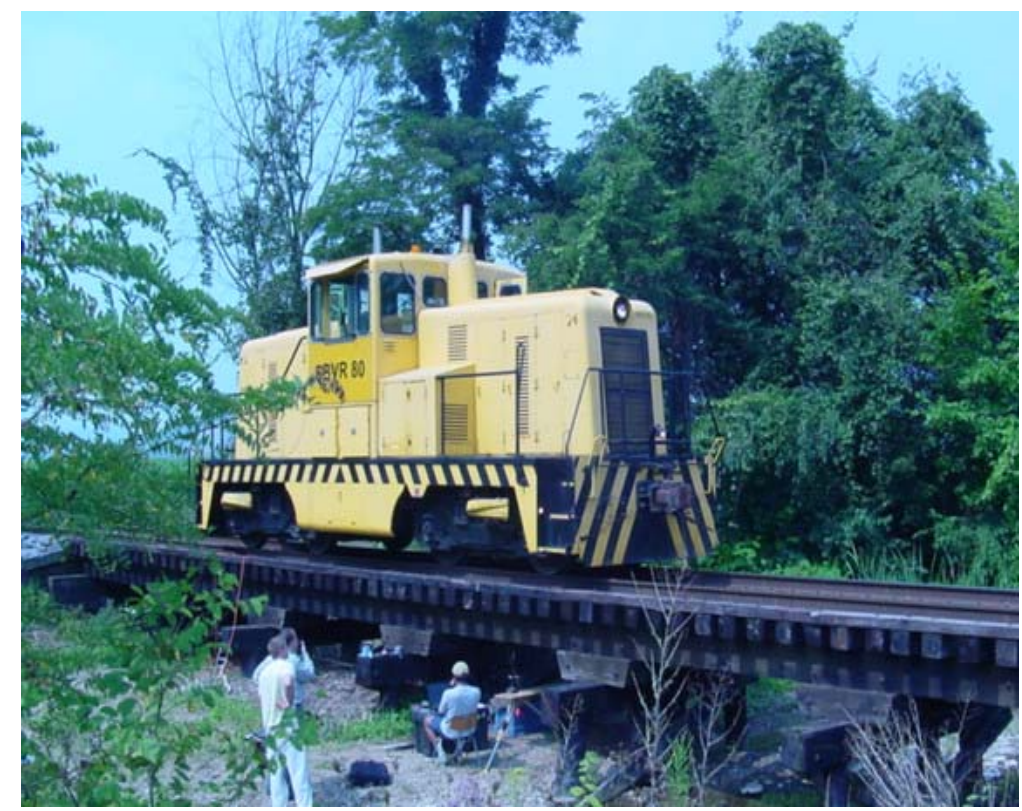

Figure 4.22. Static Testing of Bridge 568 post rehabilitation

\subsubsection{Condition Assessment}

Prior to load testing, the strengthened structure was subjected to a condition assessment at various times throughout the year. This consisted of bridge configuration measurements, visual inspection of rehabilitated members, and photographic documentation of the condition of applied GFRP composite rehabilitation. It was found that the GFRP composite material was in good condition without any debonding or peeling of GFRP. There was no moisture entrapment behind the GFRP. However, some 
discoloration of the GFRP was noticed on a pile bent that was rehabilitated during Summer 2000 (see Figure 4.23). An adequate ultra violet protective additive can be added to the resin or coating to prevent further deterioration,

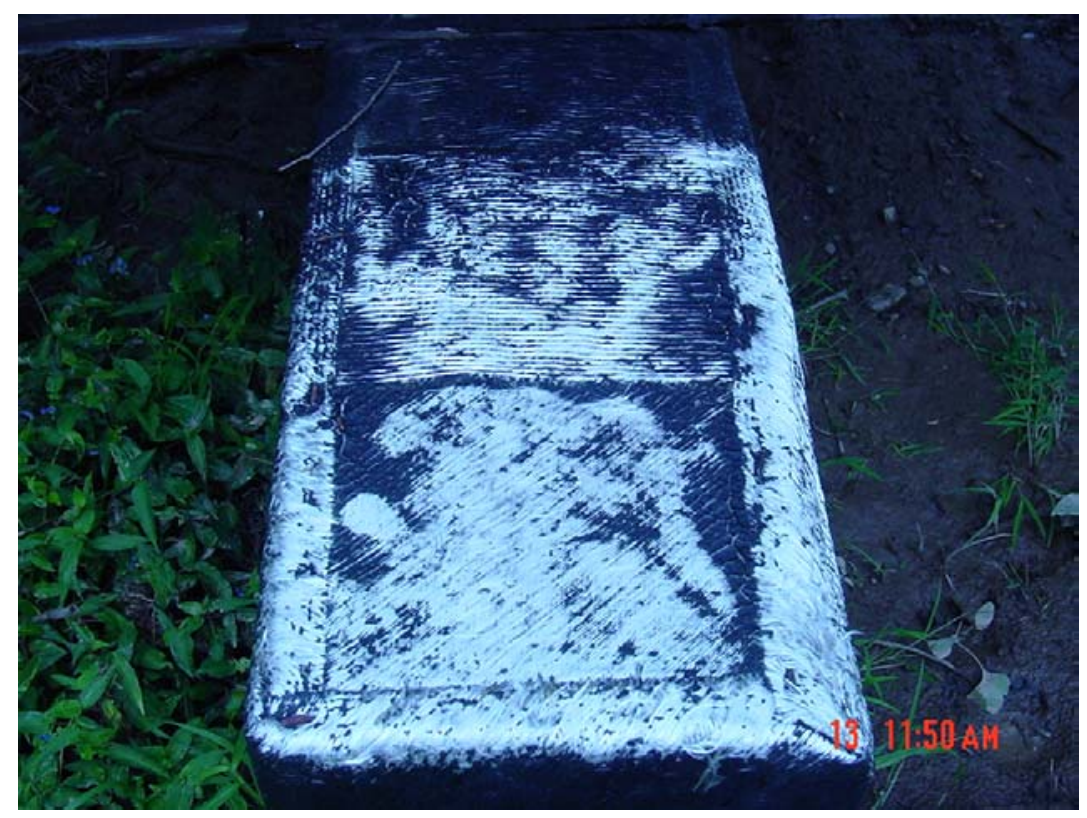

Figure 4.23. Discoloration of pile bent rehabilitated in Summer 2000. 


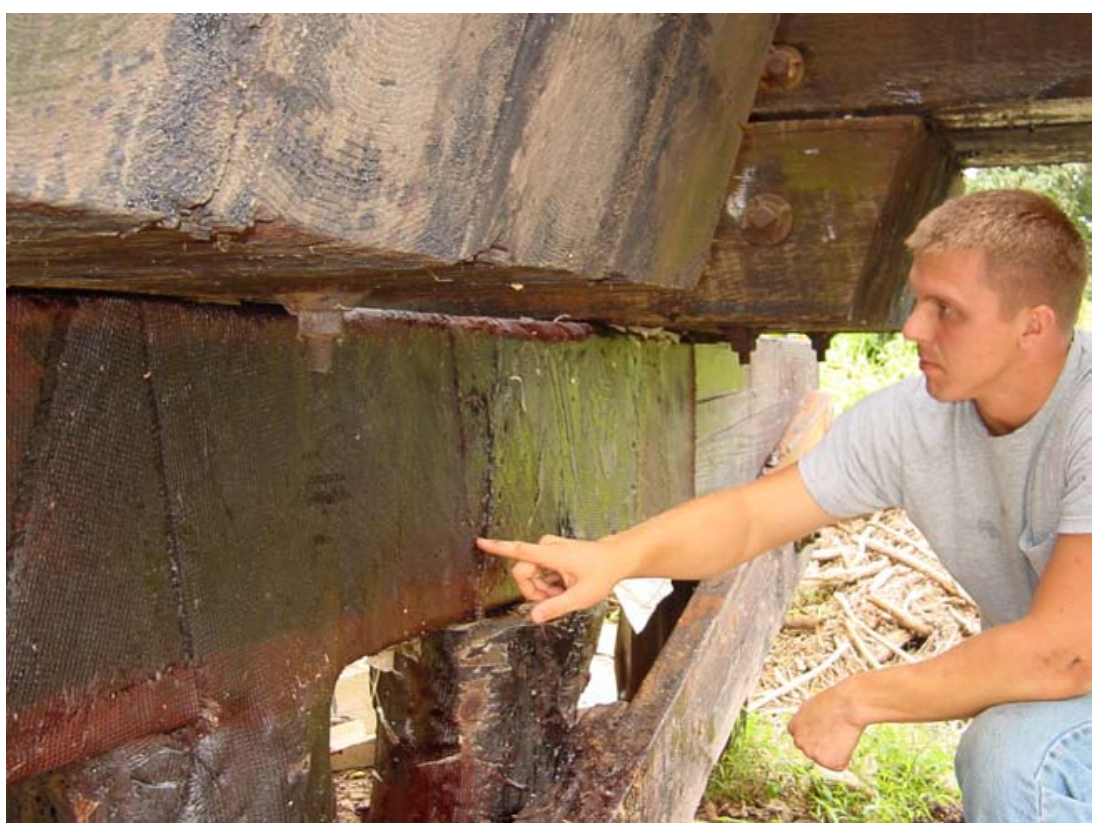

Figure 4.24. Visual Inspection of GFRP composite material post curing

Bridge 568 had been subject to periodic flooding due to heavy rains (as much as six (6) inches in six (6) hours) throughout the period between application of rehabilitation and post rehabilitation testing. No significant damage had occurred to the pile bent on which rehabilitation had been completed (See Figure 4.24). 


\section{Chapter 5 - Results \& Discussion of Field Testing}

\subsection{Introduction}

Presented in this chapter are the results of the initial field-testing and the post rehabilitation field-testing described in Chapter 4. The initial field-testing was performed prior to the joint and pile rehabilitation using GFRP composite fabric, while the post rehabilitation testing was performed after the addition of the GFRP fabric. An analysis and discussion of these results, including dynamic amplification factors and load distribution are also presented.

\subsection{Initial Field Testing}

The initial field testing was performed in Summer of 2002 on an open deck timber trestle railroad bridge for the purpose of establishing baseline data. These data were used for comparative purposes with the data collected during the post rehabilitation testing. Deflection, strain, and acceleration versus time data under static and dynamic loads for varying speeds were collected and reduced using the data acquisition system. Data plots of all pertinent information were developed for the evaluation of the static and dynamic response. Areas of specific interest included: (a) chord deflection at mid-span, (b) load distribution between stringers and chords (c) pile cap and pile stresses. The acceleration data collected during the initial field-testing were found to be corrupted by noise and was not used any further. Acceleration data were not collected during the post rehabilitation testing.

\subsubsection{Dynamic Amplification Factors (DAFs)}

The dynamic load behavior was evaluated for several speeds. Also, to obtain a comparison to the dynamic load effects, a static test was performed. The maximum deflection obtained under static loading $\left(\delta_{\text {stat }}\right)$ and the maximum dynamic deflection for a particular speed $\left(\delta_{\mathrm{dyn}}\right)$ were used to determine dynamic amplification factors (DAFs) for both chords. Typically, DAFs are calculated using the following equation: 


$$
D A F=\frac{\text { Maximum Dynamic Deflection }}{\text { Maximum Static Deflection }}
$$

The cross section at midspan of Bridge 568 is shown in Figure 5.1.

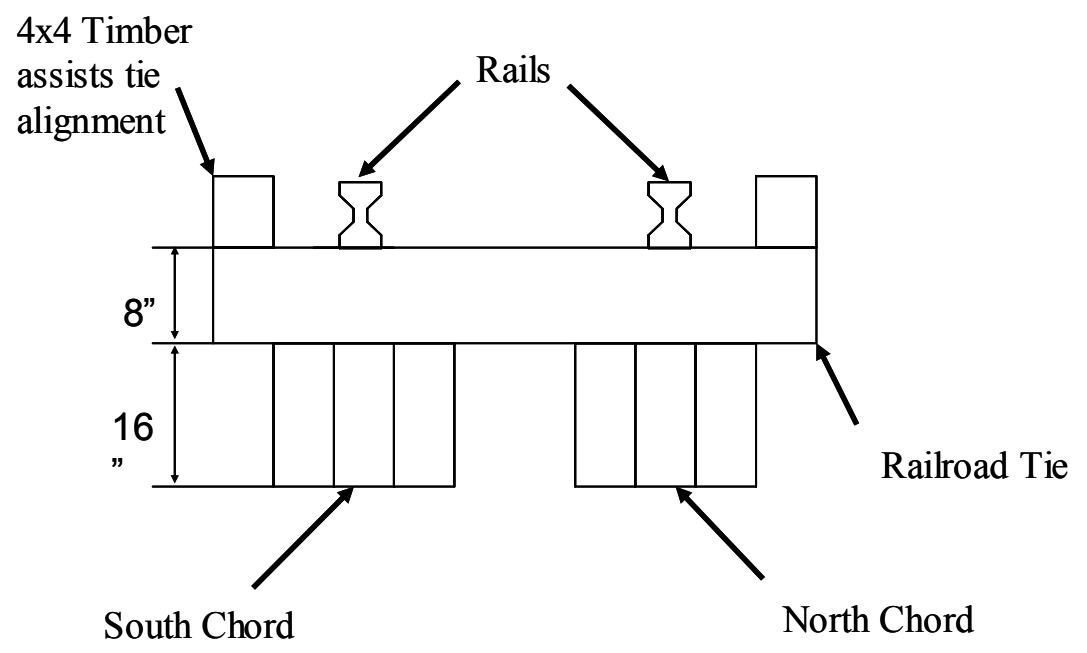

Figure 5.1. Midspan cross-section of Bridge 568

Both north and south chords were evaluated to find the maximum static deflection and the maximum dynamic deflection. Figure 5.2 shows the DAFs calculated for all three speeds on the north and south chords for Bridge 568. 


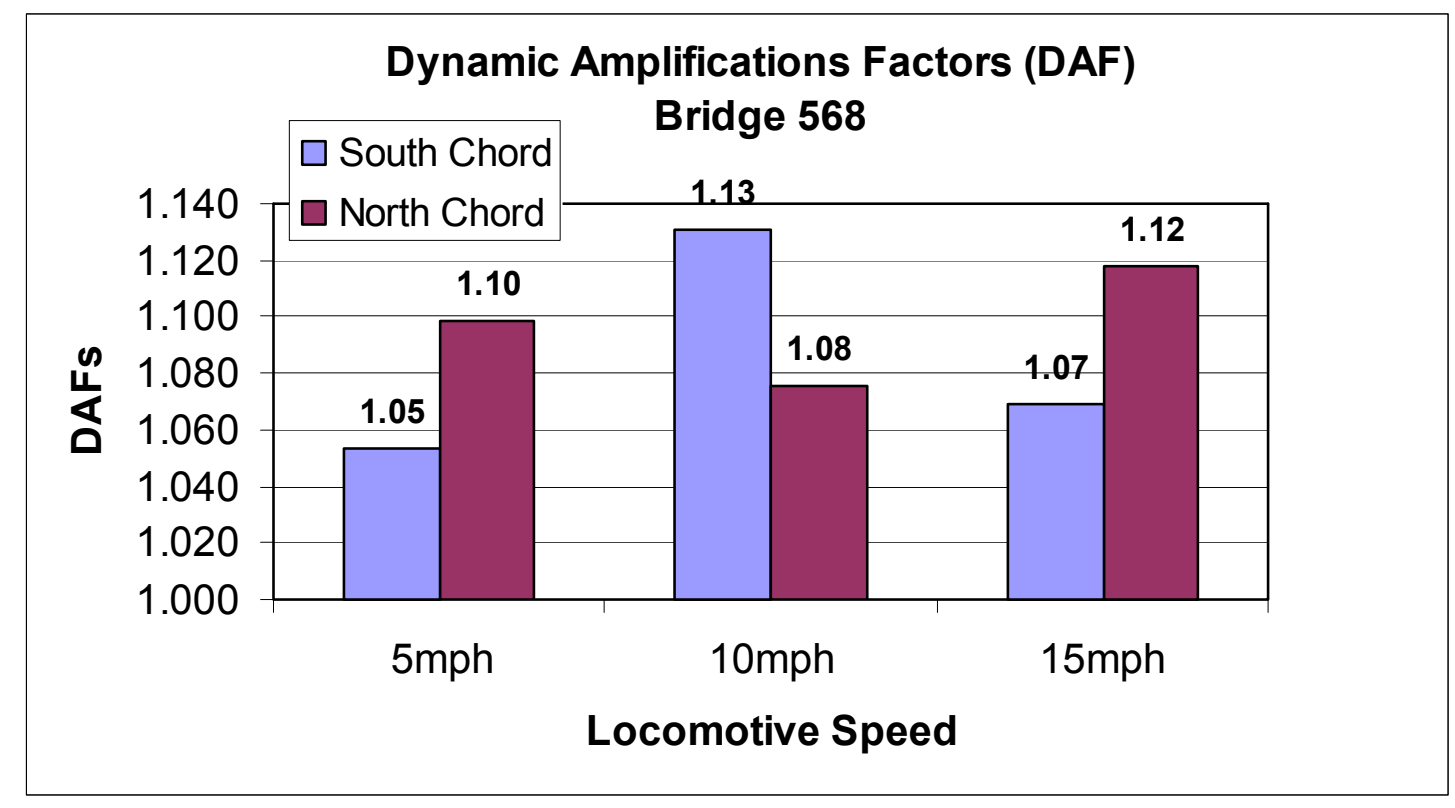

Figure 5.2. Dynamic Amplification Factor at various speeds for Bridge 568

From observation of the limited DAF data, it can be seen that a higher dynamic affect is measured with increasing speed (although the DAF dropped for the $10 \mathrm{mph}$ test on the north chord while increasing for the south chord). This drop at $10 \mathrm{mph}$ suggests that the data may be erroneous. This suggests that a dynamic amplification factor should be accounted for and used in design and analysis. Although, the highest DAF recorded for Bridge 568 (for the span tested) was 1.13 for the South Chord, it appears that the North Chord has higher DAF values for both the $5 \mathrm{mph}$ and the $15 \mathrm{mph}$ suggesting a that the North Chord is attracting more load than the South Chord.

An analysis was also performed based on the strains due to the dynamic load. The dynamic amplification factors based on strain were calculated using an equation similar to that previously discussed:

$$
D A F=\frac{\text { Maximum Dynamic Strain }}{\text { Maximum Static Strain }}
$$


North and south chords were evaluated to obtain maximum static strain and the maximum dynamic deflection. Figure 5.3 shows the DAFs calculated using strain for all three speeds on the north and south chords for Bridge 568.

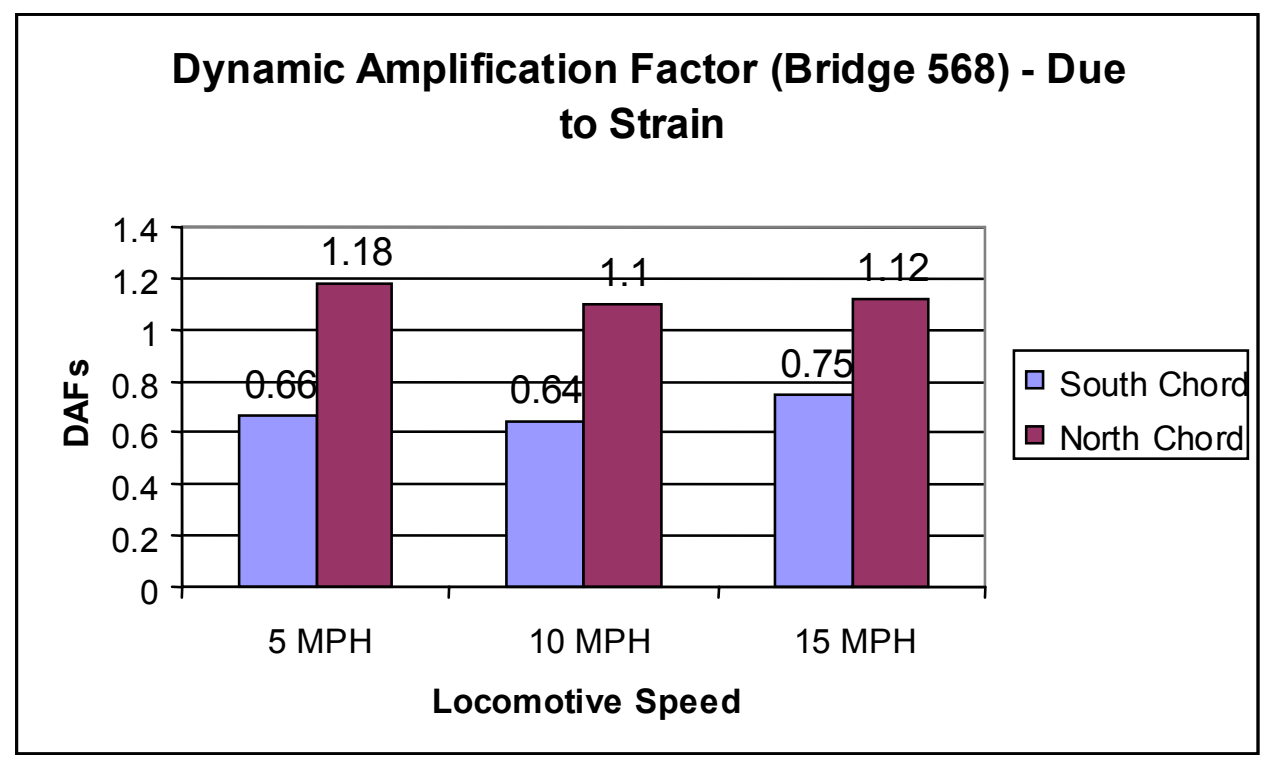

Figure 5.3. Dynamic Amplification Factor based on Strain for Bridge 568

In the north chord, the DAF's from strain and deflection are very similar. There is a decrease in the magnitude of the DAF in the $10 \mathrm{mph}$ trial for both DAFs due to deflection and strain. From Figure 5.3, the south chord did not experience greater strains during the dynamic testing than the static testing. However, Figure 5.2 shows that the south chord experienced greater deflections during the dynamic testing than in the static testing. The largest difference in deflection between static and dynamic tests was recorded in the south chord during the $10 \mathrm{mph}$ test.

The recorded deflections in the north chord were higher during the dynamic testing than in the static testing. Comparatively, the magnitude of the DAFs from deflection and strain were very close. Both exhibited a drop in the DAF during the 10 mph trail. This drop in the DAF may be attributed to the variability of the speed of the locomotive. The speed of the locomotive was not regulated electronically, but only with a speedometer.

The existence of high (>1) dynamic amplification factors (with the exception of the DAFs due to strain in the south chord) suggests that a dynamic load factor should be 
considered in timber bridge design and analysis. Existing codes do not account for a dynamic amplification factor for timber bridges because of woods ability to absorb shock and carry a greater load for short durations. Although, more recently, the AASHTO LRFD code has a dynamic allowance factor that includes bridges.

\subsubsection{Chord Strains}

A comparative analysis of the north and south chord mid-span strains was also performed for each bridge under each individual load condition for varying speeds, i.e., 5 $\mathrm{mph}, 10 \mathrm{mph}$, and $15 \mathrm{mph}$. Figure 5.4 shows various plots generated to illustrate the associated strain distribution for span 4 of Bridge 568 .
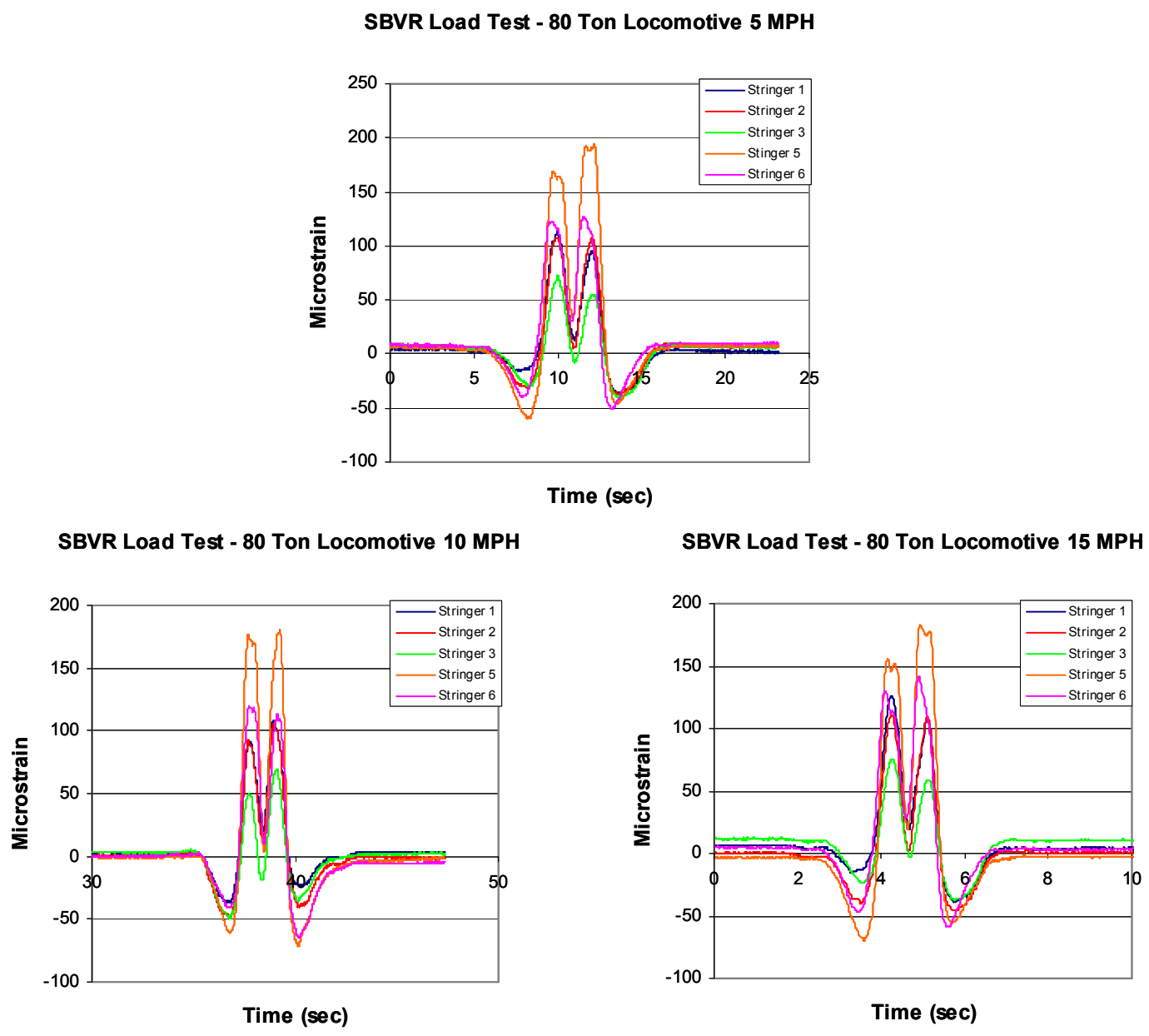

Figure 5.4. Bridge 568 Span 4 Strain Distribution 
Stringers 1,2, and 3 represent the south chord, while stringers 5 and 6 represent the north chord. Figure 5.4 shows that the north chord (stringer 5) mid span strain is considerably higher than the south chord stringer strains for all velocities. The maximum mid span strain for the north chord (stringer 5) was approximately 194 microstrains under the 5 mph speed test. While the maximum mid span strain for the south chord (stringer 1)is 126 microstrains under the $15 \mathrm{mph}$ speed test.

\subsubsection{Pile Strains}

Pile strains were also measured under various load tests. Figure 5.5 shows the location of strain gages placed on the pile bent of span 4 of Bridge 568 .

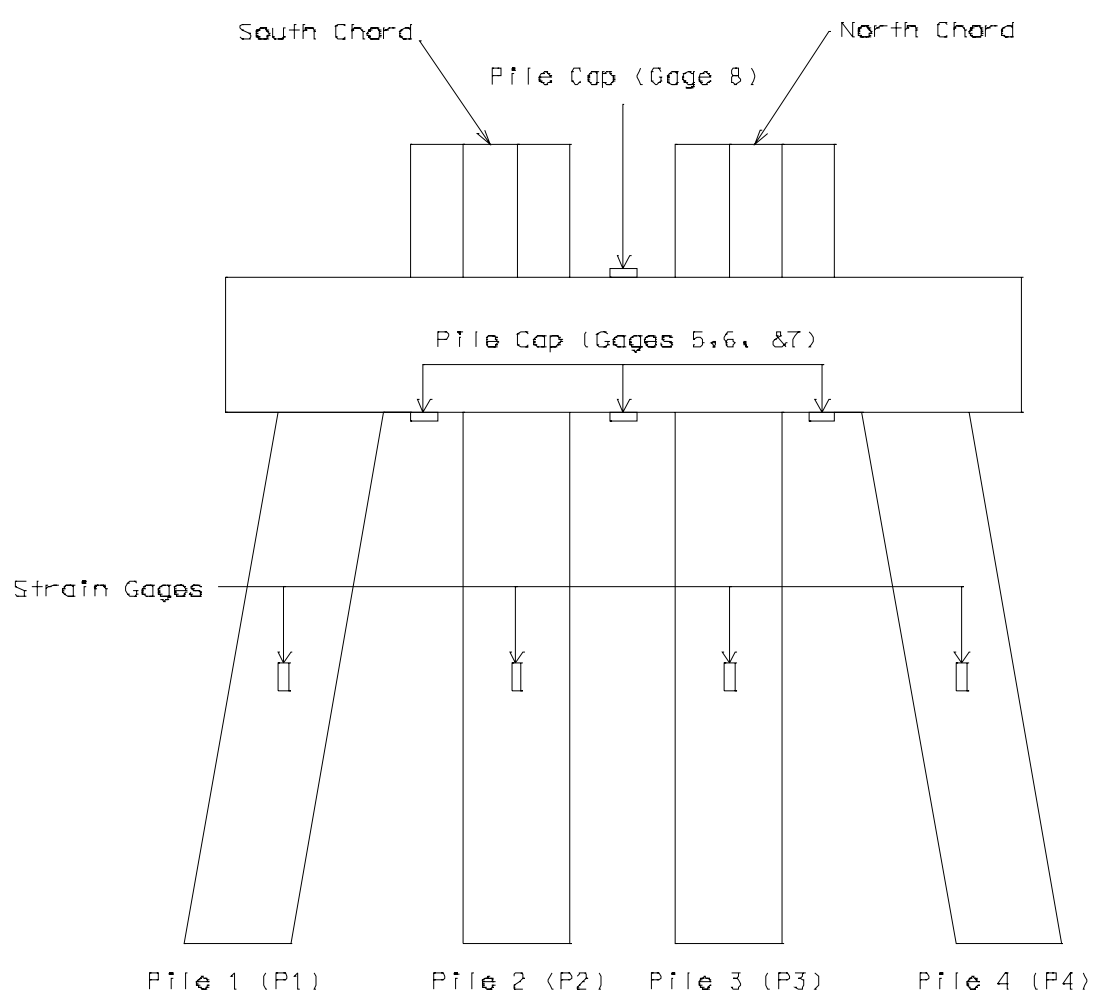

Figure 5.5. Location of Strain Gages 
A comparative analysis of pile strains was performed for each bridge under each individual load condition and for all speeds. Figure 5.6 shows various plots generated to illustrate strain distribution for the static load test and the dynamic load tests at velocities of approximately $5 \mathrm{mph}, 10 \mathrm{mph}$, and $15 \mathrm{mph}$.
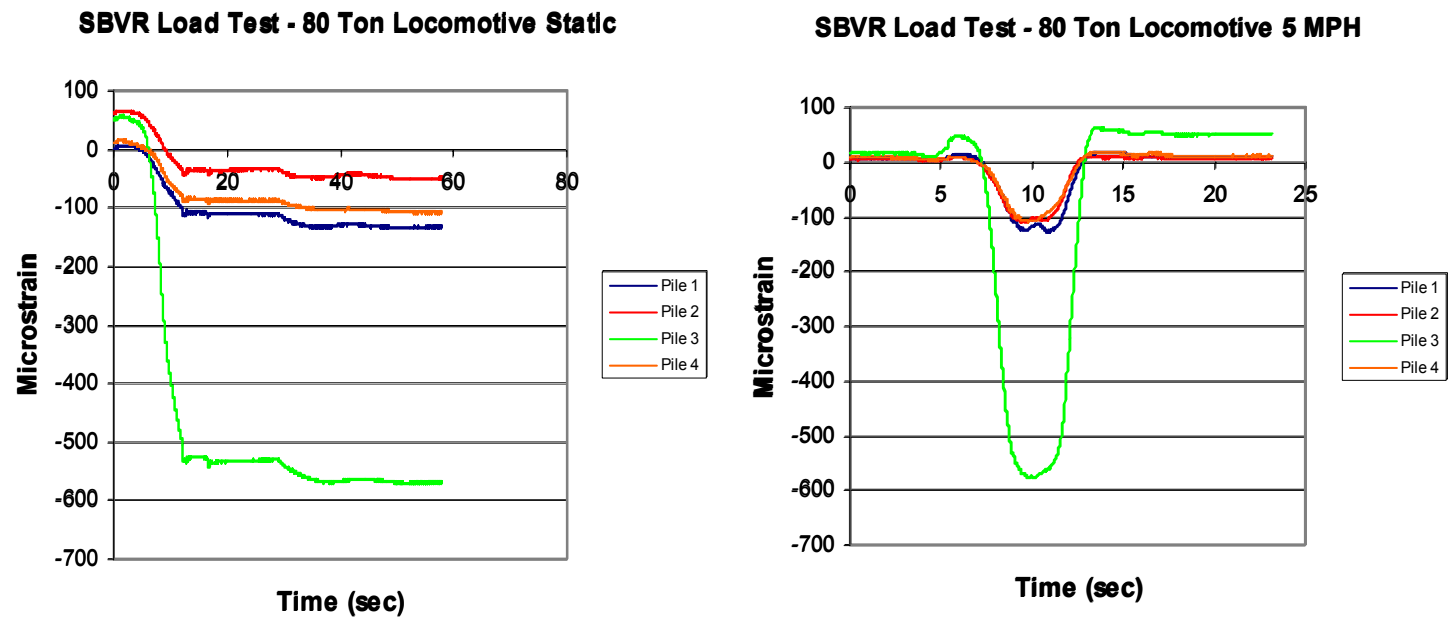

SBVR Load Test -80 Ton Locomotive $10 \mathrm{MPH}$

SBVR Load Test - 80 Ton Locomotive 15 MPh
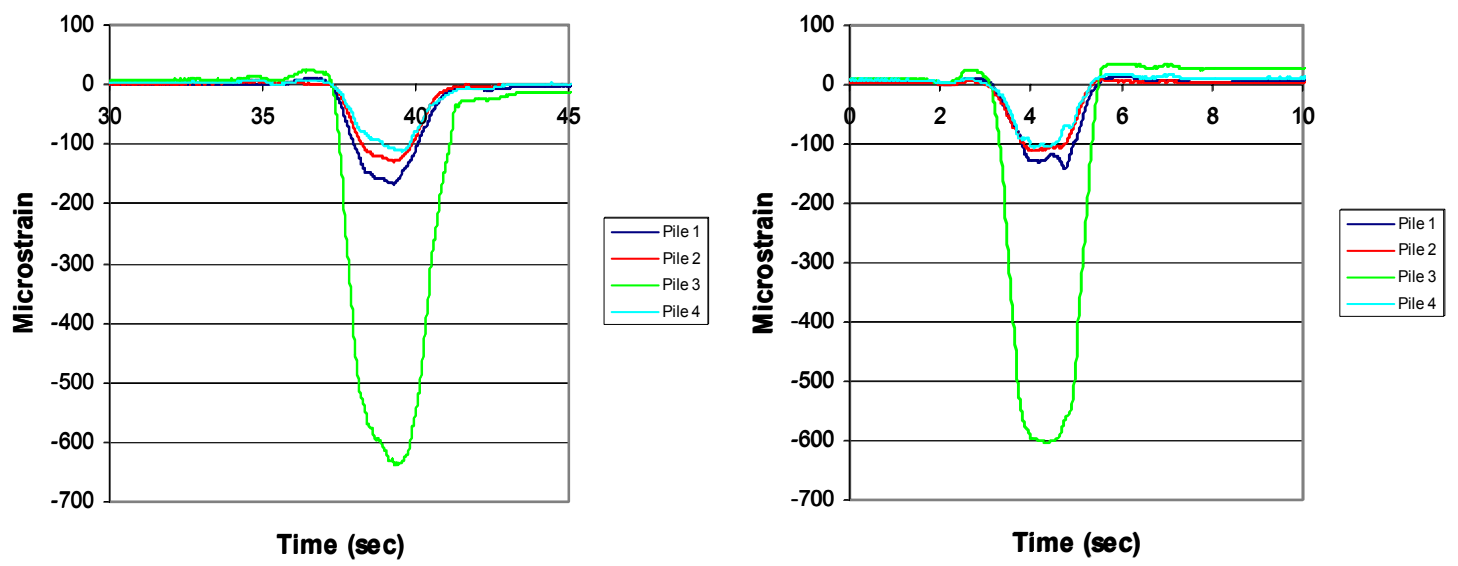

Figure 5.6 Bridge 568 span 4 pile strain distribution for varying speeds

Figure 5.6 shows that the strain is considerably higher in the $3^{\text {rd }}$ pile (P3) in the instrumented pile cap. The maximum axial strain recorded in P3 was 637 microstrains for the $10 \mathrm{mph}$ test. Figure 5.4 shows the location of Pile 3 directly under the North Chord. Since the span was 12 feet in length, one truck (i.e. train axle) was placed at midspan, providing a 40 ton point load on the span. Assuming equal distribution between the four piles on each bent, each pile will carry a 10 tons (or $20 \mathrm{kip}$ ) load. Using the 
following equations, the theoretical microstrain, which would be carried by each pile, was calculated:

$$
\begin{array}{r}
\sigma=\frac{P}{A} \\
\mathrm{E} \varepsilon=\frac{P}{A}
\end{array}
$$

Rearranging equation 5.2 to solve for strain,

$$
\begin{gathered}
\varepsilon_{\text {theory }}=\frac{P}{E A} \\
\varepsilon_{\text {theory }}=\frac{20000}{1 \times 10^{6} * 113}=177 \times 10^{-6} \text { strain }
\end{gathered}
$$

Where:

$\mathrm{E}=$ typical timber Modulus of Elasticity, psi

$\mathrm{A}=$ cross sectional area of pile, in $^{2}$

$\mathrm{P}=$ load, $\mathrm{lb}$

Therefore, if equal distribution between the piles were present, each pile would take on 177 microstrain. This compares will with Piles 1, 2, and 4 as shown in Figure 5.6

\subsubsection{Pile Cap Strains}

Another comparative analysis was that of the pile cap strain distribution for various speeds for Bridge 568 for static and dynamic load cases. Figure 5.7 shows various plots generated to illustrate strain distribution in pile cap under test for the static and dynamic load cases. 
SBVR Load Test - 80 Ton Locomotive Static

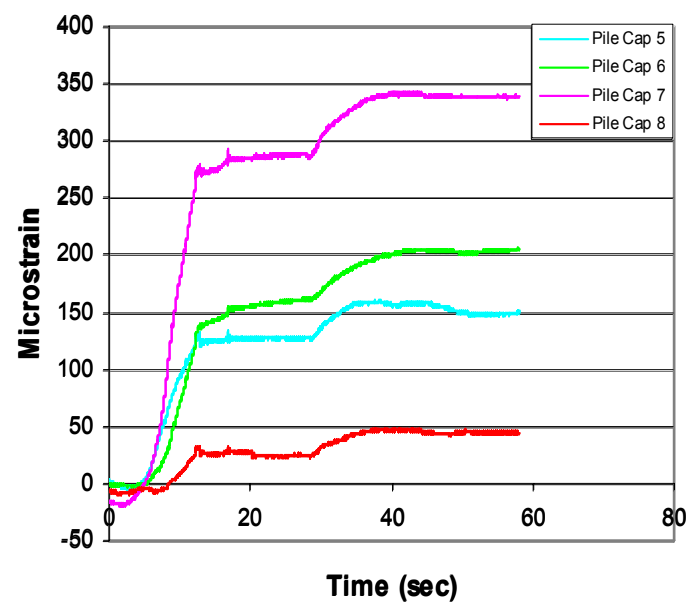

SBVR Load Test - 80 Ton Locomotive 10 MPH

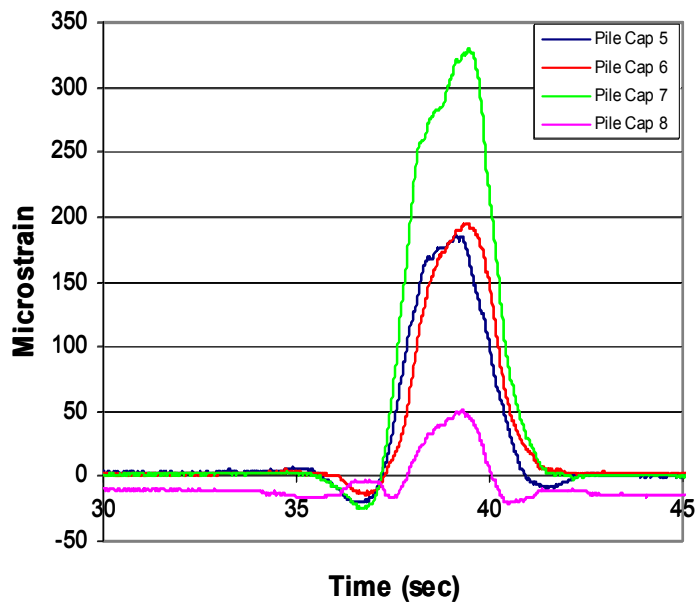

SBVR Load Test - 80 Ton Locomotive 5 MPH

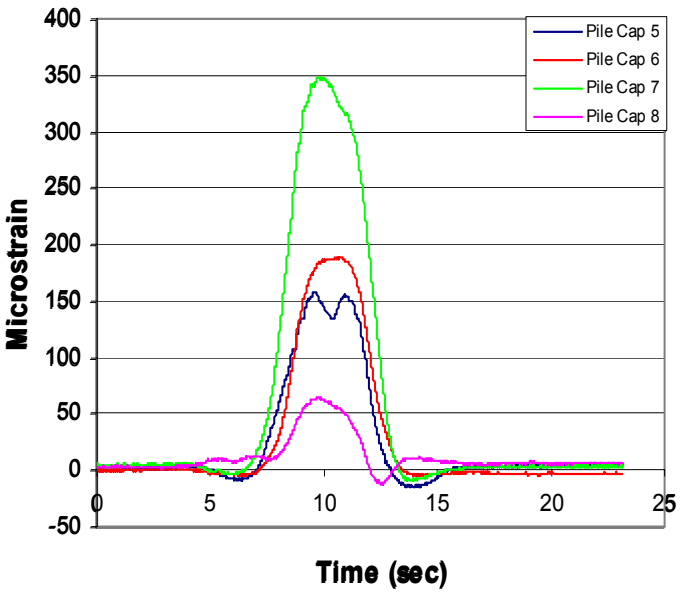

SBVR Load Test - 80 Ton Locomotive 15 MPH

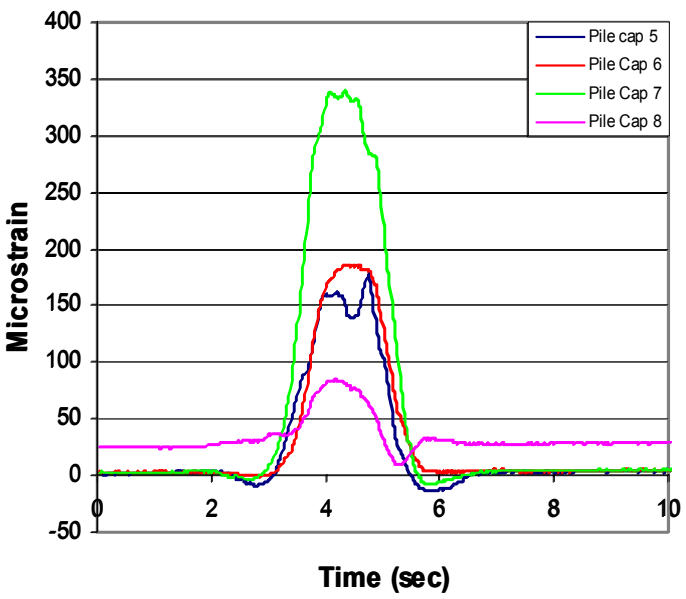

Figure 5.7. Bridge 568 span 4 pile cap strains

Figure 5.7 shows the distribution of tensile strains. The gages placed on bottom face of pile cap at pile cap locations 5, 6, \& 7 (Figure 5.4). The maximum strain recorded in the pile cap was 348 microstrains (pile cap location \# 7, under the north chord) during the 5 mph test.

\subsubsection{Chord Deflection}

Using the deflection data from both LVDTs, a general load distribution was assessed between the two chords. This was made based on the assumption that the individual instrumented stringer deflection represents the actual deflection of the entire 
chord (i.e., each chord consists of three stringers bolted together) including the tie and nail. Figure 5.8 shows a comparison of span 4 north and south chord midspan deflections for static, $5 \mathrm{mph}, 10 \mathrm{mph}$, and $15 \mathrm{mph}$ test locomotive vehicles. Figure 5.8 also shows that the north chord deflects more than the south chord for every load case.

The maximum deflection for the north chord is 0.2203 inches at $15 \mathrm{mph}$, while the maximum static deflection for the south chord is 0.2 inches. In general, the north chord deflected more than the south chord for static and various speeds.
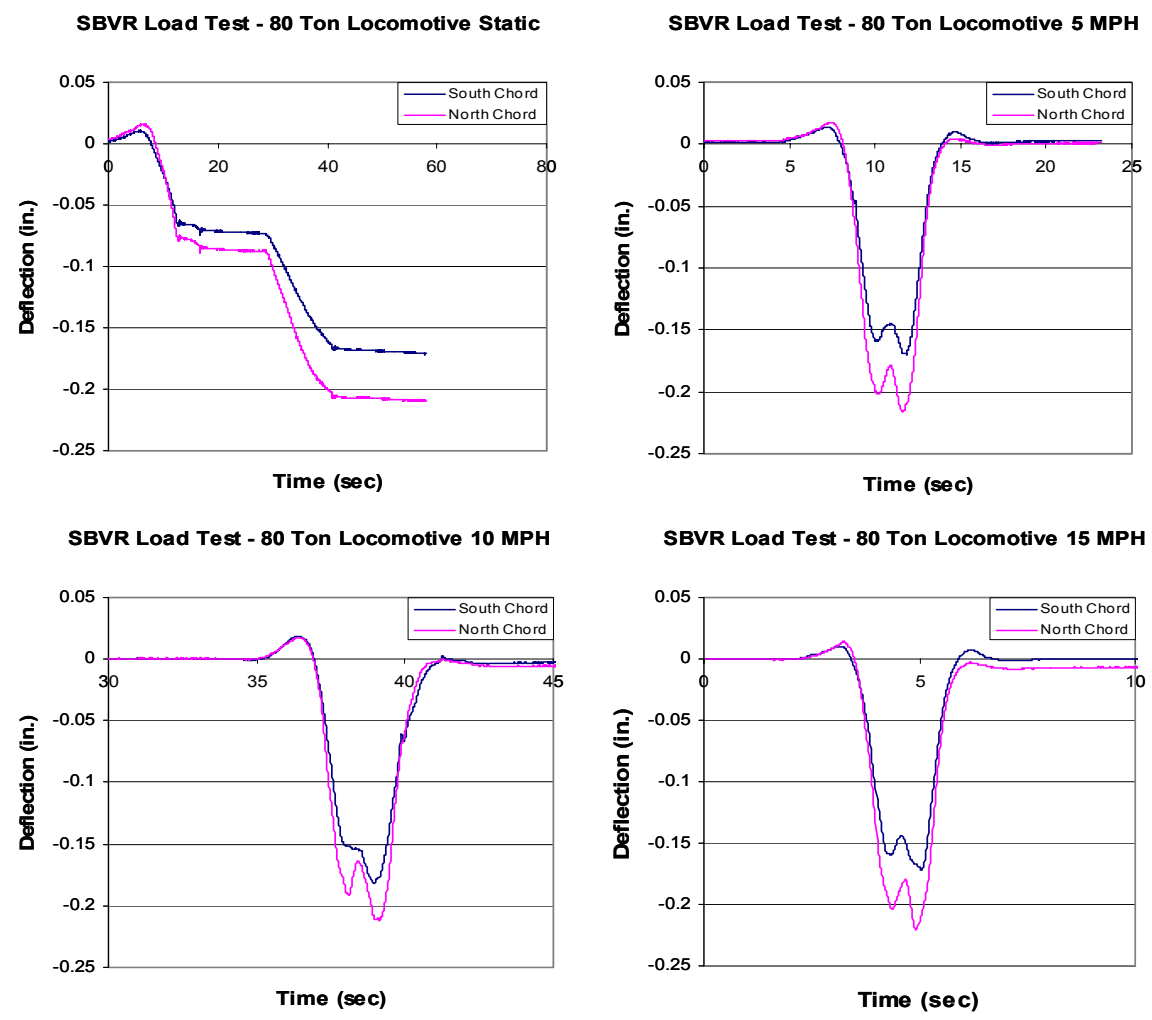

Figure 5.8 Bridge 568 North and South Chord midspan deflections

Based on the deflection data, the load distribution between the north and south chords is $56 \%$ and $44 \%$, respectively. 


\subsection{Post Rehabilitation Testing}

Post rehabilitation testing was performed on the same open deck timber trestle railroad bridge in the summer of 2003. Deflection and strain time data under static and dynamic loads for varying speeds were collected and reduced using the data acquisition system. The data collected during the testing was used for comparative analysis with the data collected in the initial field testing. This analysis was used to determine the effects of the GFRP composite wrap applied during rehabilitation. Data plots of all pertinent information were developed for the evaluation of the static and dynamic response. Areas of specific interest included: (a) chord deflection at mid-span, (b) load distribution between stringers and chords and (c) pile stresses. Pile cap stress are not presented as in the initial testing due to malfunctioning of the uniaxial strain gages.

\subsubsection{Dynamic Amplification Factor (DAFs)}

The dynamic load behavior was evaluated for speeds of $5 \mathrm{mph}, 10 \mathrm{mph}$ and 15 $\mathrm{mph}$. Also, to obtain a comparison to the dynamic load effects, a static test was performed. The maximum deflection obtained under static loading $\left(\delta_{\text {stat }}\right)$ and the maximum dynamic deflection for a particular speed $\left(\delta_{\mathrm{dyn}}\right)$ were used to determine dynamic amplification factors (DAFs) for each chord. Similarly, DAFs are calculated using the following equation:

$$
D A F=\frac{\text { Maximum Dynamic Deflection }}{\text { Maximum Static Deflection }}
$$

Both north and south chords were evaluated to find the maximum static deflection and the maximum dynamic deflection. Figure 5.9 shows the DAFs calculated for three speeds on the north and south chords for Bridge 568 . 


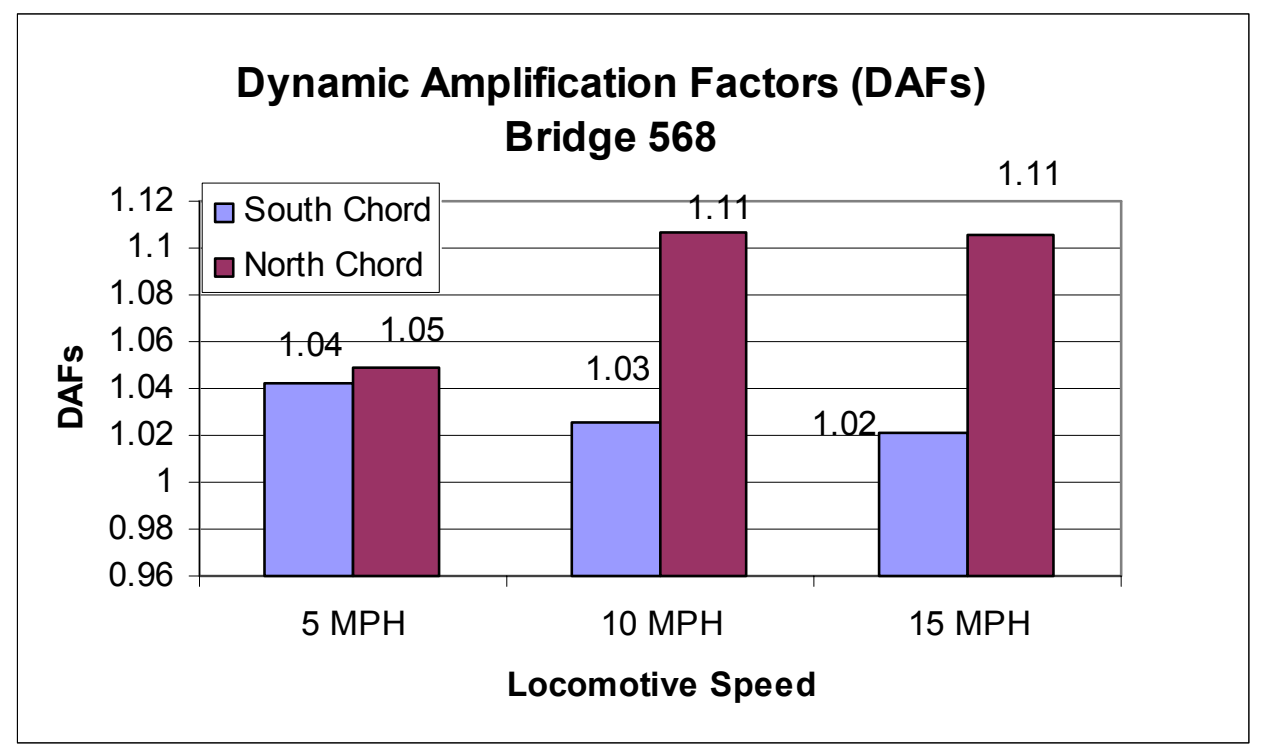

Figure 5.9. Dynamic Amplification Factors (at various speeds) due to deflection

From observation of the limited DAF data, it can be seen that a higher dynamic affect is measured with increasing speed in the North Chord. This suggests that a dynamic amplification factor should be accounted for and used in design and analysis. The highest DAF recorded for bridge 568 (for the span tested) was 1.11 for the North Chord.

There was no strengthening performed on stringers or chords prior to the post rehabilitation testing. Variations in strain distribution from the initial field-testing to the post-rehabilitation testing may be attributed to pile bent foundation settlement and overall degradation due to excessive flooding. The DAF data in the post rehabilitation testing differed slightly when compared with the DAF data in the initial field-testing. South chord DAFs in the post rehabilitation testing exhibited a decreasing tendency for DAF from $5 \mathrm{mph}-10 \mathrm{mph}$. A DAF of 1.05 was calculated for the $5 \mathrm{mph}$ trial in both the initial testing and a DAF of 1.04 was calculated for the post rehabilitation test. This indicates that the "chord action" of the south chord slightly decreased at a speed of $5 \mathrm{mph}$ between initial and post rehabilitation testing. The DAF of the south chord using deflection data in the initial testing was calculated to be 1.13 for the $10 \mathrm{mph}$ trial. For the same speed in the post rehabilitation testing, a DAF of 1.03 was calculated. This indicates a decrease in the "chord action" during the post rehabilitation testing. The DAF 
from deflection in the post rehabilitation test from the $15 \mathrm{mph}$ trial was calculated at 1.02 , this is lower than the 1.12 DAF calculated from the $15 \mathrm{mph}$ trial of the initial fieldtesting. This indicates decreased "chord action" in the south chord during the post rehabilitation testing.

The dynamic effect experienced by the north chord during the post rehabilitation testing was similar to the recorded effect during the initial field-testing. The $5 \mathrm{mph}$ DAF in the post rehabilitation testing was calculated as 1.05 , while the DAF at the same speed in the initial field test was 1.11. A DAF of 1.08 was calculated for the $10 \mathrm{mph}$ trial in the initial field-testing. While a DAF of 1.11 was calculated for the post rehabilitation test. As for the $15 \mathrm{mph}$ trial of the initial field testing a DAF of 1.12 was calculated for the north chord. For this same speed in the post rehabilitation testing a DAF of 1.11 was calculated from experimental field data.

An analysis was also performed based on the strains due to the dynamic load. The dynamic amplification factors based on strain were also calculated using an equation similar to that previously discussed:

$$
D A F=\frac{\text { Maximum Dynamic Strain }}{\text { Maximum Static Strain }}
$$

The north and south chords were evaluated to obtain maximum static strain and the maximum dynamic deflection. Figure 5.10 shows the DAFs calculated using strain for three speeds on the north and south chords for Bridge 568 . 


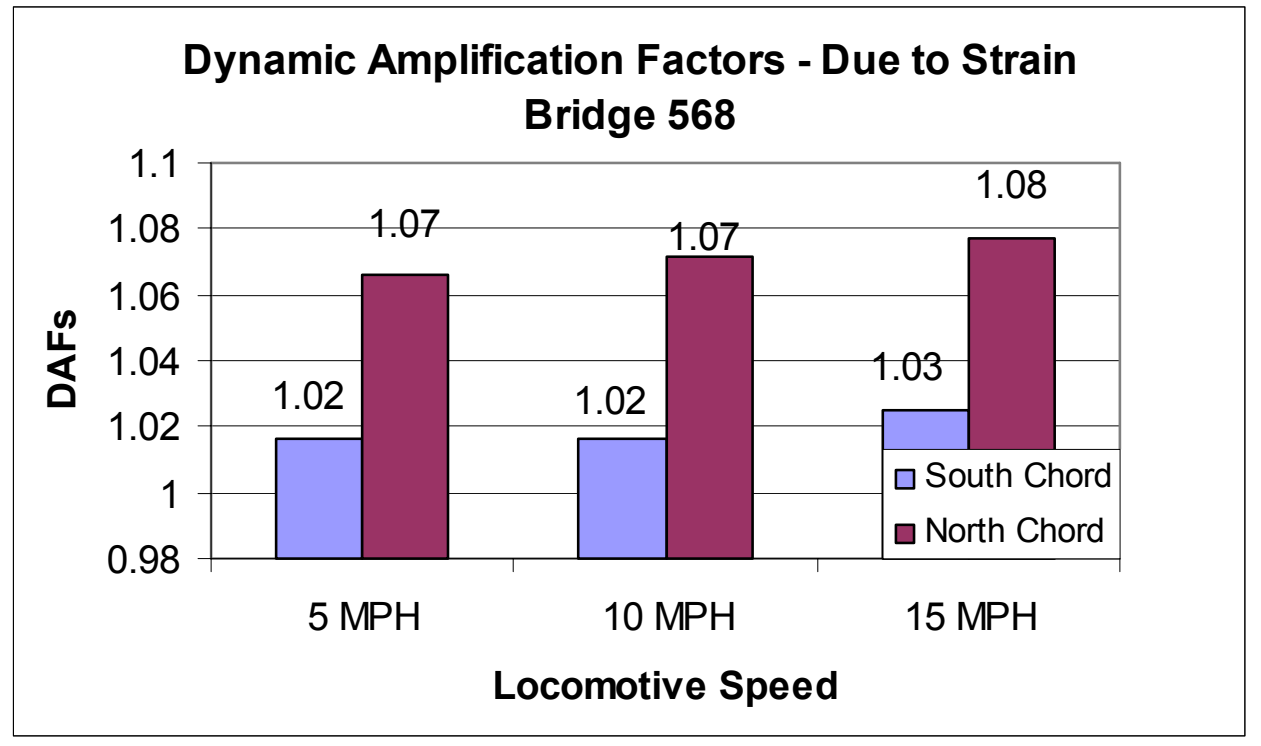

Figure 5.10. Dynamic Amplification Factors (at various speeds) due to strain

A comparison of the DAFs due to strain show several similarities and differences between the strain distribution during dynamic testing in the initial field and the post rehabilitation testing. The DAF due to strain calculated for the south chord from the 5 mph trial of the initial field-testing was 0.66 . For the same speed of the post rehabilitation testing, the south chord DAF due to strain was calculated as 1.02. The DAF due to strain of the $10 \mathrm{mph}$ trial during initial field-testing was 0.64 . A DAF of 1.02 was calculated for the south chord of the post rehabilitation testing at $10 \mathrm{mph}$. At 15 mph a DAF due to strain of 0.75 for the south chord, during initial field-testing was calculated, while a south chord DAF due to strain of 1.03 was calculated for the $15 \mathrm{mph}$ trial of the post rehabilitation testing. While the values of the DAFs between the initial and post rehabilitation vary, the trend is quite similar (i.e., the dAF for the $15 \mathrm{MPH}$ is the highest in both cases).

The calculated DAFs of the north chord are significantly higher for all test speeds of the initial field-testing and than those calculated during the post rehabilitation testing. The calculated DAF for the $5 \mathrm{mph}$ trial of the initial test is 1.18 , whereas, the DAF for the same speed in the post rehabilitation test is 1.07. The DAF for the north chord, $10 \mathrm{mph}$ test of the initial field test is 1.1 , as compared to 1.07 for the post rehabilitation value. The $15 \mathrm{mph}$ DAF for the north chord during the initial field testing is 1.12. For this same 
speed the DAF for the north chord during the post rehabilitation testing was 1.08. Although, the DAFs from strain vary, the trend is also similar for the north chord. The north chord DAFs are higher than the south chord DAFs.

\subsubsection{Chord Strains}

A comparative analysis of the north and south chord mid-span strains was also performed for each bridge under each individual load condition for varying speeds, i.e., 3 $\mathrm{mph}, 5 \mathrm{mph}, 10 \mathrm{mph}$, and $15 \mathrm{mph}$. Figure 5.11 shows various plots generated to illustrate the associated strain distribution for span 4 of Bridge 568 .

Stringers 1, 2, and 3 represent the south chord, while stringers 4, 5, and 6 represent the north chord. Figure 5.11 shows that the north chord (stringer 5) mid span strain is again higher than the south chord stringer strains for all velocities. The maximum mid span strain for the north chord (stringer 5) was approximately 196 microstrains under the $15 \mathrm{mph}$ speed test. 

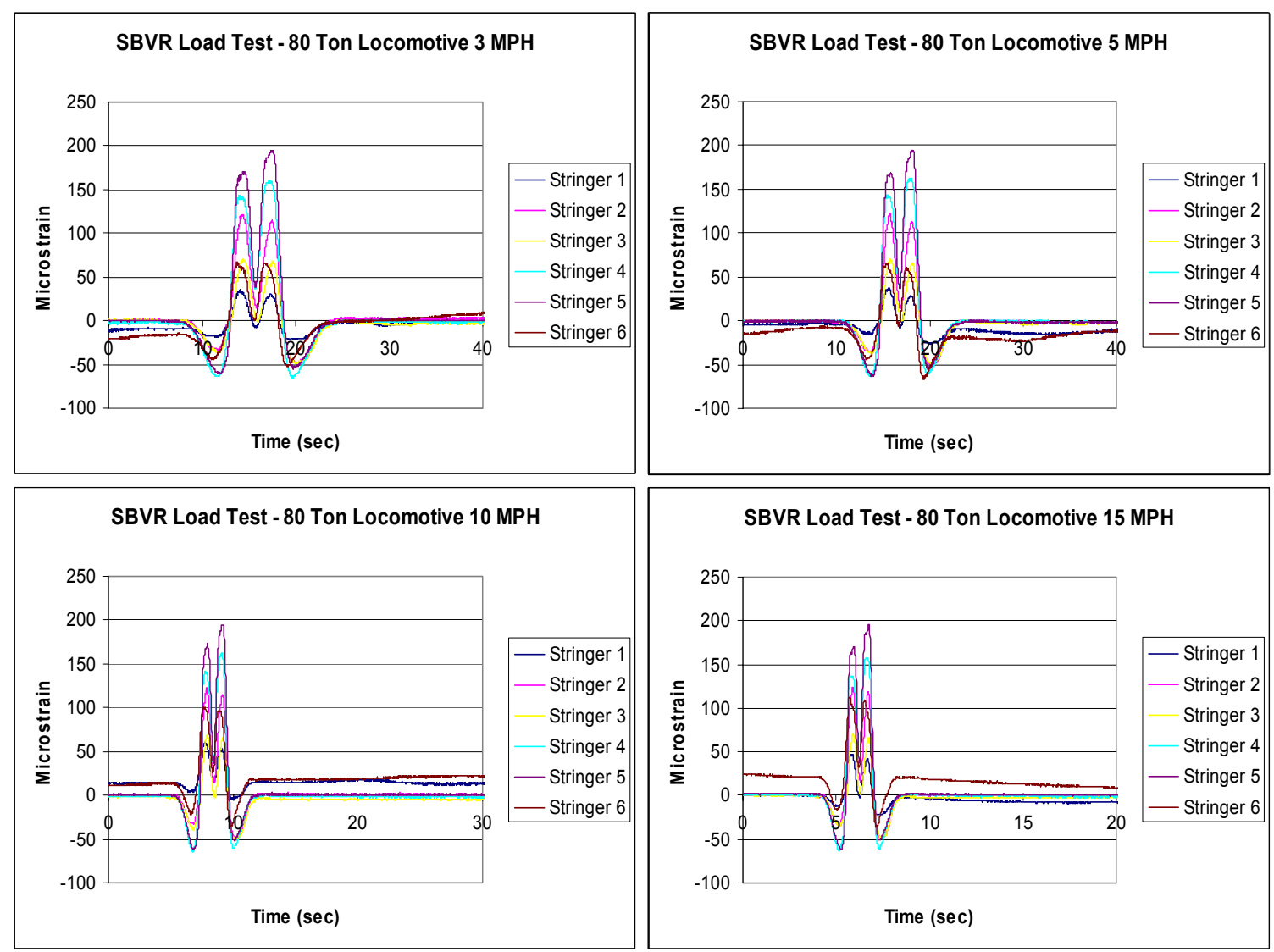

Figure 5.11. Bridge 568 Span 4 Strain Distribution

\subsubsection{Pile Strains}

Pile strains were also measured under various load tests. Figure 5.12 shows the location of strain gages placed on the pile bent of span 4 of Bridge 568 . 


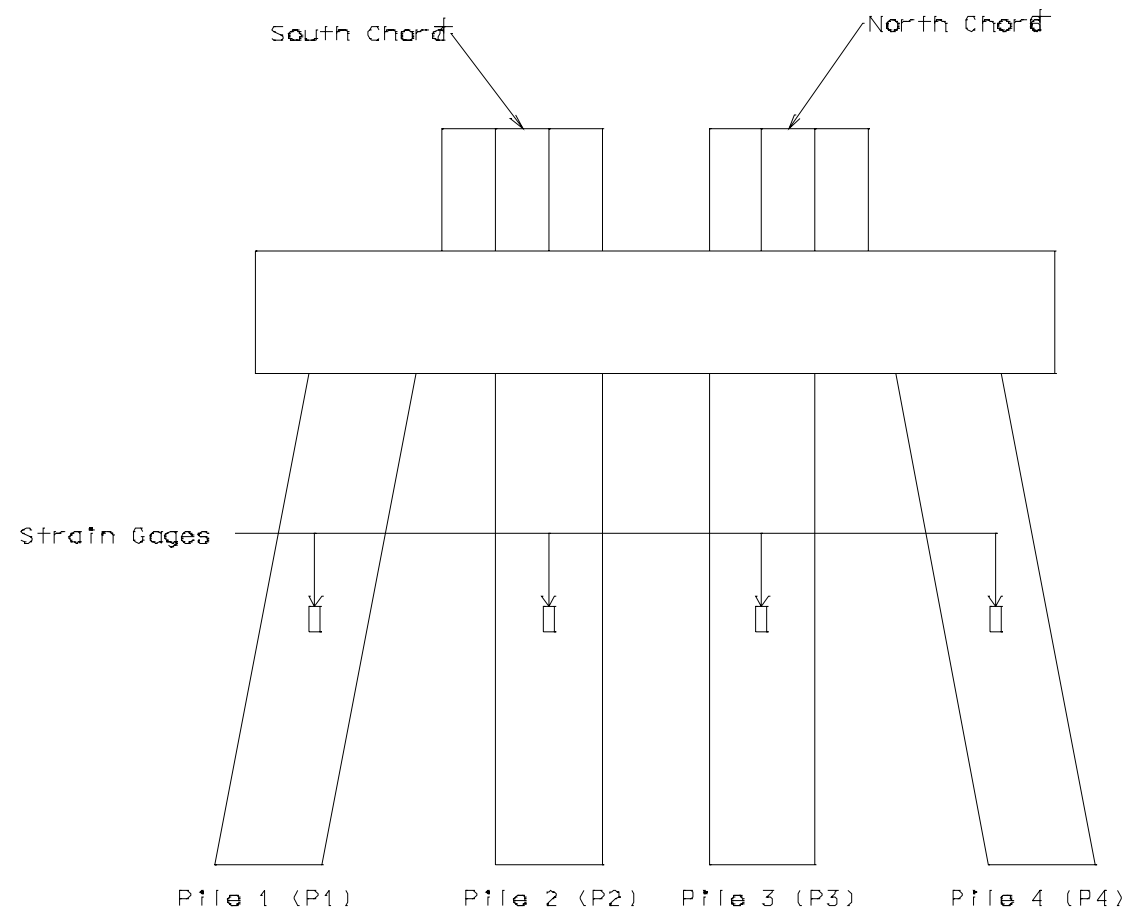

Figure 5.12 Post Rehabilitation Strain Gage Location

A comparative analysis of pile strains was performed on Bridge 568 under each individual load condition and for all speeds. Figure 5.13 shows various plots generated to illustrate strain distribution for the static load test and the dynamic load tests at velocities of approximately $3 \mathrm{mph}, 5 \mathrm{mph}, 10 \mathrm{mph}$, and $15 \mathrm{mph}$. 

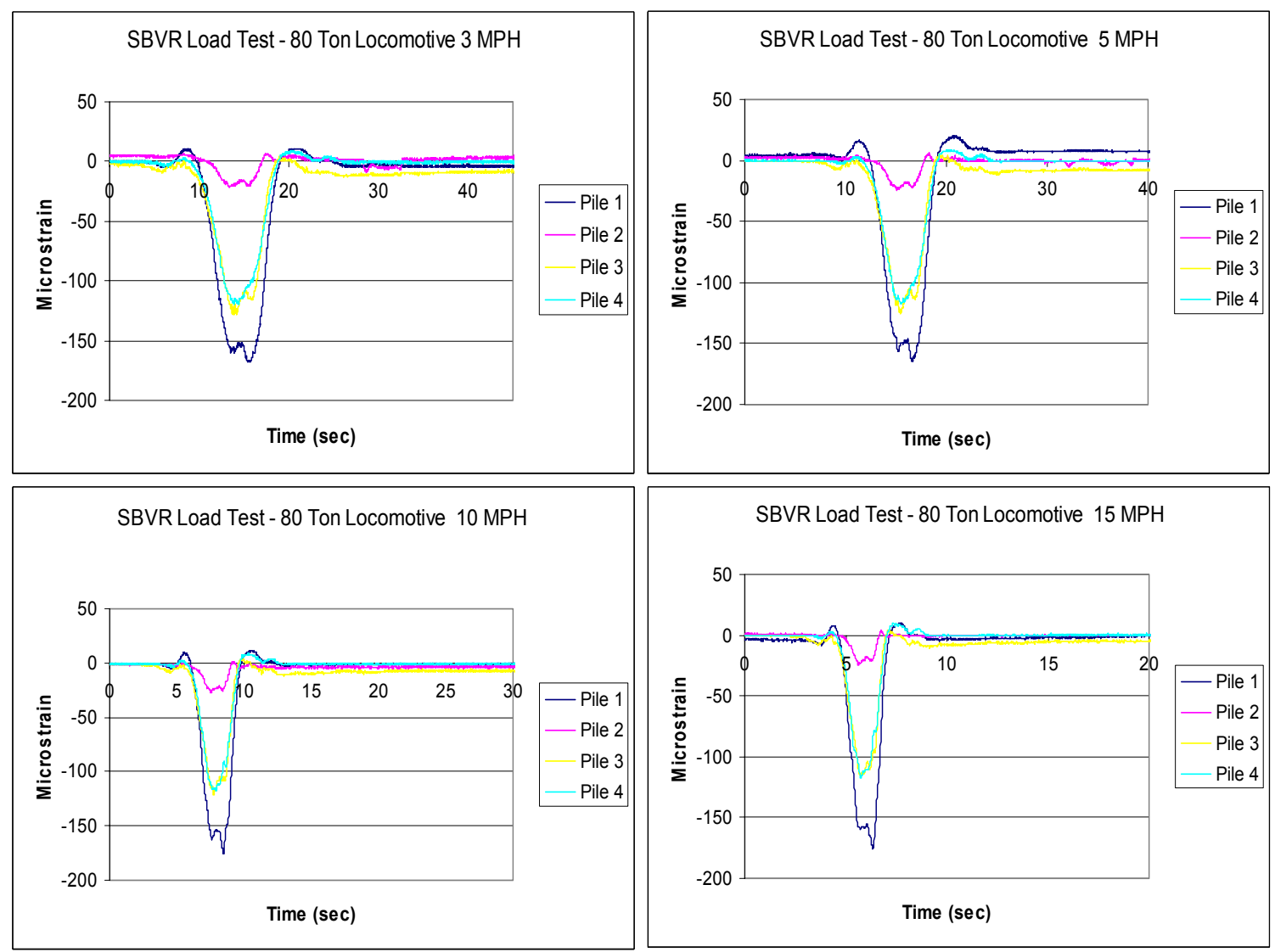

Figure 5.13. Span 4 pile strain distribution (at varying speeds) post rehabilitation

Figure 5.13 shows that the strain is considerably higher in the $1^{\text {st }}$ pile (P1) in the instrumented pile bent. The maximum strain recorded in P1 was 176 microstrains for the $15 \mathrm{mph}$ test.

The maximum strain experienced within the piles during the post rehabilitation testing is lower than the maximum strain value during the initial field-testing. As stated above, the maximum value of strain in pile 1 during the post rehabilitation testing was 176 microstrains. By comparison, the maximum strain value in the initial field-testing was recorded in pile 3 at 348 microstrain, i.e., a 50 percent drop in the maximum strain value and a shift in the maximum pile strain. These numbers suggest a more even strain and load distribution throughout the rehabilitated pile bent. During the initial fieldtesting, pile 3 was sustaining a much higher level of strain than any of the other pile. This strain concentration may cause a failure within the pile bent. In the post rehabilitation testing, the distribution of strain was more even throughout the piles and 
the maximum strain was in pile 1 rather than pile 3 . This strain distribution decreases the chances that a failure due to strain concentration will occur within the pile bent.

\subsubsection{Chord Deflection}

Using the deflection data from both LVDTs, a general load distribution was assessed between the two chords. This was made based on the assumption that the individual instrumented stringer deflection represents the actual deflection of the entire chord (i.e., each chord consists of three stringers bolted together) including the tie and nail. Figure 5.14 shows a comparison of span 4 north and south chord midspan deflections for $3 \mathrm{mph}, 5 \mathrm{mph}, 10 \mathrm{mph}$, and $15 \mathrm{mph}$ test locomotive vehicles. Figure 5.14 also shows that the north chord deflects more than the south chord for every load case.

The maximum deflection for the north chord is 0.2465 inches at $5 \mathrm{mph}$, while the maximum static deflection for the south chord is 0.176 inches. In general, the north chord deflected more than the south chord for static and various speeds. The initial test maximum deflection in the north chord is 0.2203 inches during the $15 \mathrm{mph}$ trial and the maximum deflection in the south chord is 0.2 inches during the $15 \mathrm{mph}$ trial. 

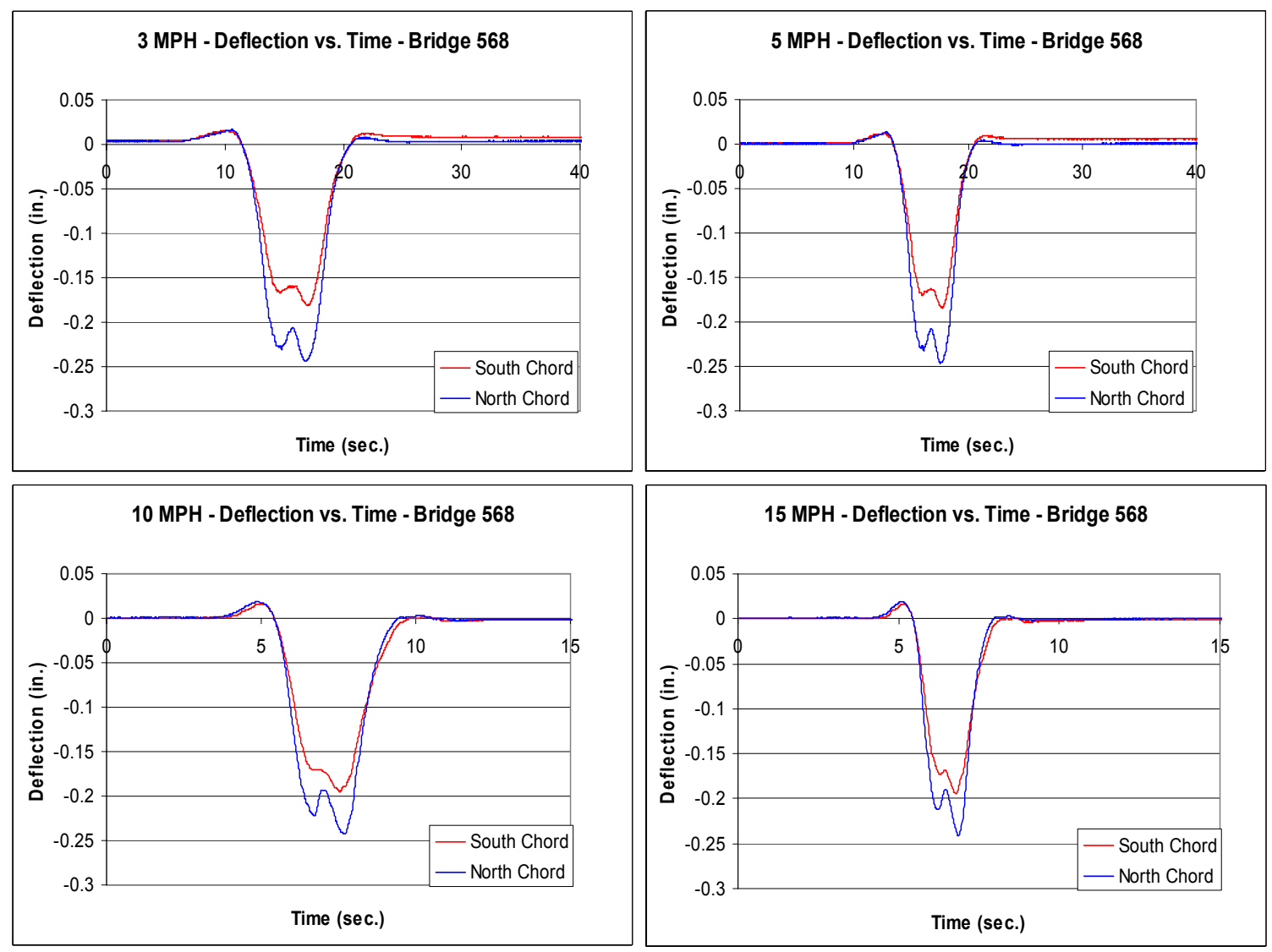

Figure 5.14. North and South Chord midspan deflections post rehabilitation

\subsubsection{Pile Cap Strains}

Due to a malfunction in the uniaxial strain gages, the pile cap stresses were not recorded during the post rehabilitation testing.

\subsection{Summary of Field Tests}

The following summary of results from the field tests are:

- The North and South chords of Bridge 568 are in reasonably good condition (NO significant checks or splits visible). Pile-cap/Pile joints are in reasonable condition except for one, which was selected for repair. Piles are in reasonably good condition also except for the one, which was also selected for rehabilitation. 
- DAFs were computed using the static and dynamic deflection data. DAFs increased with increasing speed during initial testing.

- There was a direct correlation between increasing train speed and increasing DAF in the post rehabilitation dynamic testing.

- Due to the existence of high dynamic amplification factors $(>1)$ this suggests that a dynamic load factor needs to be included in the design and analysis of timber bridges.

- Strains in the pile and pile cap under the north chord were also higher than the corresponding south chord values, for both the initial and the post rehabilitation field tests.

- Rehabilitation of a deteriorated pile cap/pile connection with GFRP composite materials can provide improved strain (i.e. stress) distribution within the substructure of a timber railroad bridge. 


\section{Chapter 6. Conclusions and Recommendations}

\subsection{Introduction}

This chapter presents conclusions and recommendations based on the finding of the laboratory and field-testing performed in Phase II of the current research.

\subsection{Conclusions}

\subsubsection{Field Testing}

- Fifty-year-old timber railroad bridges perform well under static and dynamic loading.

- Static and Dynamic tests were conducted using an 80 ton locomotive

- DAFs for the North and South Chords from deflection and strain data were computed.

- The presence of a combination of low and high density stringers, such as the stringers tested in the laboratory testing, within timber railroad bridges may cause load distribution issues throughout the bridge

- Existence of dynamic amplification factors ( $>1)$ suggests that a dynamic load factor needs to be included in the design and analysis of timber bridges.

- Data collected during the $10 \mathrm{mph}$ initial field test may be erroneous.

- Span 4 of SBVR Bridge 568, Moorefield, West Virginia was rehabilitated using GFRP composite materials. The rehabilitation involved one "pile cap/pile" joint and one above ground pile. A step-by-step procedure for the wet hand-lay up was presented. The procedure included sequential steps to properly repair "pile cap/pile" joints. Also, a detailed procedure for the repair of a damaged above ground timber pile was presented.

- Rehabilitation of a deteriorated pile cap/pile connection with GFRP composite materials can provide improved strain (i.e. stress) distribution within the substructure of a timber railroad bridge.

- The in-situ rehabilitation of timber railroad bridges with GFRP composite materials provides a viable alternative which is quick and easy to install when compared with conventional methods of railroad bridge repair. 
- GFRP composite fabric in combination with phenolic formaldehyde adhesives was found to perform well in harsh environmental conditions.

- GFRP composite material bond adequately to creosote treated timber.

\subsubsection{Laboratory Experiments}

- The primer/resin combination used during the laboratory experiments bonded well with creosote treated timber stringers.

- Using GFRP composite materials to repair as well as strengthen previously failed beams allows the recovery of $55-60 \%$ of the initial strength.

- GFRP composite repaired beams failed in bending displayed greater ductility prior to failure when compared to control specimens.

- Repaired beams failed in bending displayed a drop in bending flexural rigidity (EI $\mathrm{I}_{\text {bending }}$ ) of $37-71 \%$ and a drop in experimental flexural rigidity (EI $\mathrm{exp}_{\mathrm{p}}$ ) of $20-57 \%$.

- A transformed section analysis was conducted to determine the transformed shear modulus and flexural rigidity of the repaired specimens. Comparative analysis was used to evaluate the effects of the GFRP fabric rehabilitation applied at the location of maximum moment (Figure 3.14) and occurrence of maximum shear (Figure 3.22)

\subsection{Recommendations}

- A horizontal load test of the rehabilitated pile cap joint to determine the effectiveness of the repaired joint using GFRP.

- Strengthen timber bridge substructure joints and other superstructure members utilizing alternative application methods of GFRP materials such as nonatomizing application spray gun with chopped fibers

- A laboratory testing program of full-scale timber stringers failed and repaired utilizing alternative wrapping methods 


\section{Bibliography}

1. Mee, B., McCown, B., Davids, G.A., Nejikovsky, B., Cotton, K., “Overview of Railroad Bridges and Assessment of Methods to Monitor Railroad Bridge Integrity." United States Department of Transportation Federal Railroad Administration, DOT/FRA/ORD-94/20, June 23, 1994, Final Report

2. Radford, D.W., Peterson, M.L., VanGoethem, D., "Composite Repair of Timber Structures.”, Colorado State University, June, 2000.

3. King, B.L., GangaRao, H.V.S., "Rehabilitation of Timber Railroad Bridges using Glass Composite Fabrics." Repairing and Rehabilitating the Buildings and Bridges of the Americas-Hemispheric Workshop on Future Direction, Mayguëz, Puerto Rico, 2001.

4. Byers, W. G., "Service life of timber trestles", Probabilistic Mechanics and Structural and Geotechnical Reliability, Proceedings of the Specialty Conference Proceedings and the $19967^{\text {th }}$ Specialty Conference on Probabilistic Mechanics and Structural Reliability Aug 7-9, Worcester, MA. 1996.

5. www.osmose.com/railroad/railroad products/cop-r-plastic and osmoshield/. October 3, 2003. Osmose Holdings Inc. January 22, 2004.

6. Tech note ETL 1110-2-548, Army Corps of Engineers, 31 March 1997.

7. Neale, K. W., "FRPs for Structural Rehabilitation: A Survey of Recent Progress." Structural Engineering Materials: 2000; 2: 133-138.

8. Triantafillou, T. C., "Shear Reinforcement of Wood Using FRP Materials." Journal of Materials in Civil Engineering: May 1997.

9. Johns, K. C., Lacroix, S., “Composite Reinforcement of Timber in Bending.”, Canadian Journal of Civil Engineering, vol. 27, p.899-906, 2000.

10. Triantafillou, T.C., Deskovic, N. "Prestressed FRP sheets as external reinforcement of wood members.”, Journal of Structural Engineering, v. 118, no. 5, p.1270-1284, 1992.

11. Mosallam, A., Kreiner, J., Lancey, T., "Structural Upgrade and Repair of Wood Members Using Cross-Ply Carbon/Epoxy.", Proceedings of the Conference on Seismic Repair \& Rehabilitation of Structures 2 Mar 21-22, Fullerton, CA, 2000.

12. Laosiriphong, K., "Development and Evaluation of Glass Fiber Reinforced Composite/Wood Railroad Crossties.”, Masters Thesis, West Virginia University, 2000. 
13. Plevris, N., Triantafillou, T., "Creep Behavior of FRP-Reinforced Wood Members." Journal of Structural Engineering, vol 121, no 2, Feb, 1995.

14. Chow, P., Lewis, S.L., Reinschmidt, A.J., Barenberg, E.J., "Effects of Natural and Accelerated Aging on Oak Crossties.", American Wood-Preservers' Association Proceedings, 1987.

15. Uppal, A.S., Rizkalla, S.H., Pinkney, R.B., "Response of Timber Bridges under Train Loading." Canadian Journal of Civil Engineering, v.17, n.6, p.940-951. 1990.

16. Wipf, T.J., Ritter, M.A., Wood, D.L., "Evaluation and Field Load Testing of Timber Railroad Bridge." Journal of the Transportation Research Record, v.1, n.1696, p.323-333. 2000.

17. Ritter, M.A., Wood, D.L., Wipf, T.J., Duwadi, S.R., "Dynamic Response of Stress-Laminated-Deck Bridges." Proceedings of the $4^{\text {th }}$ International Bridge Engineering Conference Aug 28-30, Washington, D.C., v. 2, p.381-394. 1995.

18. Imbsen, R.A., Alameddine, F., Mosallam, A.S., ed., "Practical Implementation of Design Procedures for Retrofit of Bridge Columns using FRP." Proceedings of the Conference on Seismic Repair \& Rehabilitation of Structures 2 Mar.21-22, Fullerton, CA, 2000.

19. Prota, A., Nanni, A., Manfredi, G., Cosenza, E., "Seismic Upgrade of BeamColumn Joints with FRP Reinforcement," Industria Italiana del Cemento, Nov. 2000.

20. Alden, H. A., Softwoods of North America. Gen. Tech. Rep. FPL-GTR-102. Madison, WI: U.S. Department of Agriculture, Forest Service, Forest Products Laboratory. Sept. 1997.

21. Gurfinkel, G., Wood Engineering. Second Edition, Kendall/Hunt Publishing Company, Dubuque, Iowa. 1981

22. Forest Products Laboratory. 1999. Wood handbooks - Wood as an engineering material. Gen. Tech. Rep. FPL-GTR-113. Madison, WI: U.S. Department of Agriculture, Forest Service, Forest Product Laboratory.

23. Bodig, J., Jayne, B., "Mechanics of Wood and Wood Composites", Krieger Publishing Company, Malabar, Florida, 1993.

24. Lang, E., Personal Communication. West Virginia University, Davis College of Agriculture, Forestry, and Consumer Sciences, Forestry Department. 2004 